\title{
The Business Case for Systems Engineering Study: Detailed Response Data
}

Joseph P. Elm

Dennis R. Goldenson

November 2012

SPECIAL REPORT

CMU/SEI-2012-SR-011

CERT Program

http://www.sei.cmu.edu

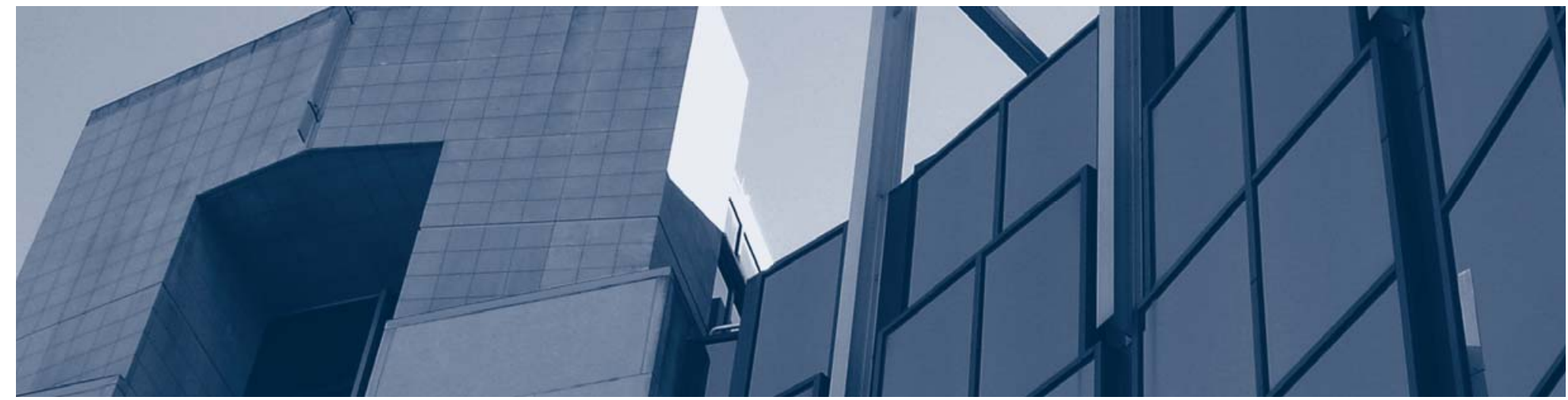

Carnegie Vellon Lniversity 


\section{Copyright 2013 Carnegie Mellon University}

This material is based upon work funded and supported by the Department of Defense under Contract No. FA8721-05-C-0003 with Carnegie Mellon University for the operation of the Software Engineering Institute, a federally funded research and development center.

Any opinions, findings and conclusions or recommendations expressed in this material are those of the author(s) and do not necessarily reflect the views of the United States Department of Defense.

This report was prepared for the

SEI Administrative Agent

AFLCMC/PZM

20 Schilling Circle, Bldg 1305, 3rd floor

Hanscom AFB, MA 01731-2125

NO WARRANTY. THIS CARNEGIE MELLON UNIVERSITY AND SOFTWARE ENGINEERING INSTITUTE MATERIAL IS FURNISHED ON AN “AS-IS” BASIS. CARNEGIE MELLON

UNIVERSITY MAKES NO WARRANTIES OF ANY KIND, EITHER EXPRESSED OR IMPLIED, AS TO ANY MATTER INCLUDING, BUT NOT LIMITED TO, WARRANTY OF FITNESS FOR PURPOSE OR MERCHANTABILITY, EXCLUSIVITY, OR RESULTS OBTAINED FROM USE OF THE MATERIAL. CARNEGIE MELLON UNIVERSITY DOES NOT MAKE ANY WARRANTY OF ANY KIND WITH RESPECT TO FREEDOM FROM PATENT, TRADEMARK, OR COPYRIGHT INFRINGEMENT.

This material has been approved for public release and unlimited distribution except as restricted below.

Internal use:* Permission to reproduce this material and to prepare derivative works from this material for internal use is granted, provided the copyright and "No Warranty" statements are included with all reproductions and derivative works.

External use:* This material may be reproduced in its entirety, without modification, and freely distributed in written or electronic form without requesting formal permission. Permission is required for any other external and/or commercial use. Requests for permission should be directed to the Software Engineering Institute at permission@sei.cmu.edu.

* These restrictions do not apply to U.S. government entities.

$\mathrm{CERT}^{\circledR}$ and $\mathrm{CMMI}^{\circledR}$ are registered marks of Carnegie Mellon University.

DM-0000794 


\section{Table of Contents}

$\begin{array}{lc}\text { Acknowledgments } & \text { ix }\end{array}$

$\begin{array}{lc}\text { Executive Summary } & \text { xi }\end{array}$

$\begin{array}{lc}\text { Abstract } & \text { xiii }\end{array}$

1 Introduction $r$

2 Questionnaire Section A - About this Project 3

3 Questionnaire Section B - About the Contract $\quad 10$

4 Questionnaire Section C - About the Organization $\quad 16$

$5 \quad$ Questionnaire Section D - Project Planning 19

6 Questionnaire Section E - Integrated Product Teams $\quad 27$

$7 \quad$ Questionnaire Section F - Risk Management $\quad 29$

8 Questionnaire Section G - Requirements Development and Management 32

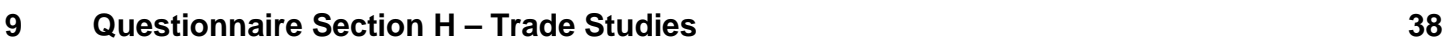

10 Questionnaire Section I - Product Architecture $\quad 40$

11 Questionnaire Section J - Product Integration 42

12 Questionnaire Section K - Verification 43

13 Questionnaire Section L - Validation $\quad 47$

14 Questionnaire Section M - Configuration Management 48

15 Questionnaire Section N - Project Performance $\quad 50$

16 Questionnaire Section O - Other Performance Measures 55

17 Questionnaire Section P - Conclusion $\quad 62$

18 Conclusion $\quad 65$

$\begin{array}{lr}\text { Appendix: Survey Questionnaire } & 67\end{array}$

$\begin{array}{lr}\text { References } & 101\end{array}$ 
CMU/SEI-2012-SR-011 | ii 


\section{List of Figures}

Figure 1: Question A.1 - Challenge Due to Precedent 3

Figure 2: Question A.2 - Challenge Due to Constraints on Quality Attributes 3

Figure 3: Question A.3 - Challenge Due to Size 4

Figure 4: Question A.4 - Challenge Due to Technology 4

Figure 5: Question A.5 - Challenge Due to Interoperability 4

Figure 6: Question A.6 - Challenge Due to Insufficient Resources 5

Figure 7: Question A.7 - Challenge Due to Insufficient Skills 5

Figure 8: Question A.9 - Project Team Past Success 6

Figure 9: Question A.10 - Well-Defined Requirements $\quad 7$

Figure 10: Question A.11 - Stable Requirements $\quad 7$

Figure 11: Question A.12 - Percentage of Undefined Requirements at Contract Award 7

Figure 12: Question A.13 - Percentage of Currently Undefined Requirements 8

Figure 13: Question A.14 - Separate Budget for SE Activities 8

Figure 14: Question A.15 - Percentage of Non-Recurring Engineering 8

Figure 15: Question A.16 - SE Estimation and Budget Methods 9

Figure 16: Question A.17 - Type of End User 9

Figure 17: Question B.1 - Current Contract Value 10

Figure 18: Question B.2 - Initial Contract Value $\quad 10$

Figure 19: Question B.3 - Reason for Change in Contract Value 11

Figure 20: Question B.4 - Current Project Duration 11

Figure 21: Question B.5 - Initial Planned Project Duration 12

Figure 22: Question B.6 - Reason for Schedule Change 12

Figure 23: Question B.7 - Initial Total Budget 13

Figure 24: Question B.8 - Current Total Budget 13

Figure 25: Question B.9 - Reason for Budget Change 13

Figure 26: Question B.10 - Number of Contract Change Orders 14

Figure 27: Question B.11 - Provisions for Additional Payments 14

Figure 28: Question B.12 - Current Completion Status 15

Figure 29: Question B.13 - Type of Contract 15

Figure 30: Question C.1 - Previous Success with Similar Projects 16

Figure 31: Question C.2 - SE Organization 16

Figure 32: Question C.3 - Type of Industry or Service 17

Figure 33: Question C.4 - Location of Design and Development Engineering Work 17 
Figure 34: Question D.1 - Use of Documented SE Processes

Figure 35: Question D.2 - Use of a WBS 19

Figure 36: Question D.3 - Accuracy and Currency of the WBS 20

Figure 37: Question D.4 - Involvement of Systems Engineers in Maintaining the WBS 20

Figure 38: Question D.5 - Involvement of Stakeholders in Maintaining the WBS 20

Figure 39: Question D.6 - Quality of the Technical Approach 21

Figure 40: Question D.7 - Involvement of SE in Maintaining the Technical Approach 21

Figure 41: Question D.8 - Involvement of Stakeholders in Maintaining the Technical Approach 21

Figure 42: Question D.9 - Existence of a Top-Level Plan 22

Figure 43: Question D.10 - Coverage of the Top-Level Plan 22

Figure 44: Question D.11 - Consistency of the Top-Level Plan with the WBS 22

Figure 45: Question D.12 - Quality of the Schedule 23

Figure 46: Question D.13 - Key Technical Accomplishments in the Schedule 23

Figure 47: Question D.14 - Measurable Basis for the Schedule 23

Figure 48: Question D.15 - The Schedule's Consistency with the WBS 24

Figure 49: Question D.16 - Critical Path in the Schedule 24

Figure 50: Question D.17 - Plan for Periodic Technical Reviews 24

Figure 51: Question D.18 - SE involvement in Project Planning 25

Figure 52: Question D.19 - SE Involvement in Tracking and Reporting Progress 25

Figure 53: Question D.20 - Acquirer-Provided SE Plan 25

Figure 54: Question D.21 - Plan for Integrated Technical Effort 26

Figure 55: Question D.22 - SEMP Consistency with the Acquirer's SE Plan 26

Figure 56: Question E.1 - Effectiveness of IPTs 27

Figure 57: Question E.2 - Acquirer Participation in IPTs 27

Figure 58: Question E.3 - Supplier Participation in IPTs 28

Figure 59: Question E.4 - IPT Responsibility for SE 28

Figure 60: Question E.5 - SE Representation on IPTs 28

Figure 61: Question F.1 - List of project risks 29

Figure 62: Question F.2 - Risk Management and Contingency Plans 29

Figure 63: Question F.3 - Risk Mitigation Status and Resource Status Monitoring 30

Figure 64: Question F.4 - Schedule Risk Assessment 30

Figure 65: Question F.5 - Risk Management in Decision Making 30

Figure 66: Question F.6 - Risk Management Integration with Cost Management 31

Figure 67: Question F.7 - Risk Management Integration with Program Scheduling 31

Figure 68: Question F.8 - Integration of Supplier Risk Management Processes 31

Figure 69: Question G.1 - Documentation of Customer Requirements 32 
Figure 70: Question G.2 - Documentation of Derived Requirements

Figure 71: Question G.3 - Hierarchical Allocation of Requirements 33

Figure 72: Question G.4 - Operational Concepts and Scenarios 33

Figure 73: Question G.5 - Use Cases 34

Figure 74: Question G.6 - Installation, Maintenance, and Support Concepts 34

Figure 75: Question G.7 - Criteria for Authorizing Requirements Providers 34

Figure 76: Question G.8 - Criteria for Accepting Requirements 35

Figure 77: Question G.9 - Approval Process for Requirements 35

Figure 78: Question G.10 - Requirements Impact Assessments 35

Figure 79: Question G.11 - Stakeholder-Based Requirements 36

Figure 80: Question G.12 - Requirements Management System 36

Figure 81: Question G.13 - Configuration Control of Requirements 36

Figure 82: Question G.14 - Accessibility of Requirements 37

Figure 83: Question H.1 - Stakeholders Involvement in Trade Studies 38

Figure 84: Question H.2 - Effectiveness of Trade Studies 38

Figure 85: Question H.3 - Trade Study Documentation 39

Figure 86: Question I.1 - Quality of Interface Descriptions 40

Figure 87: Question I.2 - Management of Interface Descriptions 40

Figure 88: Question I.3 - Maintained Documentation of the Product Structure 41

Figure 89: Question I.4 - Multiple Views of the Product Structure 41

Figure 90: Question I.5 - Accessibility of Product Structure Documentation 41

Figure 91: Question J.1 - Documented Product Integration Process 42

Figure 92: Question K.1 - Documented Verification Procedures 43

Figure 93: Question K.2 - Documented Acceptance Criteria for Verification 43

Figure 94: Question K.3 - Documented and Practiced Review Process 44

Figure 95: Question K.4 - Training for the Review Process 44

Figure 96: Question K.5 - Criteria for Selecting Work Products for Review 44

Figure 97: Question K.6 - Action Item Tracking 45

Figure 98: Question K.7 - Inclusion of Risk Management in the Review Process 45

Figure 99: Question K.8 - Inclusion of Configuration Baselines in the Review Process 45

Figure 100: Question K.9 - Documentation of Review Results 46

Figure 101: Question L.1 - Documented Validation Procedures $\quad 47$

Figure 102: L.2 -- Documented Acceptance Criteria for Validation 47

Figure 103: Question M.1 - Items Under Configuration Control 48

Figure 104: Question M.2 - Configuration Control Board 48

Figure 105: Question M.3 - Change Records 49 
Figure 106: Question M.4 - Configuration Baselines $\quad 49$

Figure 107: Question N.1 - Cost and Schedule Baselines 50

Figure 108: Question N.2 - Availability of EVMS Data 50

Figure 109: Question N.3 - Requirement for Suppliers to Track and Report EVMS Data 51

Figure 110: Question N.4 - Defined Variance Thresholds for CPI and SPI 51

Figure 111: Question N.5 - EVMS Connections to the WBS and IMS 52

Figure 112: Question N.6 - Strategy for Updating the EVMS Baseline 52

Figure 113: Question N.7 - Projected Cost Variance 53

Figure 114: Question N.8 - Projected Schedule Variance 53

Figure 115: Question N.9 - Current EVMS CPI 54

Figure 116: Question N.10 - Current EVMS SPI 54

Figure 117: Question 0.1 - Percentage of Award Fees Collected in the Current Period 55

Figure 118: Question 0.2 - Percentage of Award Fees Collected During the Whole Project 55

Figure 119: Question 0.3 - Satisfaction of Requirements 56

Figure 120: Question 0.4 - Compliance with Approved Schedule 56

Figure 121: Question 0.5 - Current Schedule Variance 56

Figure 122: Question O.6 - Post-fielding Problem Tracking 57

Figure 123: Question O.7 - Engineering Assessments of Problems 57

Figure 124: Question O.8 - Customer Satisfaction with Schedule 57

Figure 125: Question O.9 - Customer Satisfaction with Cost 58

Figure 126: Question 0.10 - Customer Satisfaction with Compliance to Requirements 58 


\section{List of Tables}

Table 1: $\quad$ Mapping of the Questionnaire to Report Sections 2

Table 2: $\quad$ Question A.8 - Other Sources of Challenge 6

Table 3: Question B.3 - Other Sources of Contract Value Change 11

Table 4: Question B.9 - Other Sources of Budget Change 14

Table 5: Question B.13 - Other Contract Types 15

Table 6: Question C.5 - Other Notes of Importance About the Project 18

Table 7: $\quad$ Question O.11 - Other Useful Performance Indicators 59

Table 8: Question 0.12 - Other Desired Information That Was Unavailable to the Project 60

Table 9: Question O.13 - Other SE Effectiveness Indicators Currently Used 61

Table 10: Question O.14 - Other SE Effectiveness Indicators 61

Table 11: Question P.1 - Other SE Comments About the Project or the Survey 62 


\section{Acknowledgments}

We created this report based on the collaborative efforts of the National Defense Industrial Association (NDIA) Systems Engineering Division, the Institute of Electrical and Electronic Engineers (IEEE) Aerospace and Electronic Systems Society, the Software Engineering Institute (SEI) of Carnegie Mellon University, and the Systems Engineering Effectiveness Working Group of the International Council on Systems Engineering (INCOSE).

Primary contributors to this effort include

$\begin{array}{lll}\text { Alan R. Brown } & \text { Julie Cohen } & \text { Geoff Draper } \\ \text { Robert Epps } & \text { Paul Frenz } & \text { Dave Griffith } \\ \text { William F. Lyons } & \text { Jim McCurley } & \text { Judy Scharmann } \\ \text { Derrick Spooner } & \text { Robert Rassa } & \text { Garry Roedler }\end{array}$

Michael J. Zuccher

Members of the NDIA-IEEE-SEI Systems Engineering Effectiveness Committee include

$\begin{array}{lll}\text { Al Brown } & \text { Dale Blair } & \text { Clyde Chittister } \\ \text { Geoff Draper } & \text { Dan Goddard } & \text { Clarence Gooden } \\ \text { Dave Griffith } & \text { Eric Honour } & \text { Bill Lyons } \\ \text { Bob Lyons } & \text { Michael McLendon } & \text { Marty Meth } \\ \text { Tom McDermott } & \text { Christopher Miller } & \text { Roger Oliva } \\ \text { Ken Ptack } & \text { Bob Rassa } & \text { Annette Reilly } \\ \text { Garry Roedler } & \text { Marina Ruggieri } & \text { Theo Saunders } \\ \text { Steve Teahan } & \text { Hal Wilson } & \end{array}$

The International Council on Systems Engineering (INCOSE) Systems Engineering Effectiveness Committee was also instrumental in reaching survey participants. Members include

John Ackley

Mick Edwards

Summer Fowler

Dawn Gilbert

Leroy Hanneman

John Howard

Steve Mazeika

Paul Miller

Chris Orlowski

Jean-Claude Roussel

Richard Sidley

Tim Spencer

Ron Carson
Bruce Elliott
Rick Frazer
Heidi Hahn
Eric Honour
Carol Hutchinson
Ryan McCullough
Joan Nolan
Garry Roedler
Frank Sciulli
Dale Smith
George Walley

Ron Carson

Quoc Do

Joseph Elm

Paul Frenz

Sandra Hammond

Robert Horner

Ebad Jahanger

Bill Miller

Beth O’Donnell

Nancy Roseberry

Keiko Shimazu

Jim Smith

Kevin Weinstein

We are grateful for the thorough reviews done for this report's companion draft on The Business Case for Systems Engineering Study: Results of the Systems Engineering Effectiveness Survey that were provided by

Elliot Axelband Al Brown Geoff Draper Joan Nolan Sarah Sheard

We offer our appreciation to the following people for their enduring support of this project:

Clyde Chittister Paul Nielsen Richard D. Pethia William R. Wilson

And finally, we offer our appreciation to our editor, Sandy Shrum, for making our ramblings readable. 
CMU/SEI-2012-SR-011 | x 


\section{Executive Summary}

The National Defense Industrial Association (NDIA) Systems Engineering Division collaborated with the Institute of Electrical and Electronic Engineers (IEEE) Aerospace and Electronic Systems Society and the Software Engineering Institute (SEI) of Carnegie Mellon ${ }^{\circledR}$ to obtain quantitative evidence of the benefit of systems engineering (SE) best practices on project performance. The team developed and executed this survey of system developers to identify SE best practices used on projects, collect performance data on these projects, and search for relationships between the application of these SE best practices and project performance.

The researchers surveyed a sample of system developers obtained through the memberships of the NDIA, IEEE, and International Council on Systems Engineering (INCOSE) using a questionnaire developed with the SE expertise and the broadly diverse experience of research team members. The questionnaire consists of three sections:

1. one to identify the characteristics of the responding project

2. a second to assess the project's use of SE best practices

3. a third to collect measures of project performance

The survey was executed by the SEI via the web. Policies ensuring the anonymity of the respondents and the confidentiality of their responses were enforced to protect the competition-sensitive information supplied. Responses sufficient for most analyses were received from a total of 148 projects. Responding projects ranged in contract value from $\$ 100$ thousand to $\$ 20$ billion. U.S. defense-related contracts accounted for $69 \%$ of respondents.

Responses were analyzed by the SEI to identify statistical relationships between the deployment of SE best practices and overall project and program performance. Summaries of the responses to each question in the survey are presented in this report. Only aggregated responses are presented; no information that is traceable to any individual respondent, project, or organization is included.

The questionnaire was designed to assess a project's use of SE best practices by querying the respondent regarding the existence and characteristics of various work products resulting from SE processes. Project performance was assessed based on satisfaction of project cost, schedule, and technical goals.

To better understand the relationship between SE capability and project performance, the questionnaire's assessment of SE capability addressed the project's use of SE best practices in 11 management and technical process groups. As with the relationship between total SE capability and project performance, the responses were analyzed to identify relationships between project performance and the project's use of SE best practices in each of the process groups. The survey also examined the relationships between project performance and other factors such as project challenge and prior experience.

${ }^{\circledR}$ Carnegie Mellon is registered in the U.S. Patent and Trademark Office by Carnegie Mellon University. 
The analysis of responses to identify relationships between the project's deployment of SE best practices and the project's performance is presented in a companion report The Business Case for Systems Engineering Study: Results of the SE Effectiveness Survey [Elm 2012b], which is available at http://www.sei.cmu.edu/library/abstracts/reports/12sr009.cfm.

To support the companion results report, this report provides details of the survey responses. The information contained in this report constitutes an industry benchmark of SE deployment that can serve as a point of comparison for the processes and practices of system developers.

With this knowledge, system acquirers and system developers can inform their judgments regarding the application of SE to their projects and improve their SE practices to further enhance project outcomes. 


\section{Abstract}

This report contains detailed response data from The Effectiveness of Systems Engineering: A Survey. The survey had the goal of quantifying the connection between the application of systems engineering (SE) best practices to projects and programs and the performance of those projects and programs. The survey population consisted of projects and programs executed by system developers reached through the National Defense Industrial Association (NDIA) Systems Engineering Division, the Institute of Electrical and Electronics Engineers (IEEE) Aerospace and Electronic Systems Society, and the International Council on Systems Engineering (INCOSE). Analysis of survey responses revealed strong statistical relationships between project performance and several categories of SE best practices. The survey results show notable differences in the relationship between SE best practices and performance between more challenging and less challenging projects. The statistical relationship with project performance is quite strong for survey data of this kind when both SE capability and project challenge are considered together. 


\section{Introduction}

The National Defense Industrial Association (NDIA) Systems Engineering Division, the Institute of Electrical and Electronics Engineers (IEEE) Aerospace and Electronic Systems Society, and the Software Engineering Institute (SEI) of Carnegie Mellon University are collaborating to expand and extend the 2007 NDIA SE Effectiveness Study [Elm 2008] to develop a business case for systems engineering (BCSE).

The mission of this new study is to assist the SE community in achieving a quantifiable and persistent improvement in project performance through the appropriate application of systems engineering principles and practices. The primary steps in the BCSE process are

1. Identify SE principles and practices shown to provide benefit to project performance. This activity is an extension and a confirmation of the prior NDIA survey.

2. Facilitate the adoption of the survey findings through the development of tools, training, and guidance for SE educators, system developers, and system acquirers.

3. Establish an ongoing means of monitoring and tracking the impact of SE to enable continuous improvement of the SE framework and the business case for SE, thereby driving continuous improvement of project results.

As part of this new study, researchers developed a survey to identify SE principles and practices applied to development projects and the performance achieved by those projects. The survey identified the SE activities applied to individual system development projects by assessing work products resulting from specific SE activities. The survey assessed project performance in terms of satisfaction of schedule, budget, and technical requirements. The resulting survey instrument is included in the appendix.

The survey was deployed via the internet to system developers worldwide through the resources of the NDIA, IEEE, and the International Council on Systems Engineering (INCOSE). To encourage truthful responses, and to protect confidential and proprietary information, all responses were submitted anonymously with no reference to the respondent, the project, or the respondent's organization. The research team collected 148 complete responses between October 2011 and March 2012.

Responses were analyzed to assess the performance of each project, the SE activities used on the project, the degree of challenge posed by the project, and several other factors that could affect project performance. We then analyzed the relationships between these various measures as a means of identifying the impact of SE activities. The results of these analyses are provided in the companion report, The Business Case for Systems Engineering: Results of the SE Effectiveness Survey [Elm 2012b].

That report along with the detailed response data available in this report can serve as an industrywide benchmark of SE practices deployed on system development projects. This benchmark also may be used as a reference against which the SE practices of a company may be gauged. 
The questionnaire contained the 16 sections listed in Table 3 . The responses to the questions in each section of the questionnaire are summarized in the subsequent sections of this report.

Table 1: $\quad$ Mapping of the Questionnaire to Report Sections

\begin{tabular}{|c|c|c|}
\hline $\begin{array}{l}\text { Questionnaire } \\
\text { Section }\end{array}$ & Questionnaire Section Title & $\begin{array}{l}\text { Report } \\
\text { Section }\end{array}$ \\
\hline A & About this Project & 2 \\
\hline B & About the Contract & 3 \\
\hline C & About the Organization & 4 \\
\hline D & Systems Engineering - Project Planning & 5 \\
\hline E & Systems Engineering - Integrated Product Teams & 6 \\
\hline $\mathrm{F}$ & Systems Engineering - Risk Management & 7 \\
\hline G & Systems Engineering - Requirements Development and Management & 8 \\
\hline $\mathrm{H}$ & Systems Engineering - Trade Studies & 9 \\
\hline I & Systems Engineering - Product Architecture & 10 \\
\hline $\mathrm{J}$ & Systems Engineering - Product Integration & 11 \\
\hline K & Systems Engineering - Verification & 12 \\
\hline $\mathrm{L}$ & Systems Engineering - Validation & 13 \\
\hline M & Systems Engineering - Configuration Management & 14 \\
\hline $\mathrm{N}$ & Project Performance - Project Performance & 15 \\
\hline $\mathrm{O}$ & Project Performance - Other Performance Measures & 16 \\
\hline $\mathrm{P}$ & Conclusion & 17 \\
\hline
\end{tabular}




\section{Questionnaire Section A - About this Project}

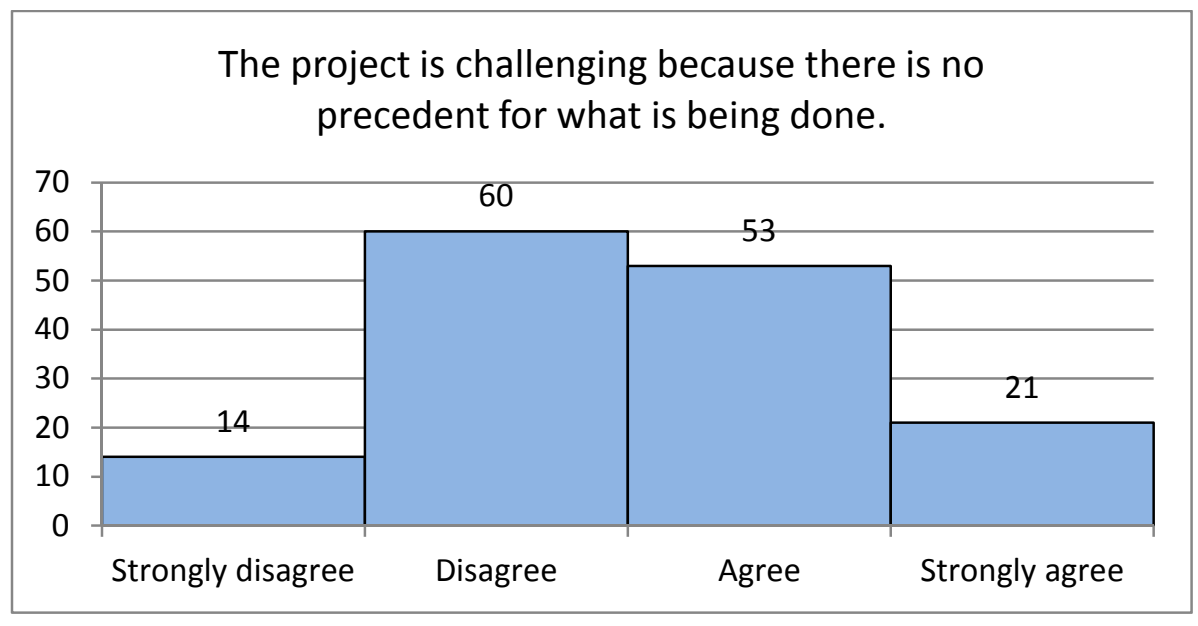

Figure 1: Question A.1 - Challenge Due to Precedent

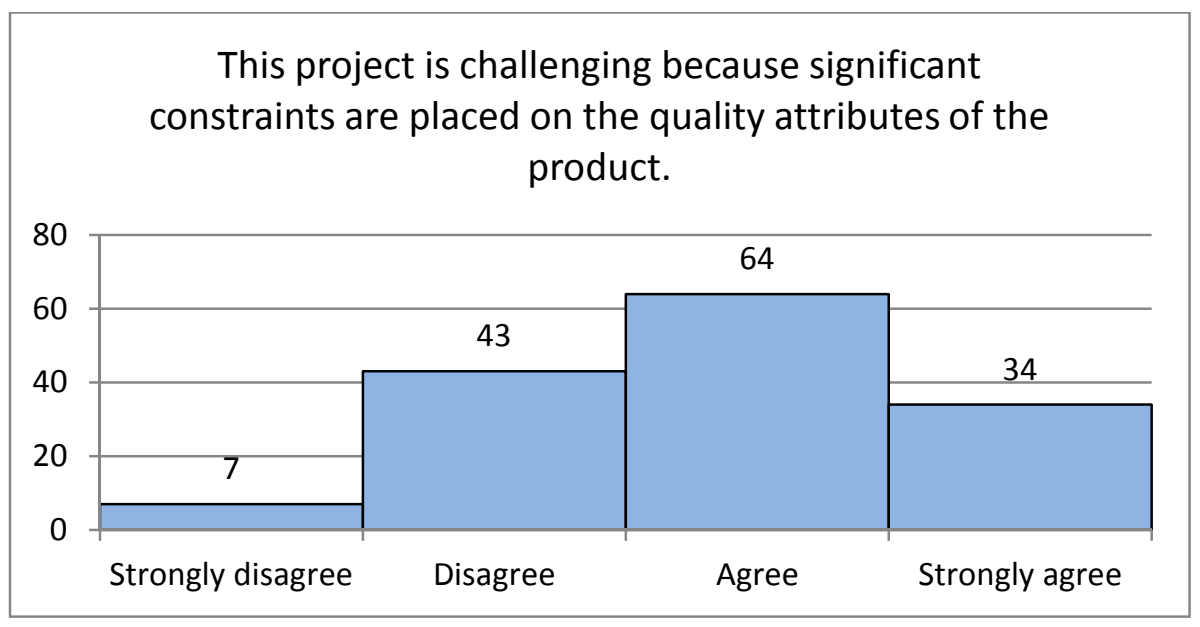

Figure 2: $\quad$ Question A.2 - Challenge Due to Constraints on Quality Attributes 


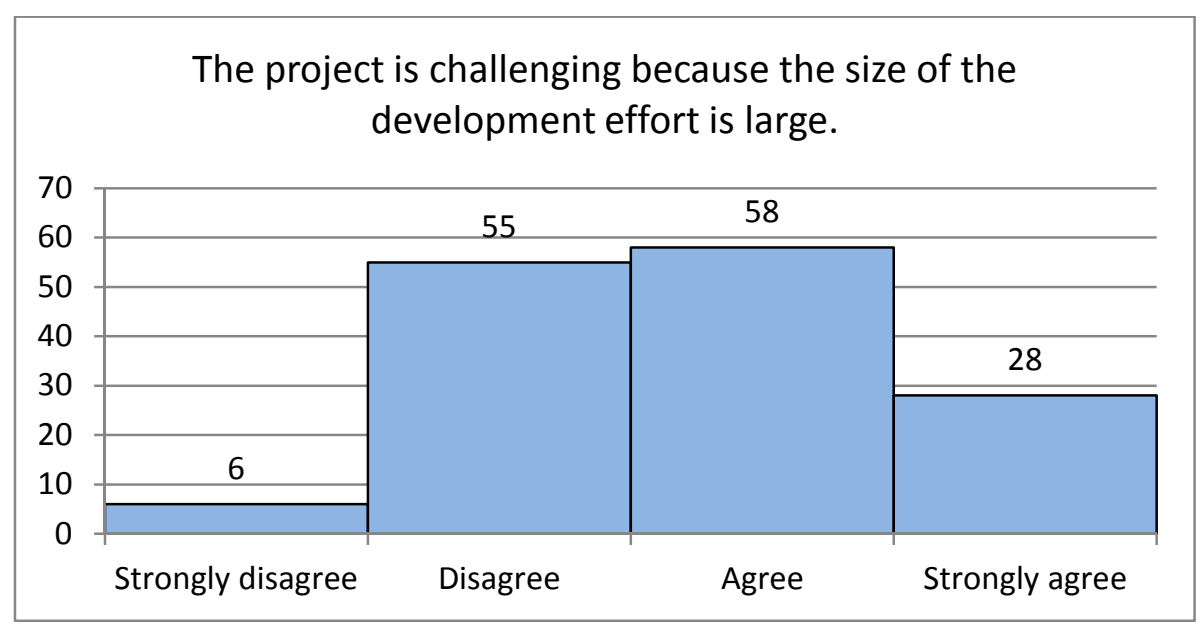

Figure 3: Question A.3 - Challenge Due to Size

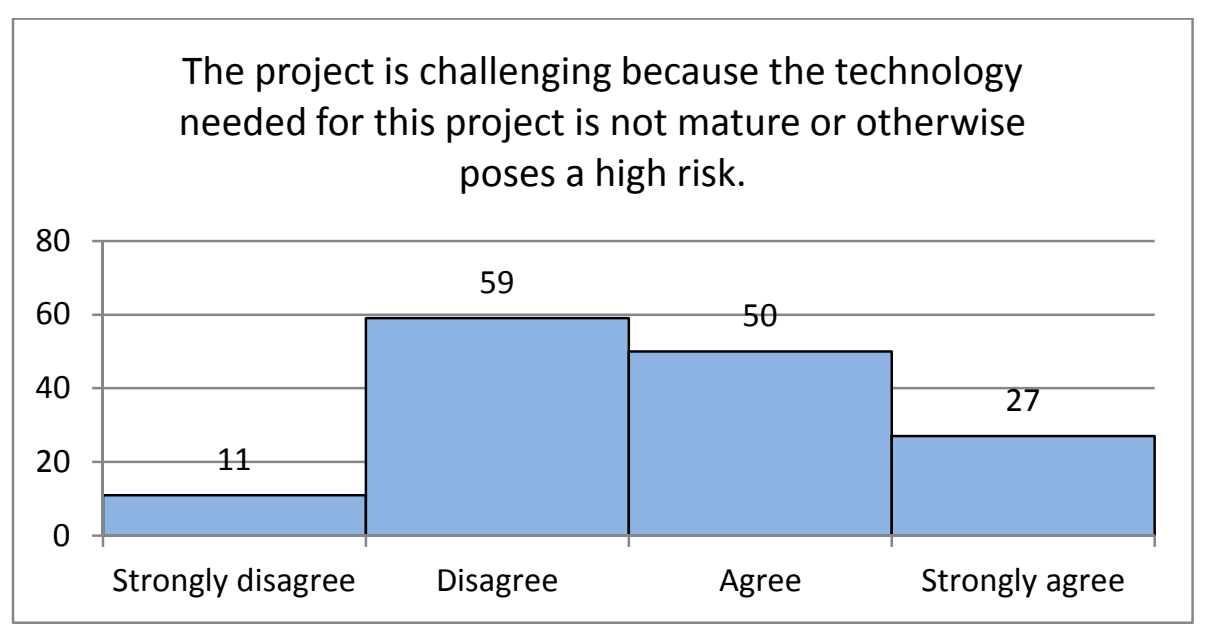

Figure 4: Question A.4 - Challenge Due to Technology

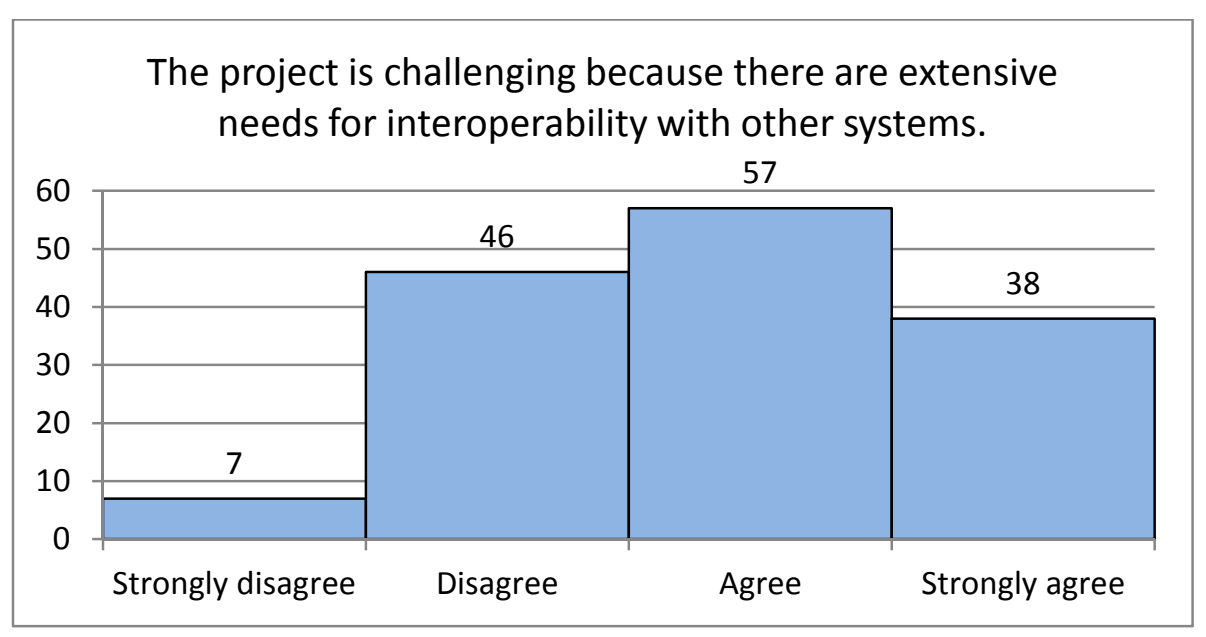

Figure 5: Question A.5 - Challenge Due to Interoperability 


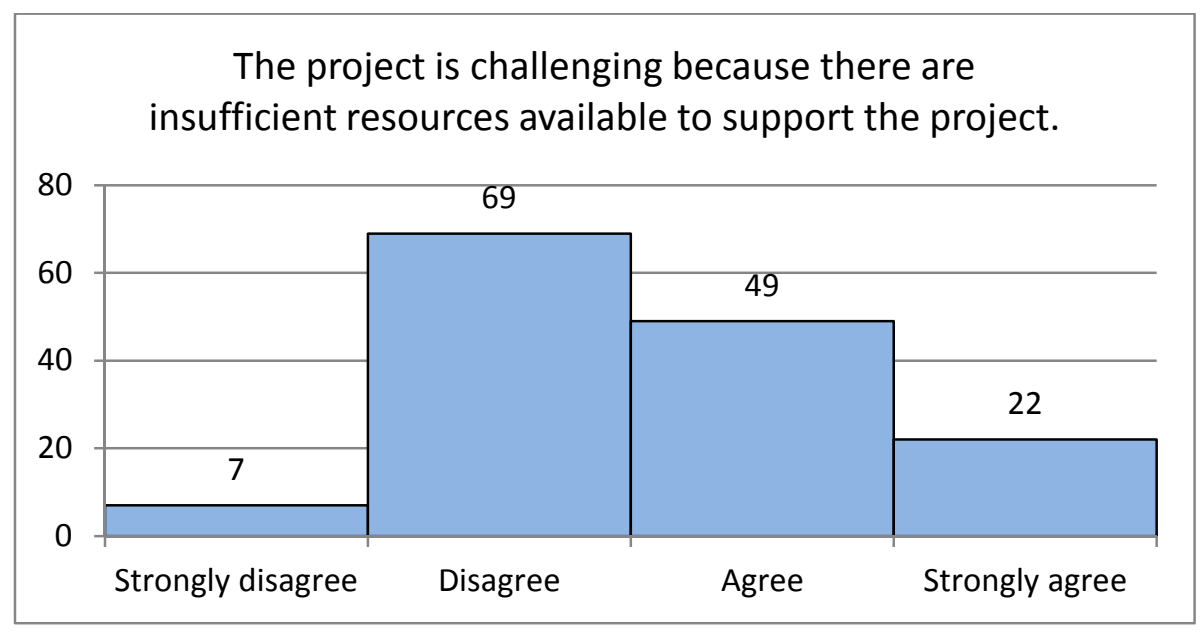

Figure 6: Question A.6 - Challenge Due to Insufficient Resources

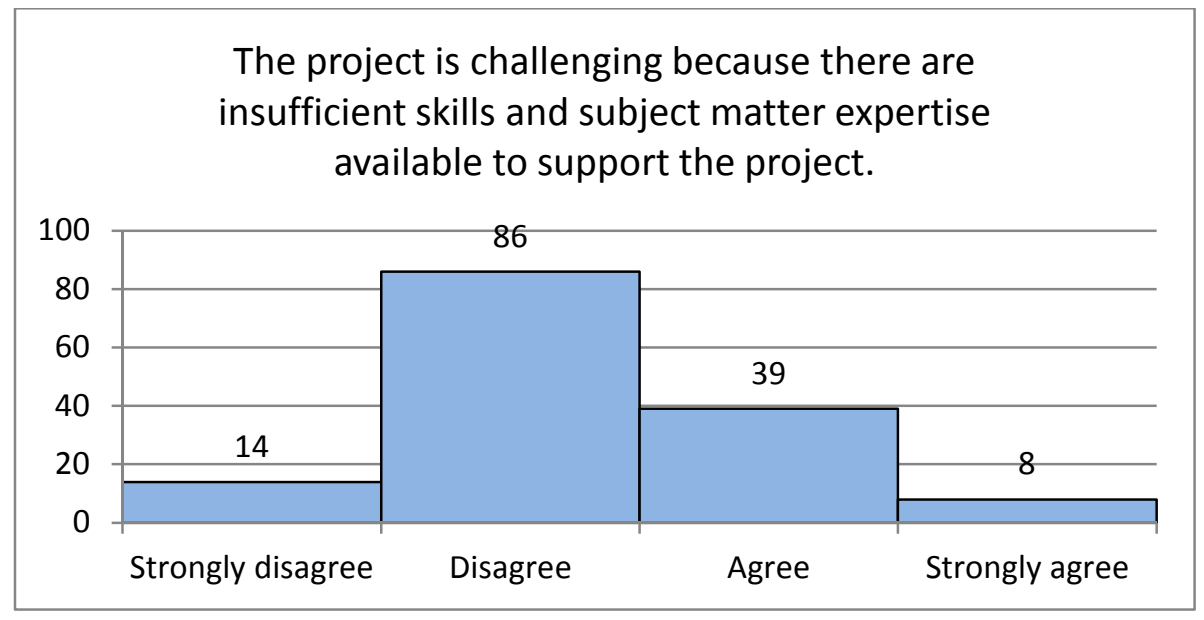

Figure 7: $\quad$ Question A.7 - Challenge Due to Insufficient Skills 
Table 2: Question A.8 - Other Sources of Challenge

\section{A.8 The project is challenging for other reasons:}

Technical challenges (complexity, interactions, harsh environment, COTs utilization, technology immaturity, physical constraints, complex integration)

Insufficient experience (new product area, new development methodology [agile])

Organizational challenges (complicated teaming arrangements, geographic distribution, multi-national supply chain, ongoing reorganizations, organizational politics, subcontractor management)

Acquirer challenges (lack of SE experience, poor requirements definition, changing scope, insufficient engagement, incompetence, micro-management, poor communications)

Insufficient budget and schedule

Engineering processes (lack of standardized processes, lack of training)

Insufficient SE (lack of $\mathrm{PM}^{1}$ support for SE, lack of SE skills across organization)

Legacy products (reverse engineering, lack of reach-back, building on outdated products, building on defective product foundation, defective GFE²)

Export regulations

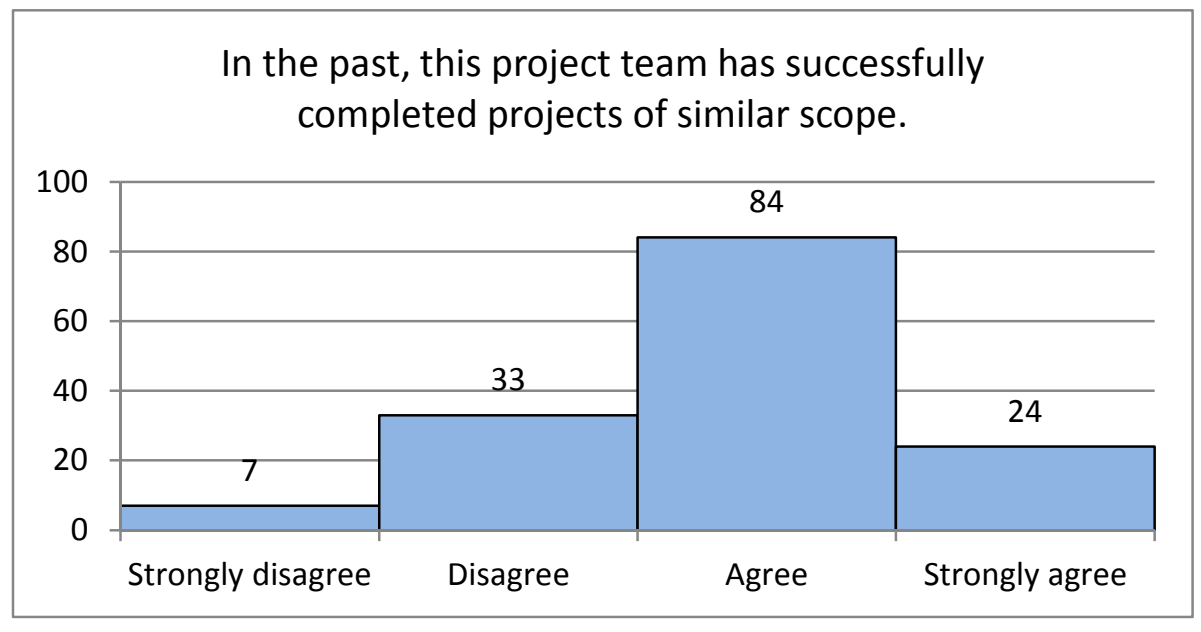

Figure 8: $\quad$ Question A.9-Project Team Past Success

1 project manager

2 government furnished equipment 


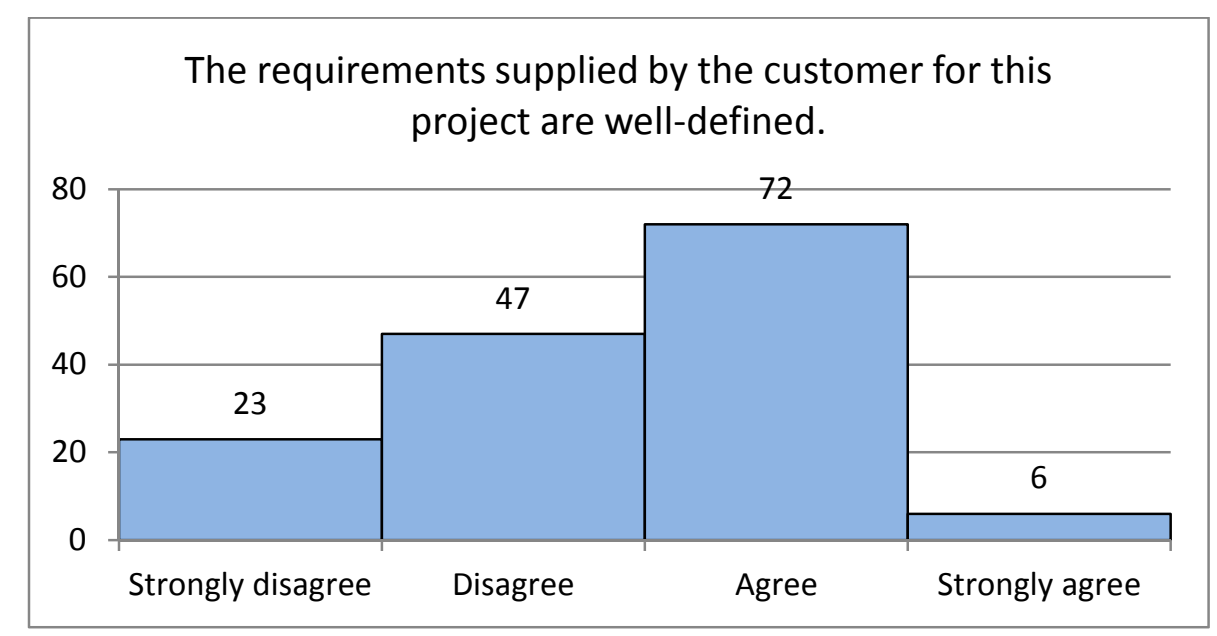

Figure 9: Question A.10 - Well-Defined Requirements

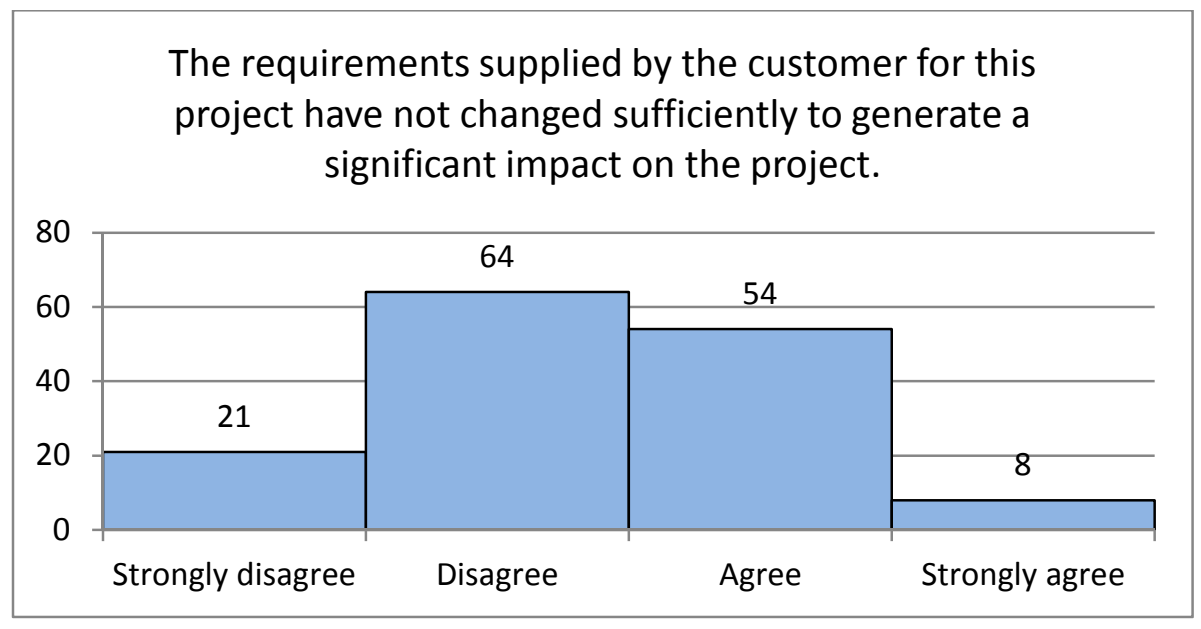

Figure 10: Question A.11 - Stable Requirements

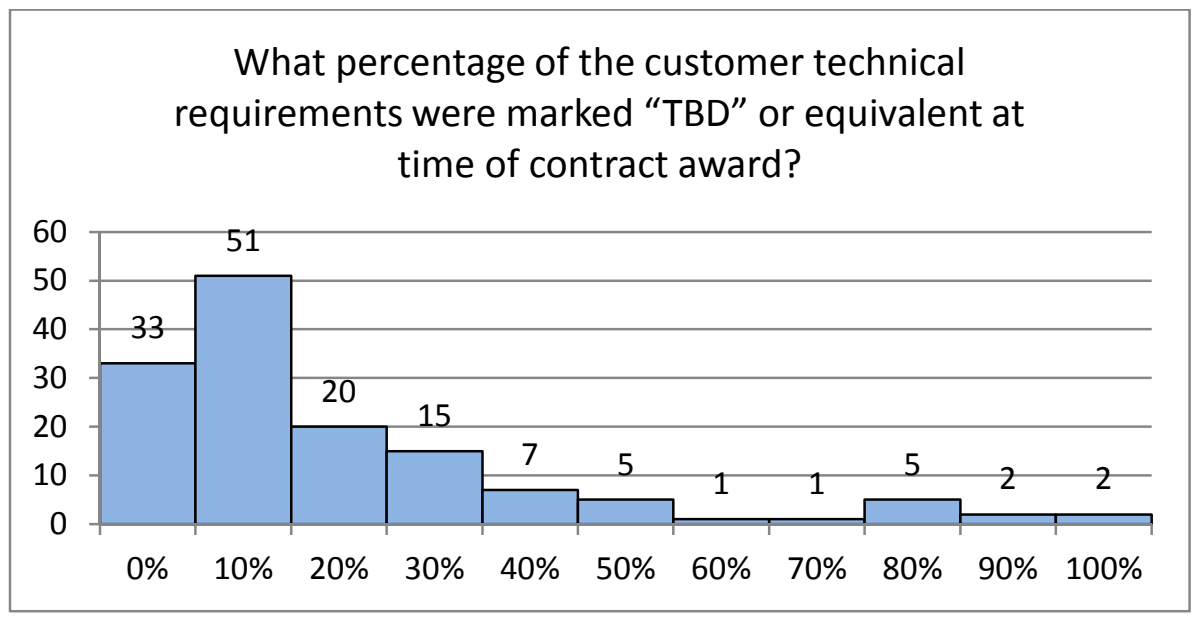

Figure 11: Question A.12 - Percentage of Undefined Requirements at Contract Award 


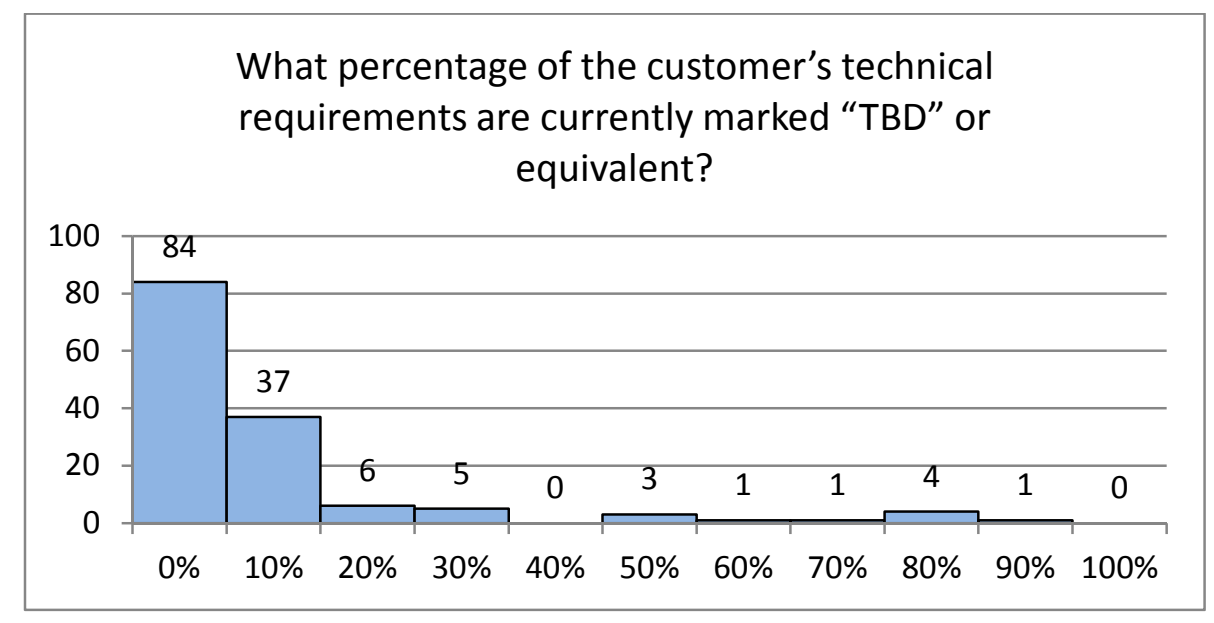

Figure 12: Question A.13 - Percentage of Currently Undefined Requirements

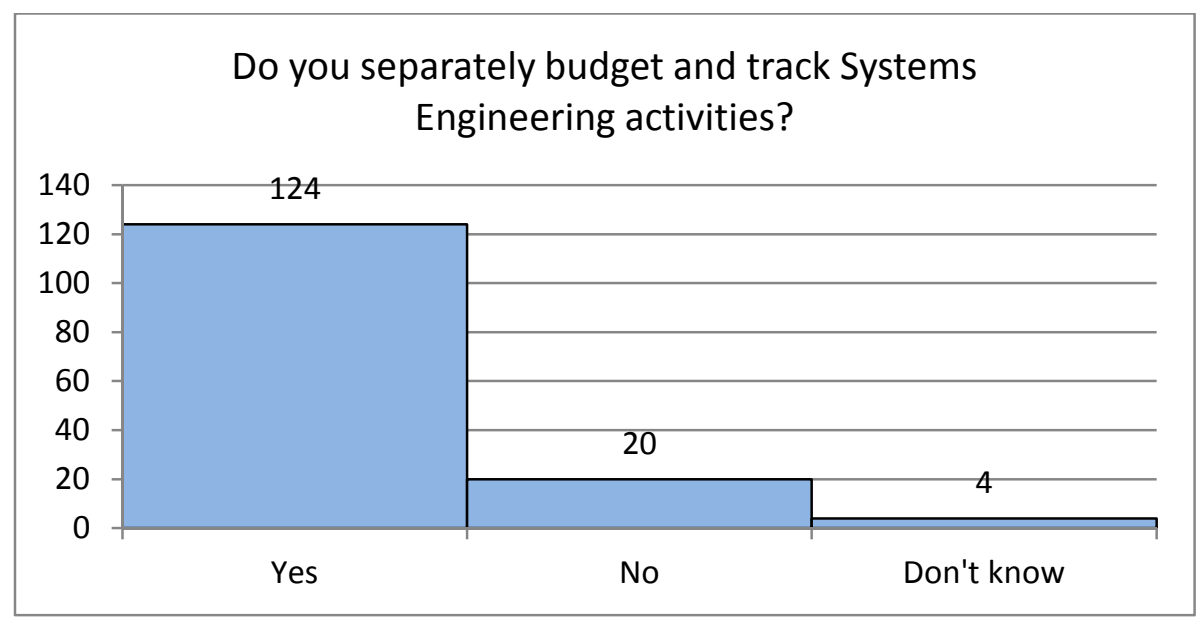

Figure 13: Question A.14 - Separate Budget for SE Activities

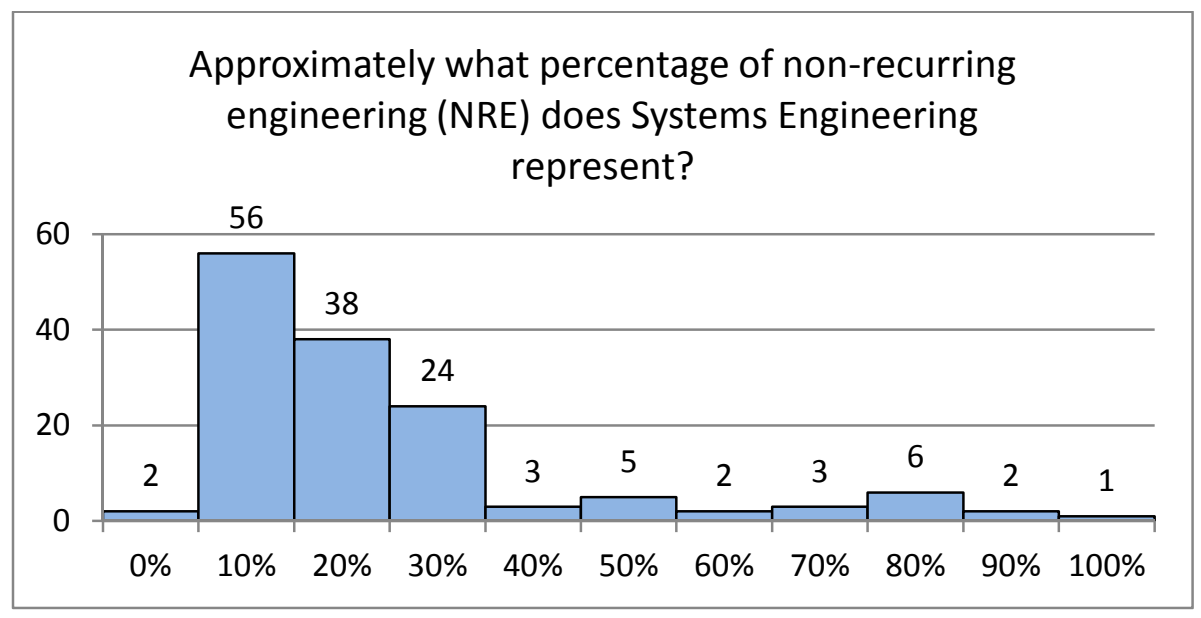

Figure 14: Question A.15 - Percentage of Non-Recurring Engineering 


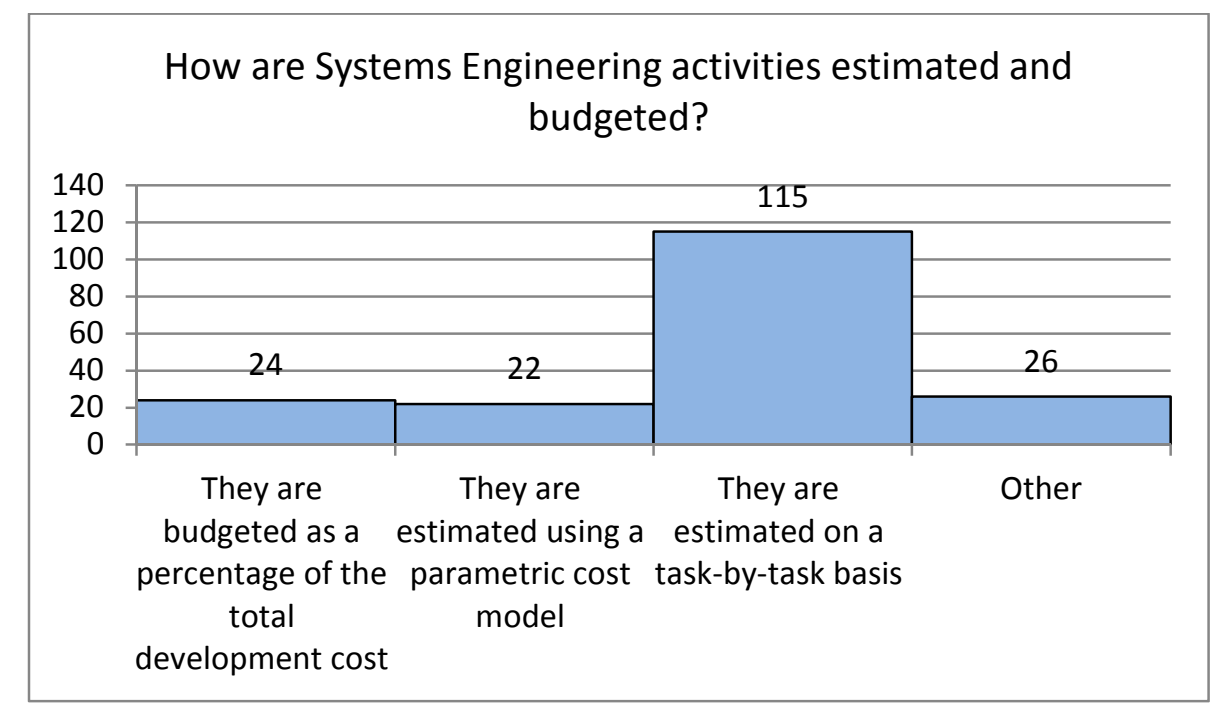

Figure 15: Question A.16 - SE Estimation and Budget Methods

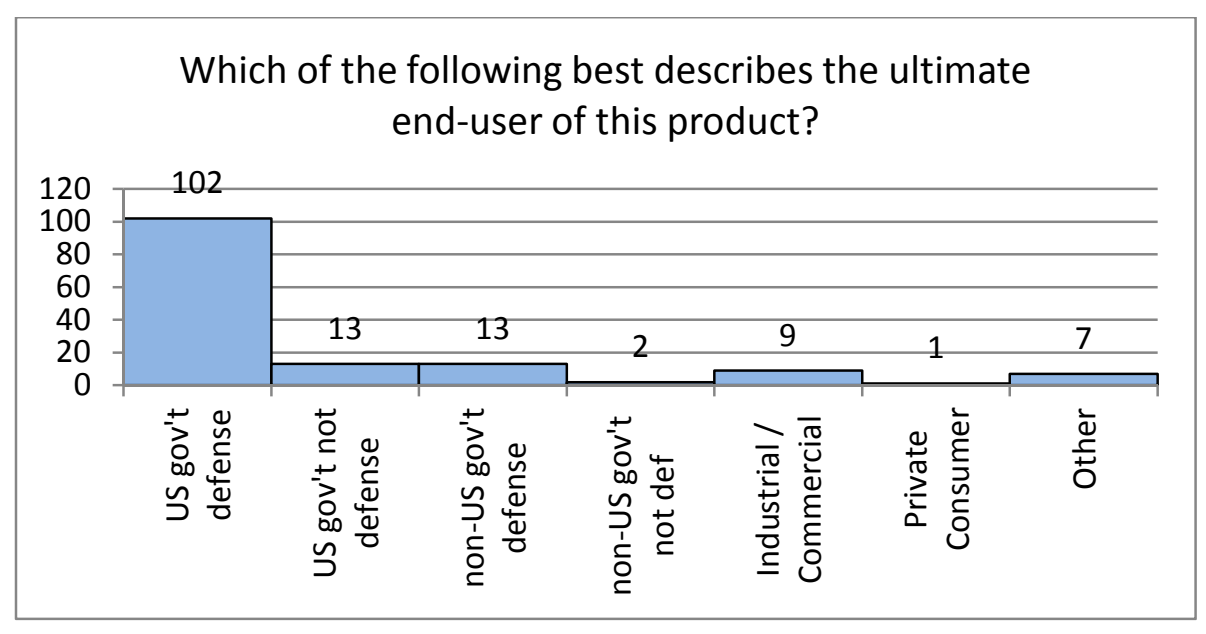

Figure 16: Question A.17 - Type of End User 


\section{Questionnaire Section B - About the Contract}

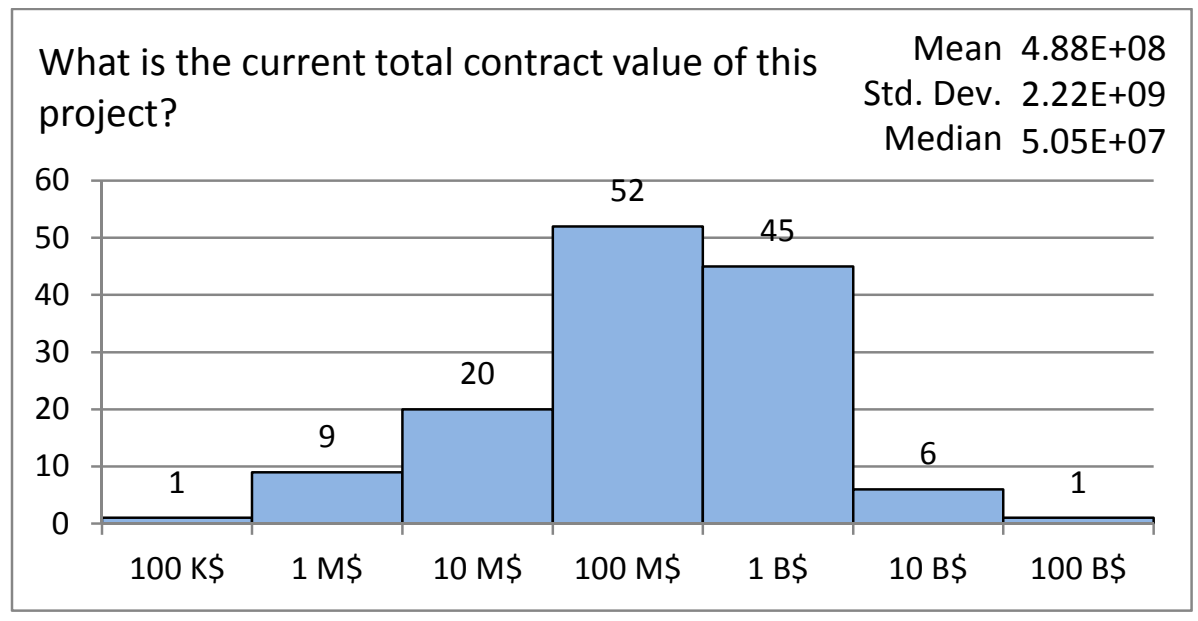

Figure 17: Question B.1 - Current Contract Value

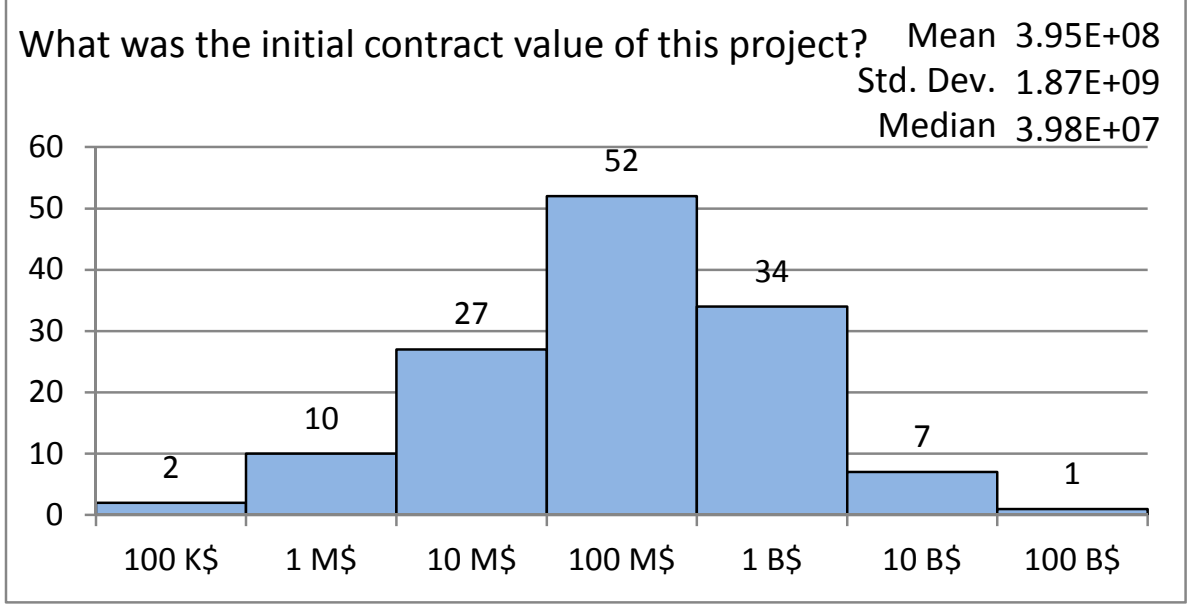

Figure 18: Question B.2 - Initial Contract Value 


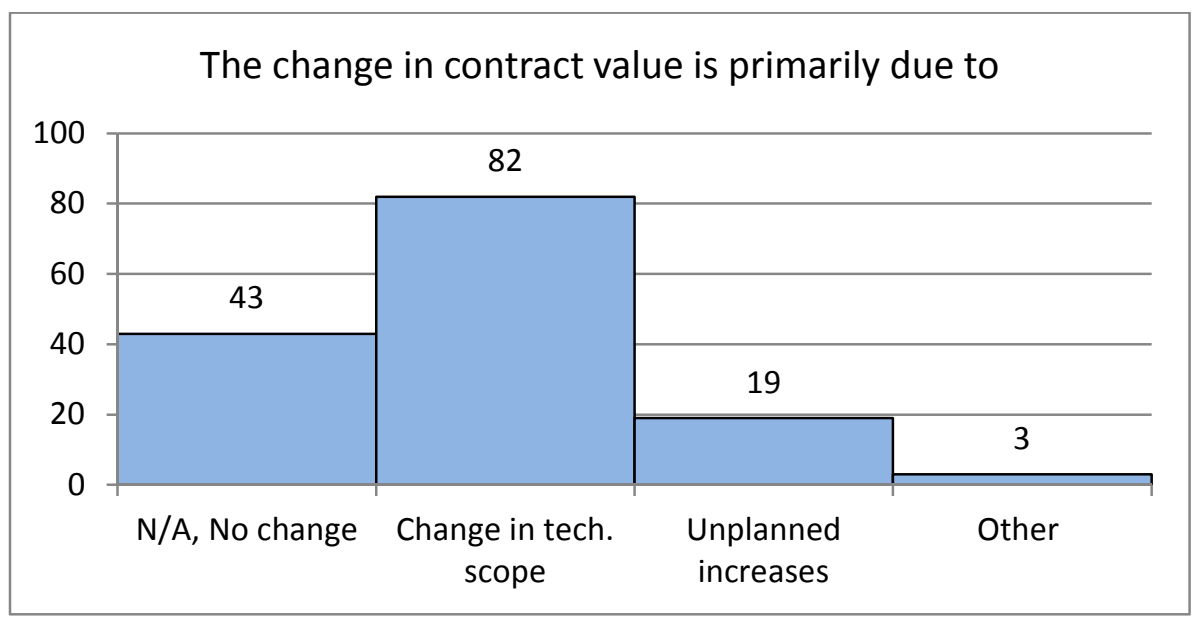

Figure 19: Question B.3 - Reason for Change in Contract Value

Table 3: Question B.3 - Other Sources of Contract Value Change

\section{B.3 Other sources of contract value change ${ }^{3}$}

There is no development contract. There are multiple customers for the end product which is sold as individual/group licenses. The project is not a standard contract development effort.

Customer funded the project incrementally due to their budgetary constraints.

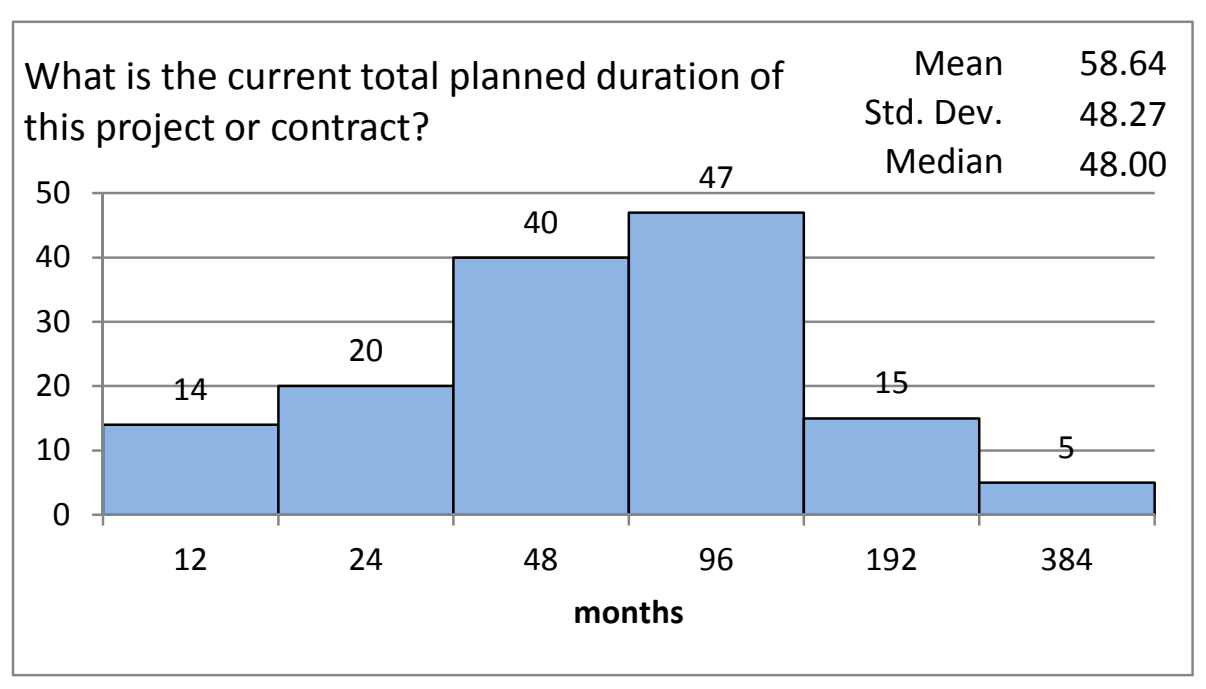

Figure 20: Question B.4 - Current Project Duration

$3 \quad$ Responses to this question included more selections of "other." Based on the analyst's interpretation of the accompanying text explanations, many of these responses were dispositioned to the other three categories. 


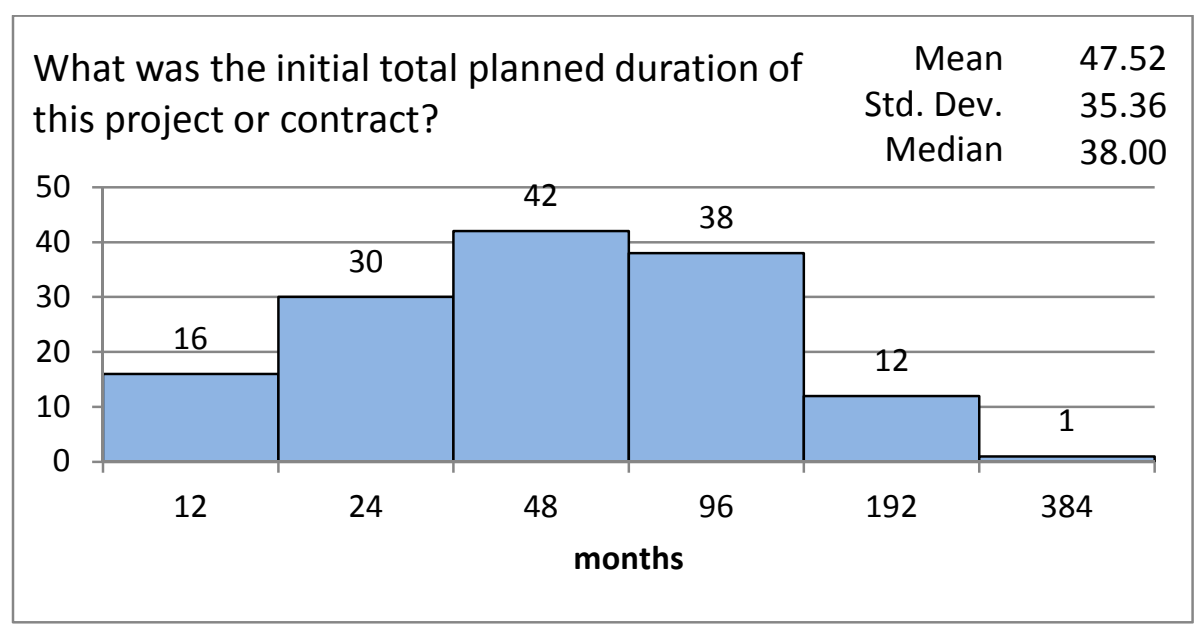

Figure 21: Question B.5 - Initial Planned Project Duration

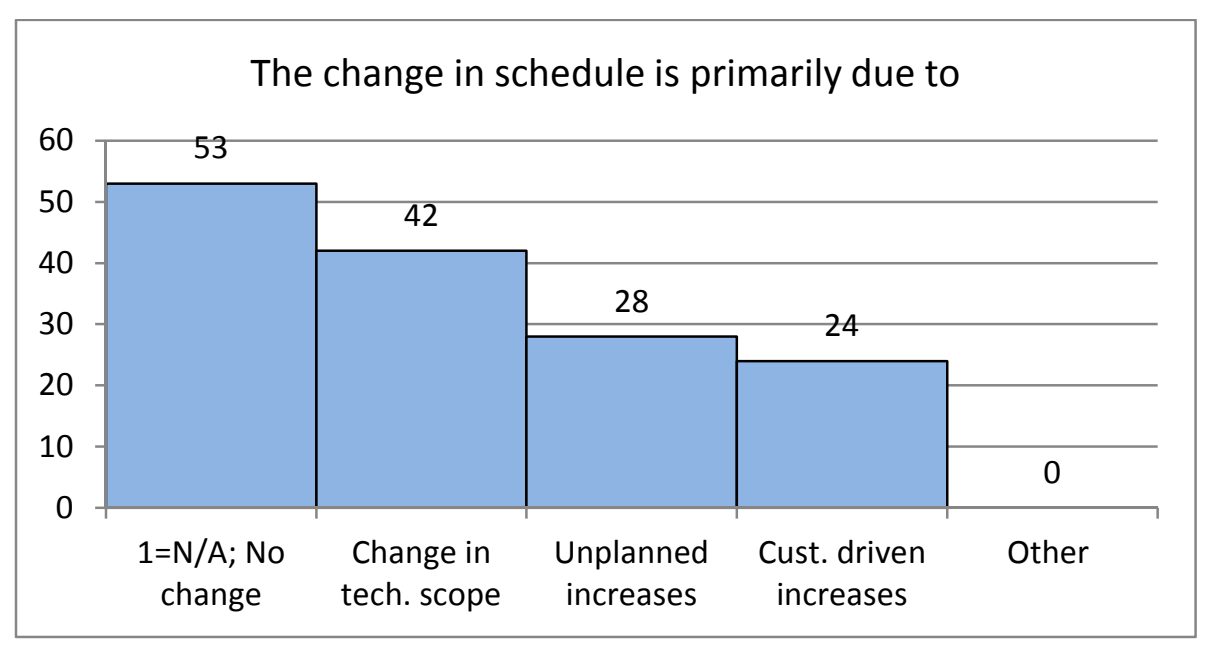

Figure 22: Question B.6 - Reason for Schedule Change4 accompanying text explanations, many of these responses were dispositioned to the other three categories. 


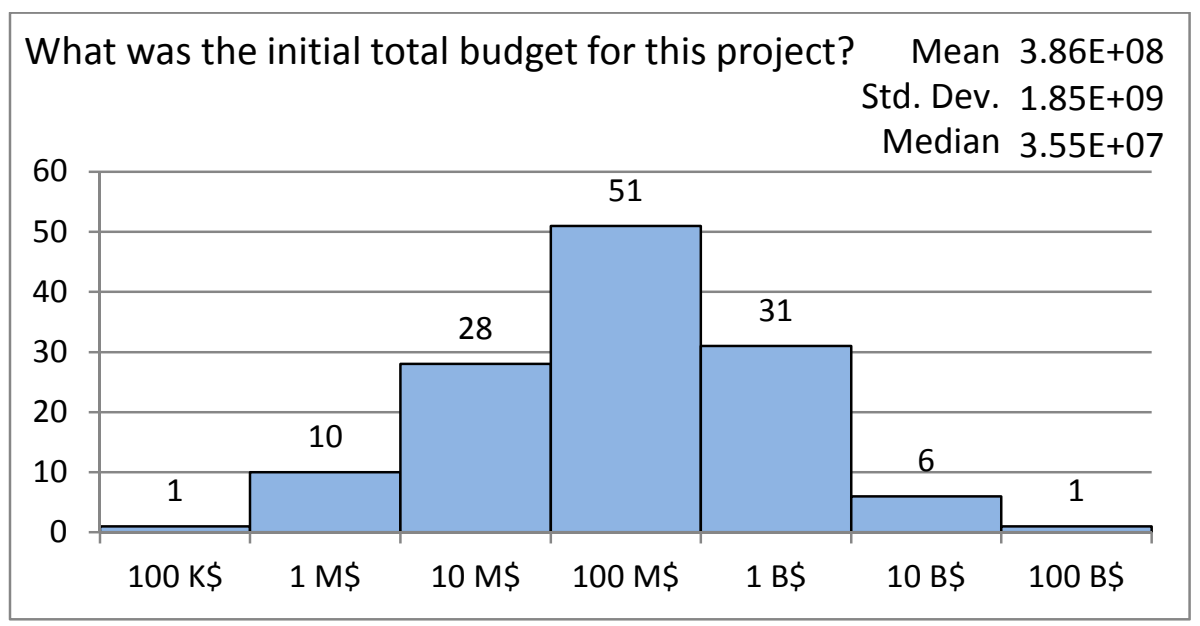

Figure 23: Question B.7 - Initial Total Budget

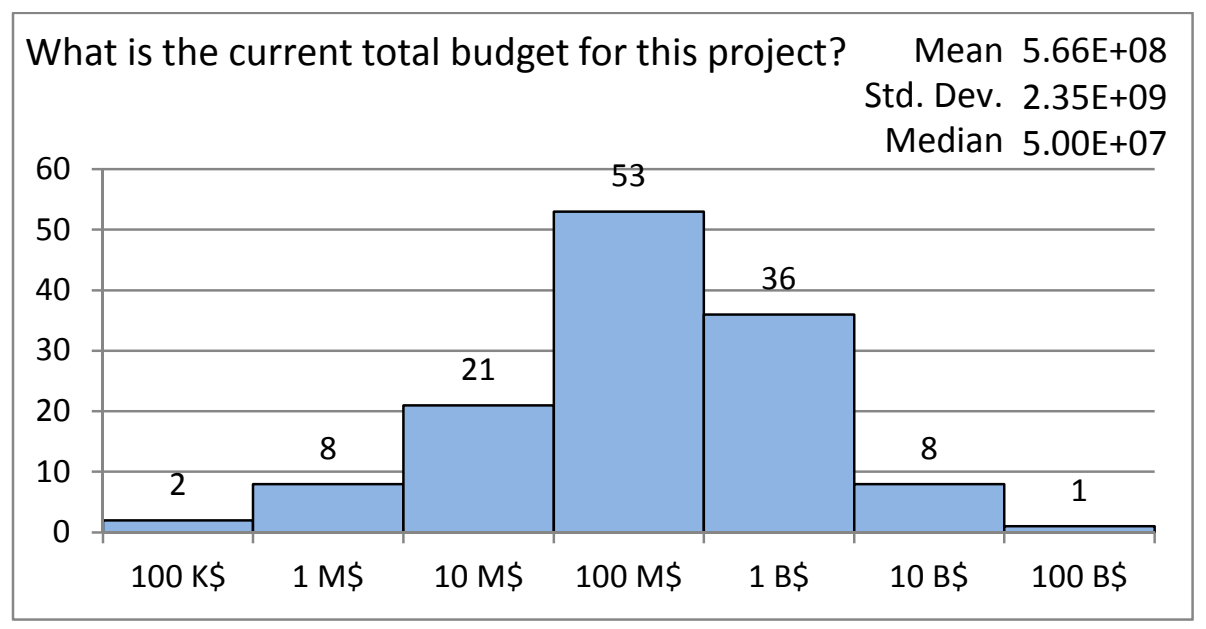

Figure 24: Question B.8 - Current Total Budget

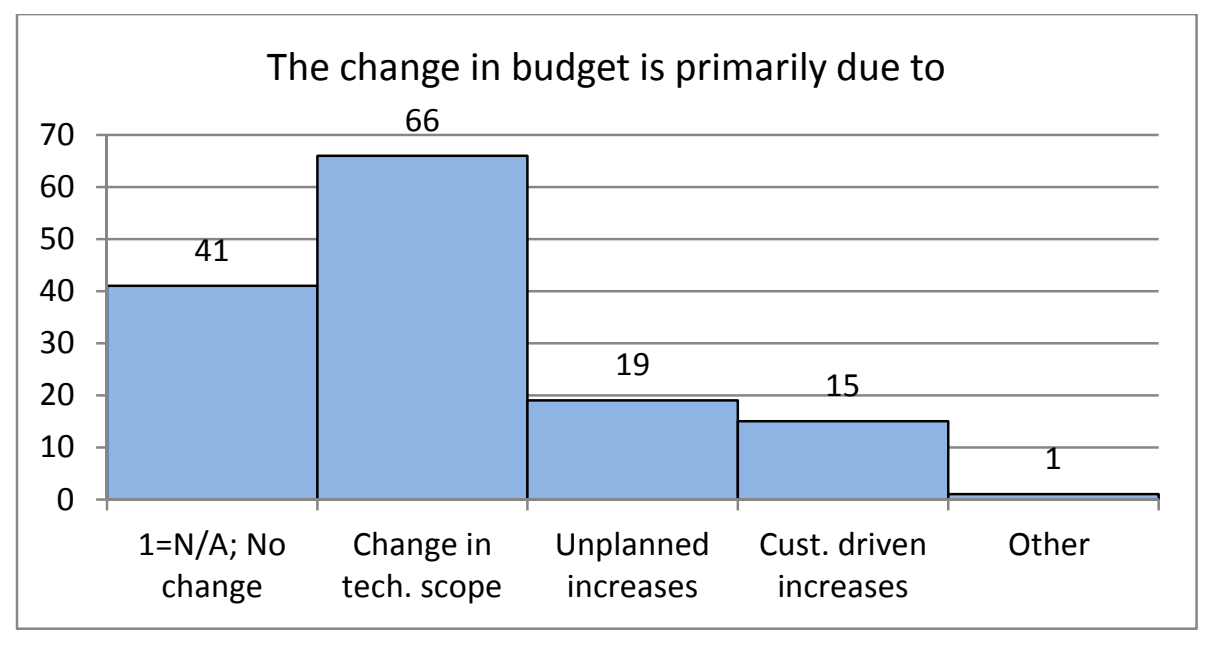

Figure 25: Question B.9-Reason for Budget Change 
Table 4: Question B.9 - Other Sources of Budget Change

\section{B.9 Other sources of budget change ${ }^{5}$}

Fixed price contract

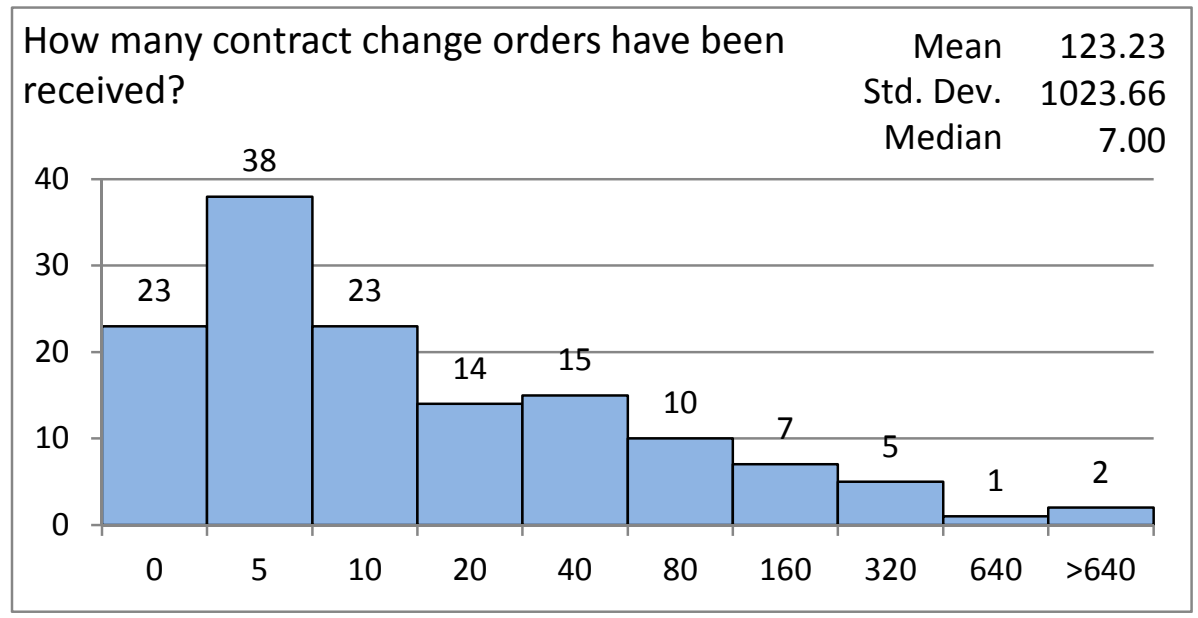

Figure 26: Question B.10 - Number of Contract Change Orders

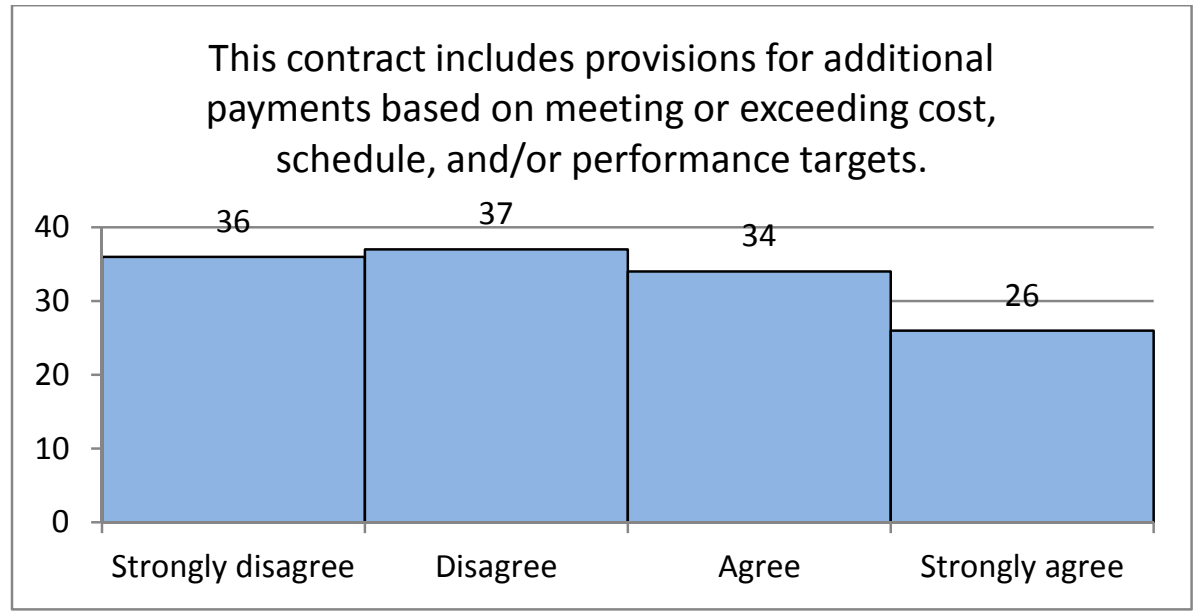

Figure 27: Question B.11 - Provisions for Additional Payments 


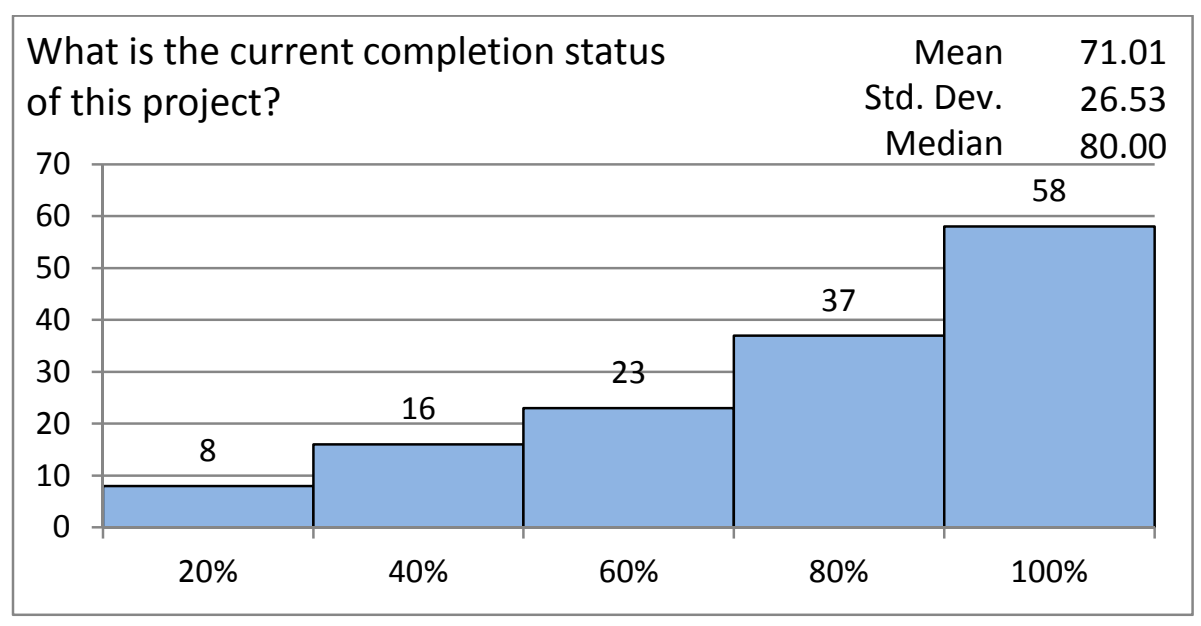

Figure 28: Question B.12 - Current Completion Status

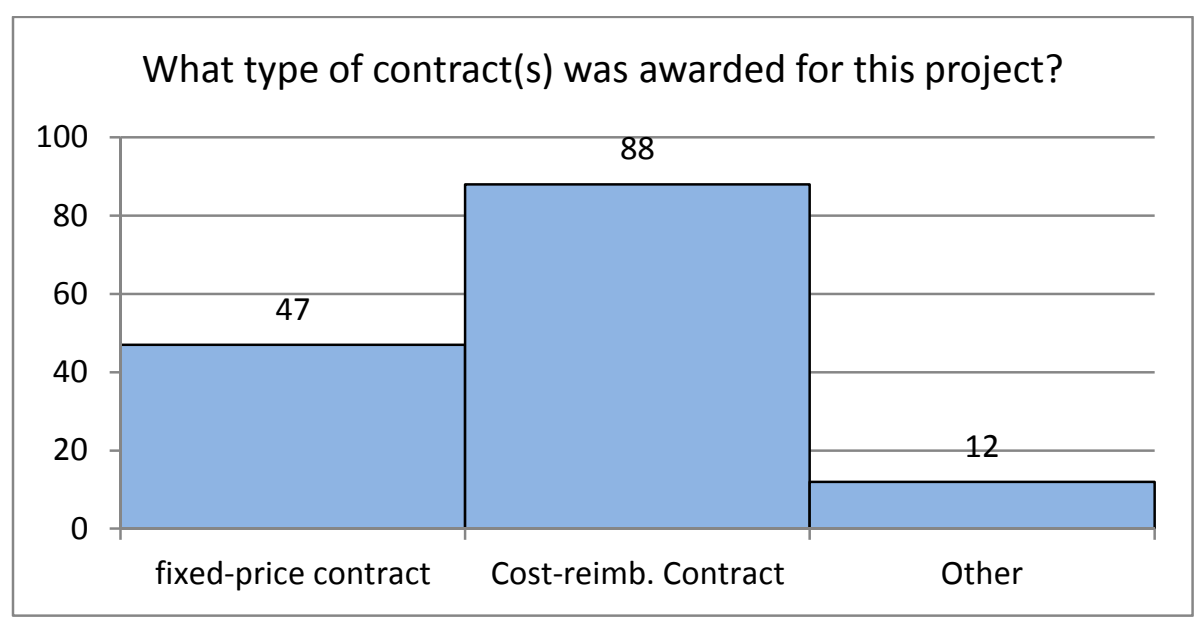

Figure 29: Question B.13 - Type of Contract

\section{Table 5: Question B.13 - Other Contract Types}

\begin{tabular}{l} 
B.13 Other contract types 6 \\
$\begin{array}{l}\text { Project is an internally funded software product development. Contracts are for individual/group software licenses on } \\
\text { the end product. }\end{array}$ \\
\hline The contract has multiple CLINs with different contract types including CPAF, LOE, and FFP. \\
\hline Three different CLINs include LOE, CPFF, and FFP. \\
\hline Task Order \\
\hline Internal business investment with some third party R\%T investment \\
\hline Internally governed project - internal cost agreement \\
\hline Not contracted
\end{tabular}

$6 \quad$ Responses to this question included more selections of "other." Based on the analyst's interpretation of the accompanying text explanations, many of these responses were dispositioned to the other two categories. 


\section{Questionnaire Section C - About the Organization}

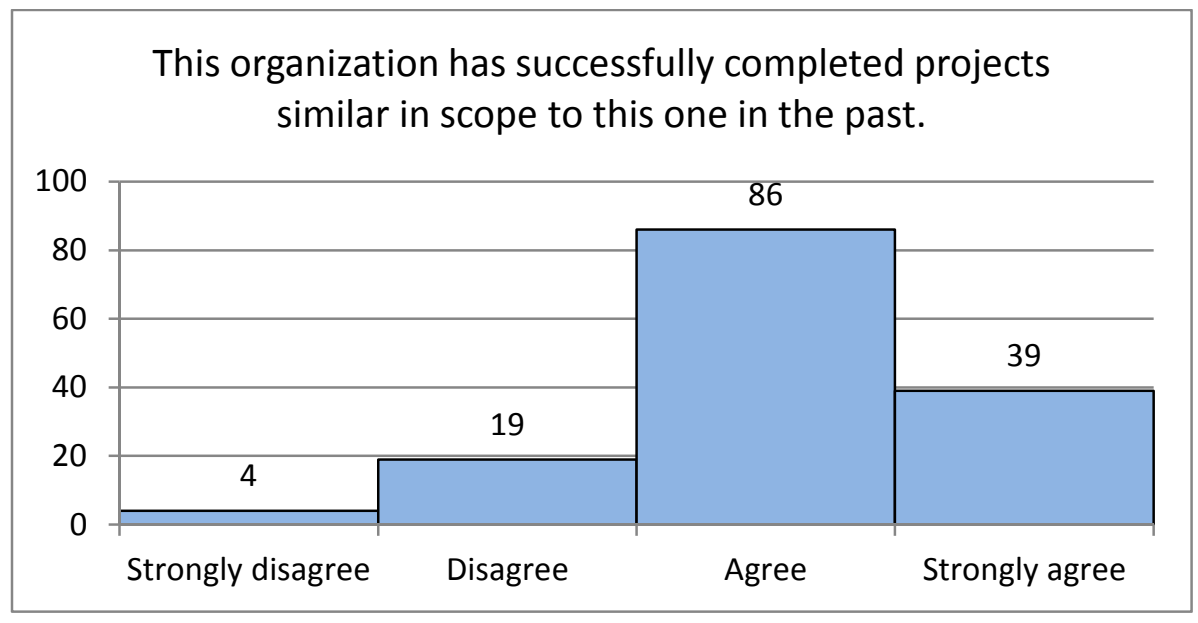

Figure 30: Question C.1 - Previous Success with Similar Projects

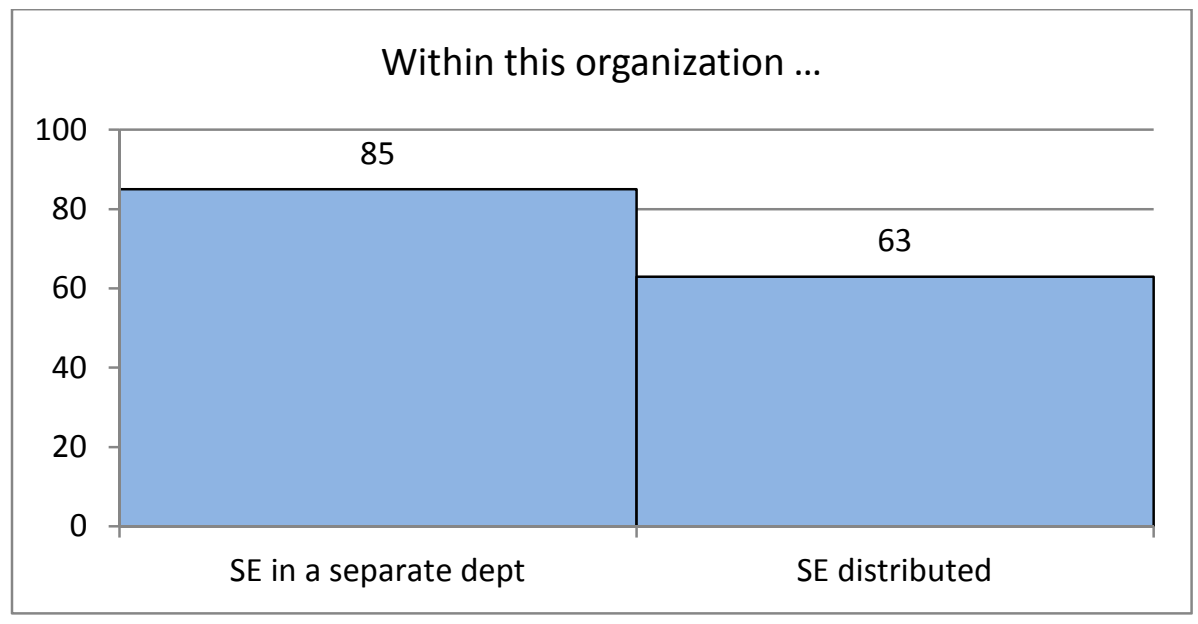

Figure 31: Question C.2 - SE Organization 


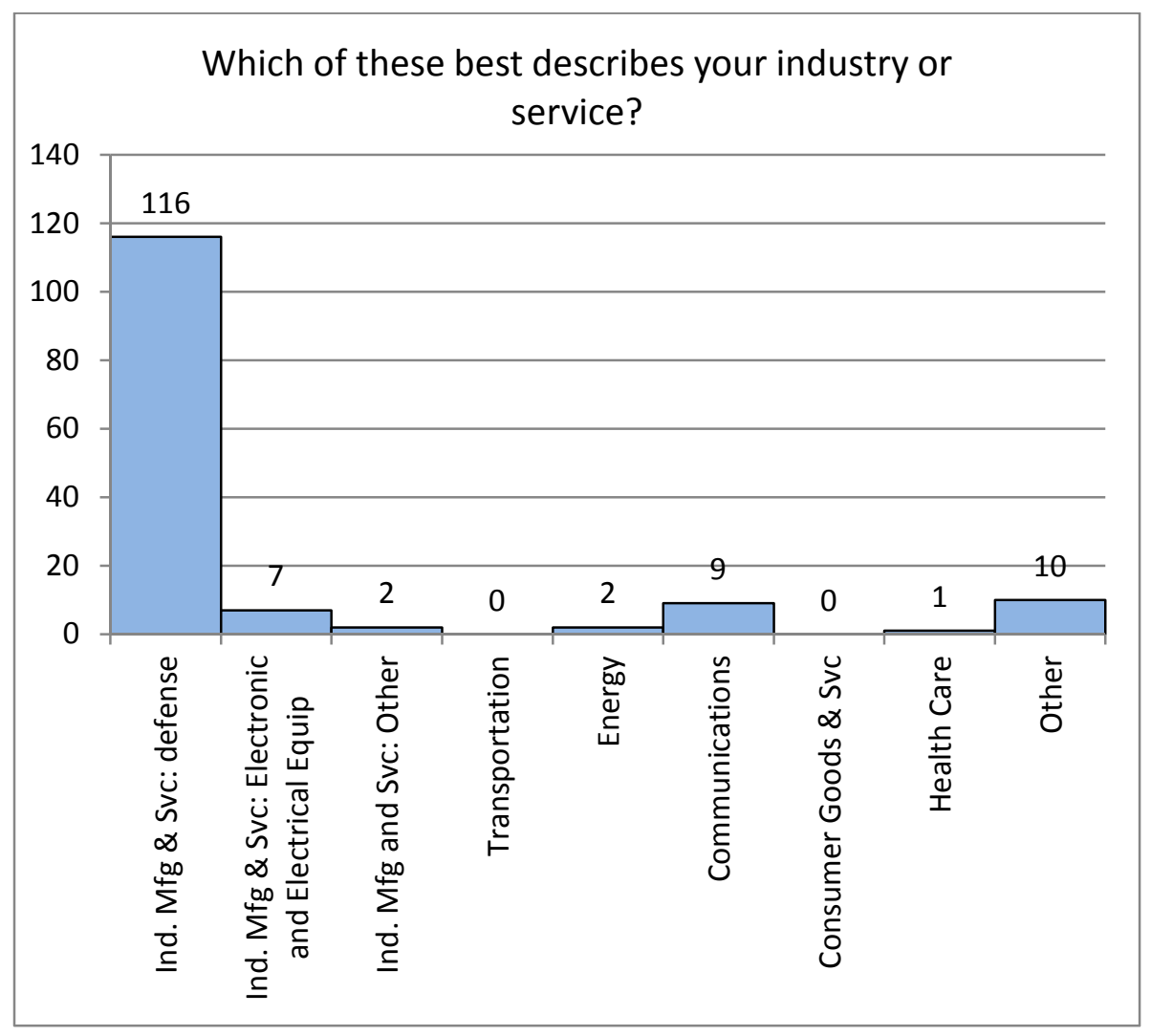

Figure 32: Question C.3 - Type of Industry or Service

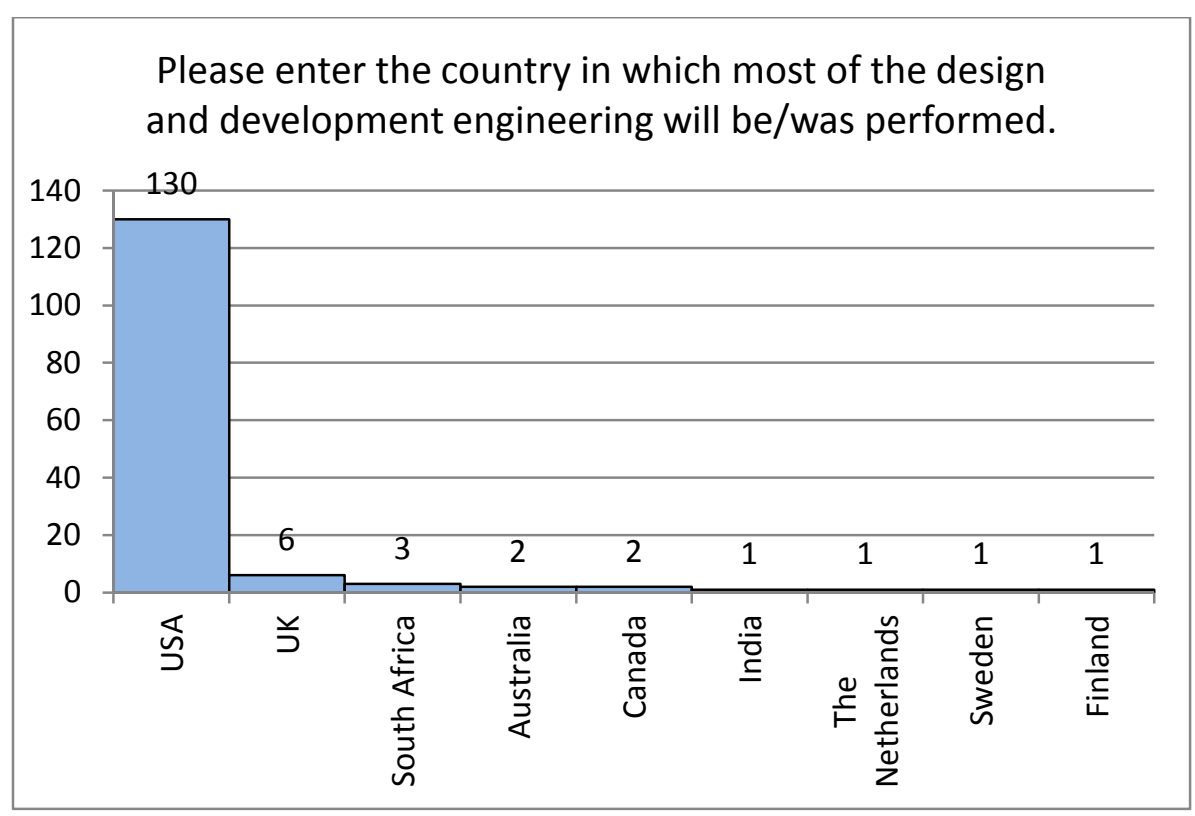

Figure 33: Question C.4 - Location of Design and Development Engineering Work 
Table 6: Question C.5 - Other Notes of Importance About the Project

C.5 Is anything else particularly important in characterizing your project, product, contract, or organization within which it resides?

Security classification issues (lack of cleared staff)

Organizational issues (complex multi-national supply chain, subcontractors are also competitors, re-organizations, geographic distribution)

Acquirer issues (multiple customers, incomplete requirements)

Legacy products (defective GFE)

Technology issues (reliability, environment, complexity, technology immaturity)

Skill and resource issues (inexperienced developers, not enough SEs, PM discourages SE use) 


\section{Questionnaire Section D - Project Planning}

This project utilizes/utilized a documented set of Systems Engineering processes for the planning and execution of the project.

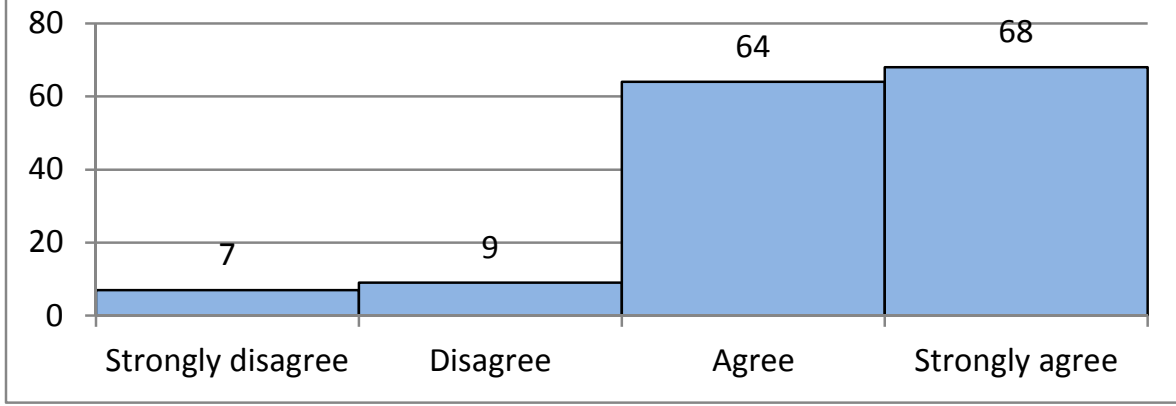

Figure 34: Question D.1 - Use of Documented SE Processes

This project has/had an accurate and up-to-date WBS that included task descriptions and work package descriptions.

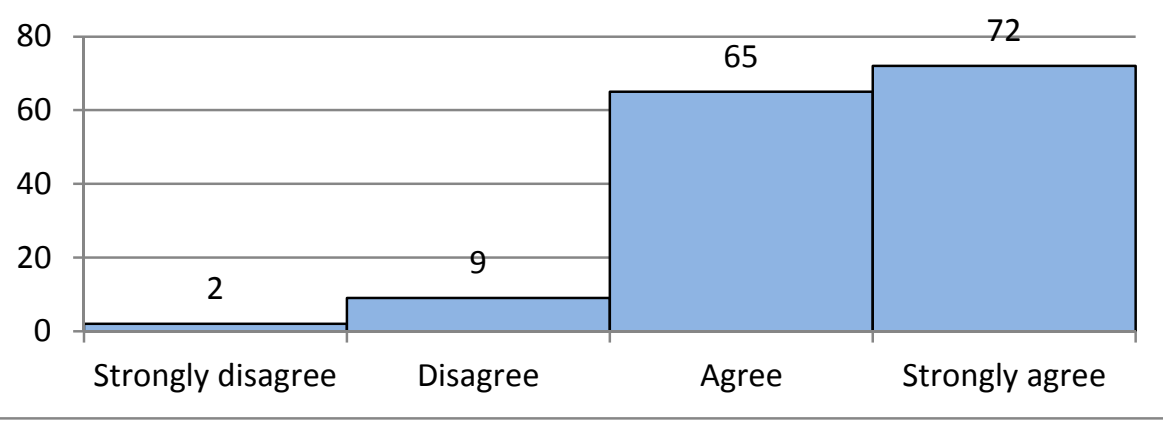

Figure 35: Question D.2 - Use of a WBS 


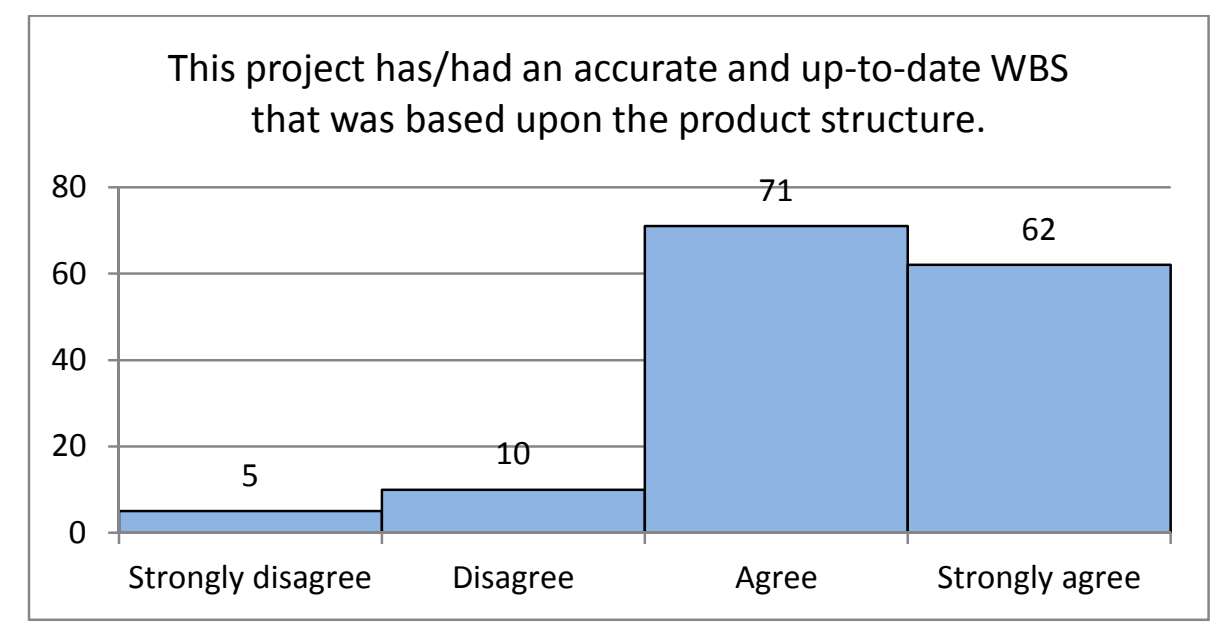

Figure 36: Question D.3 - Accuracy and Currency of the WBS

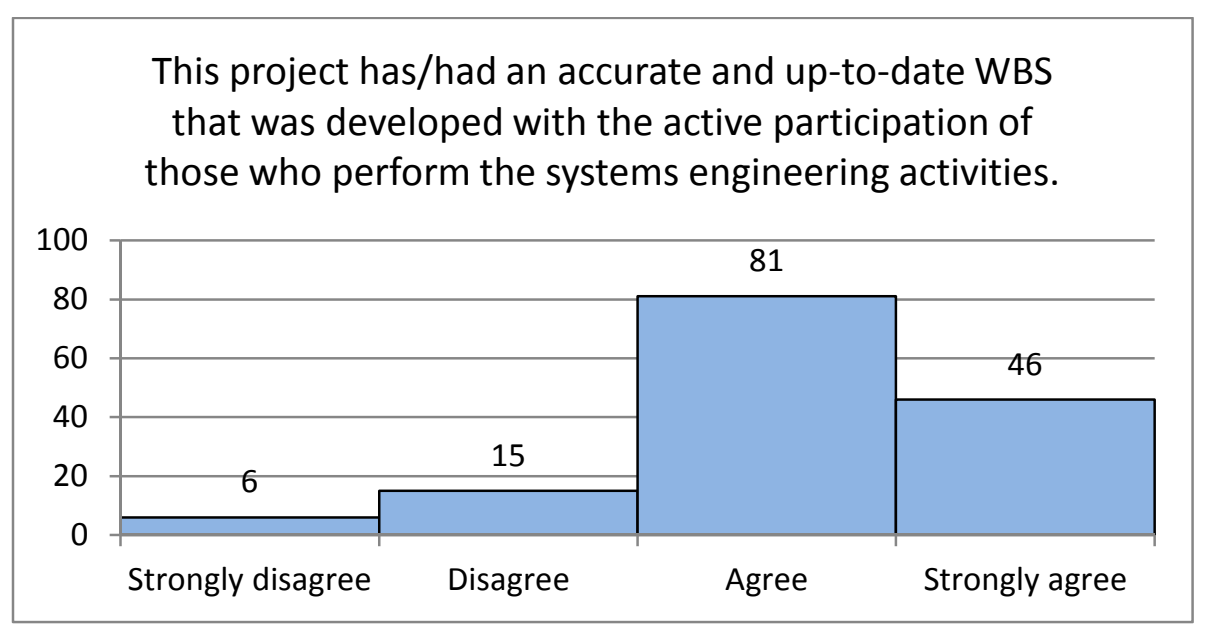

Figure 37: Question D.4 - Involvement of Systems Engineers in Maintaining the WBS

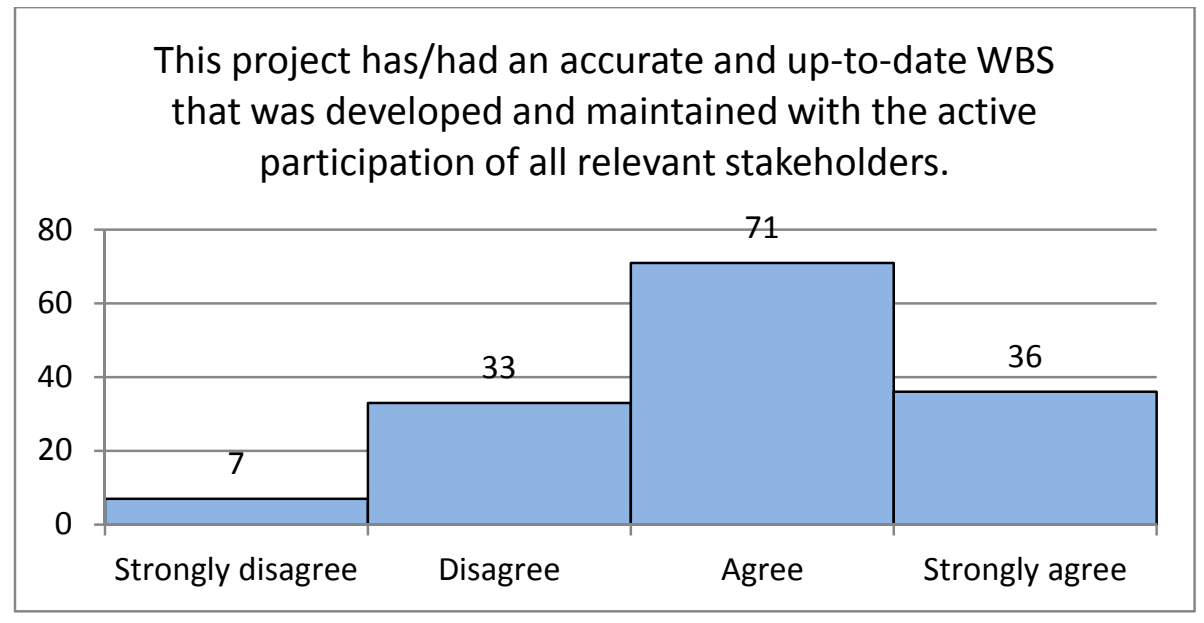

Figure 38: Question D.5 - Involvement of Stakeholders in Maintaining the WBS 


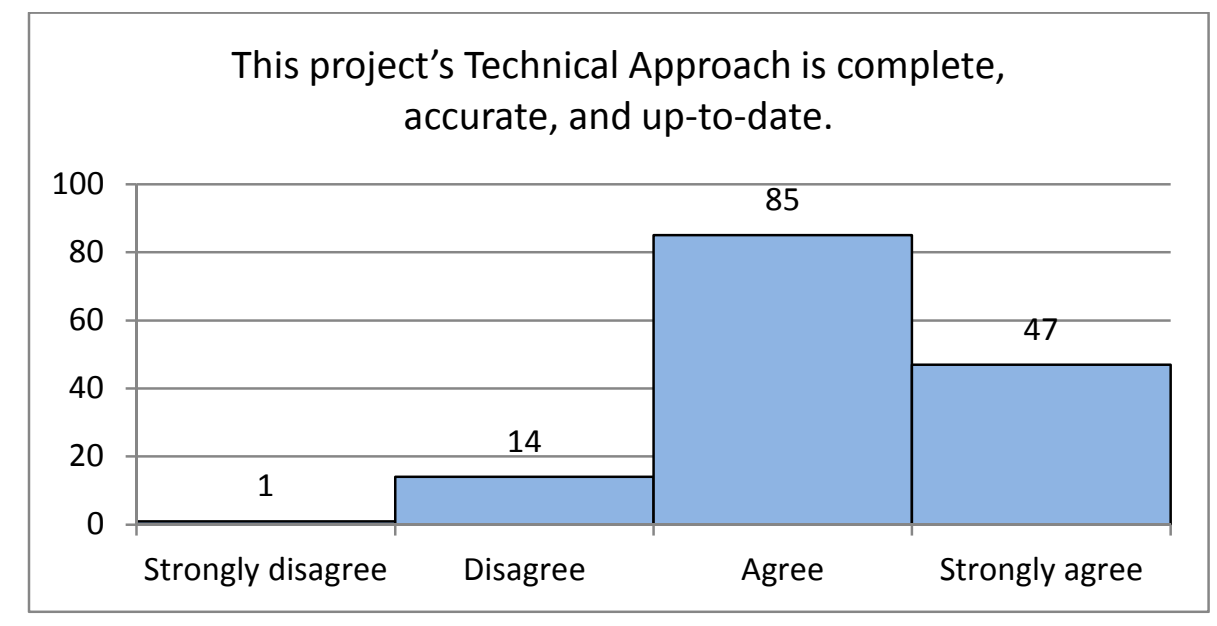

Figure 39: Question D.6 - Quality of the Technical Approach

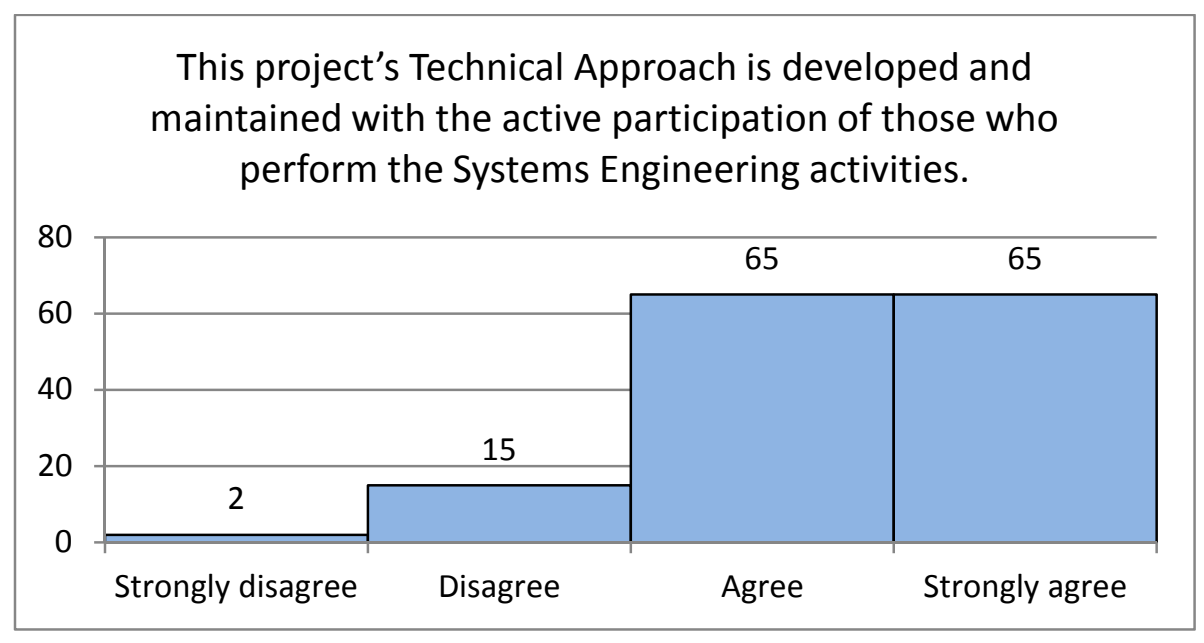

Figure 40: Question D.7 - Involvement of SE in Maintaining the Technical Approach

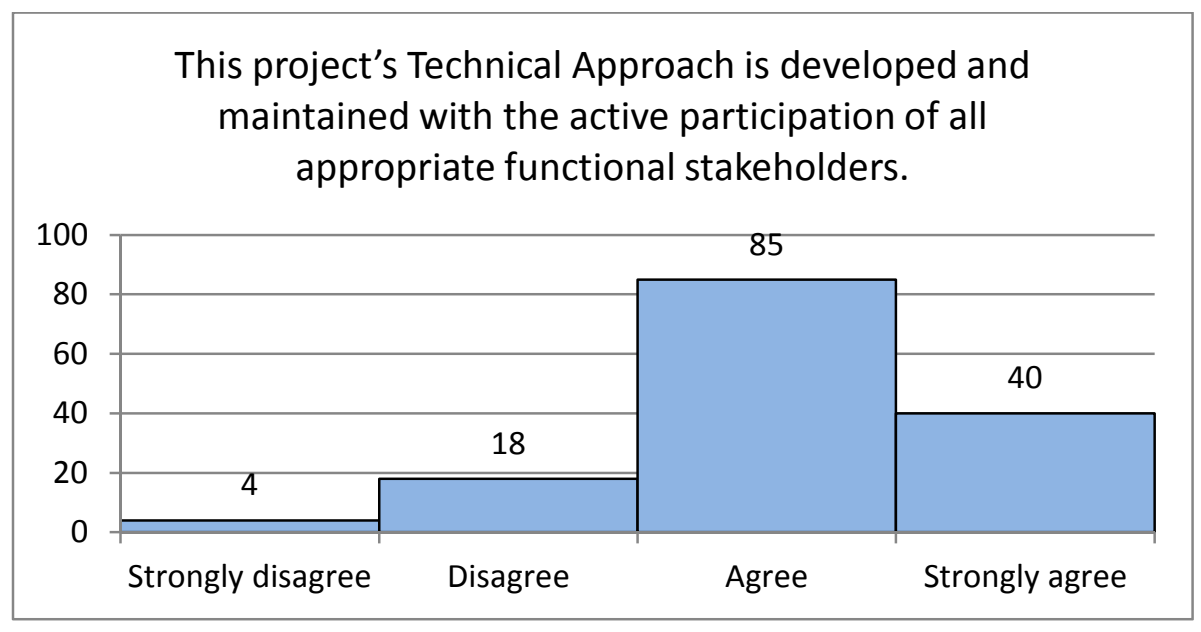

Figure 41: Question D.8 - Involvement of Stakeholders in Maintaining the Technical Approach 


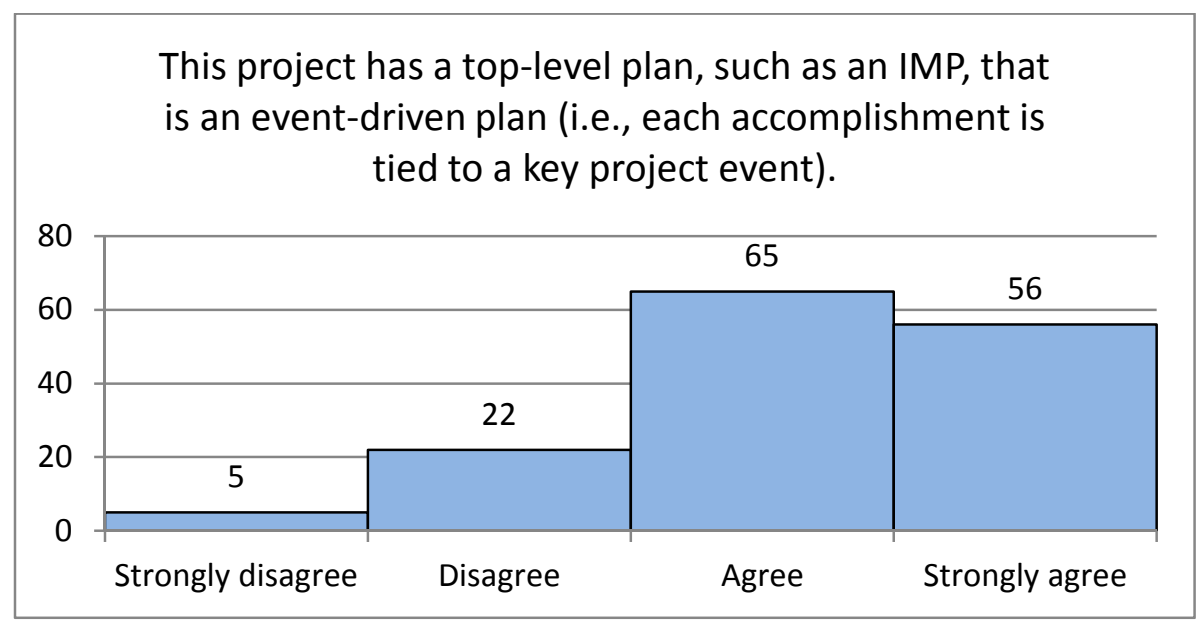

Figure 42: Question D.9-Existence of a Top-Level Plan

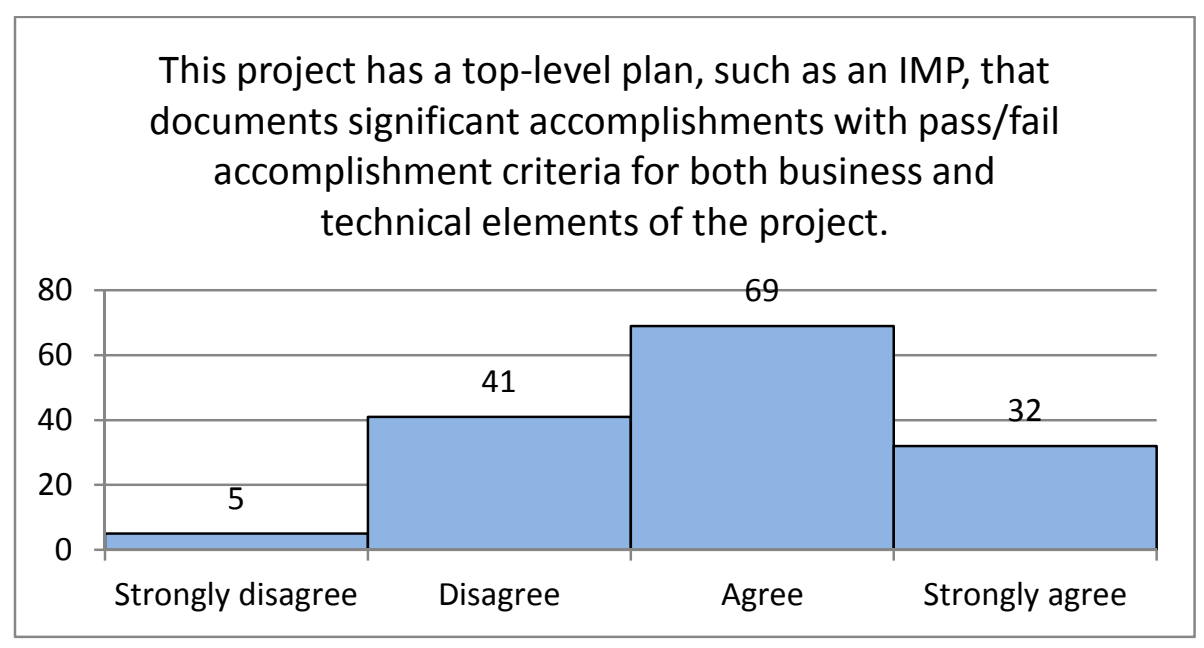

Figure 43: Question D.10 - Coverage of the Top-Level Plan

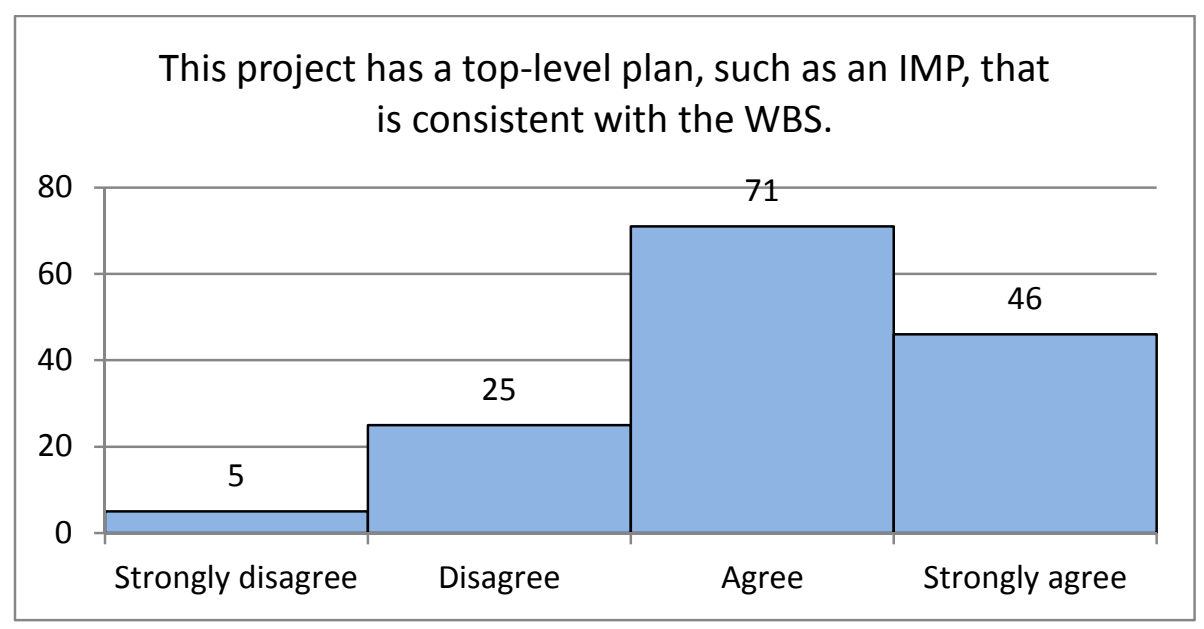

Figure 44: Question D.11 - Consistency of the Top-Level Plan with the WBS 


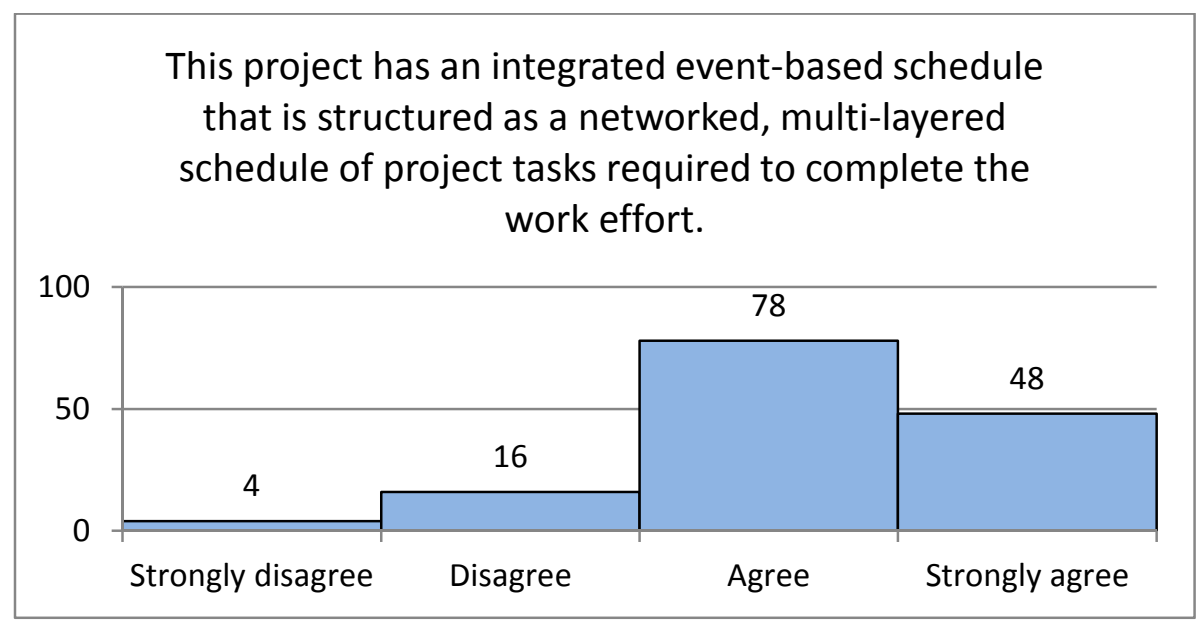

Figure 45: Question D.12 - Quality of the Schedule

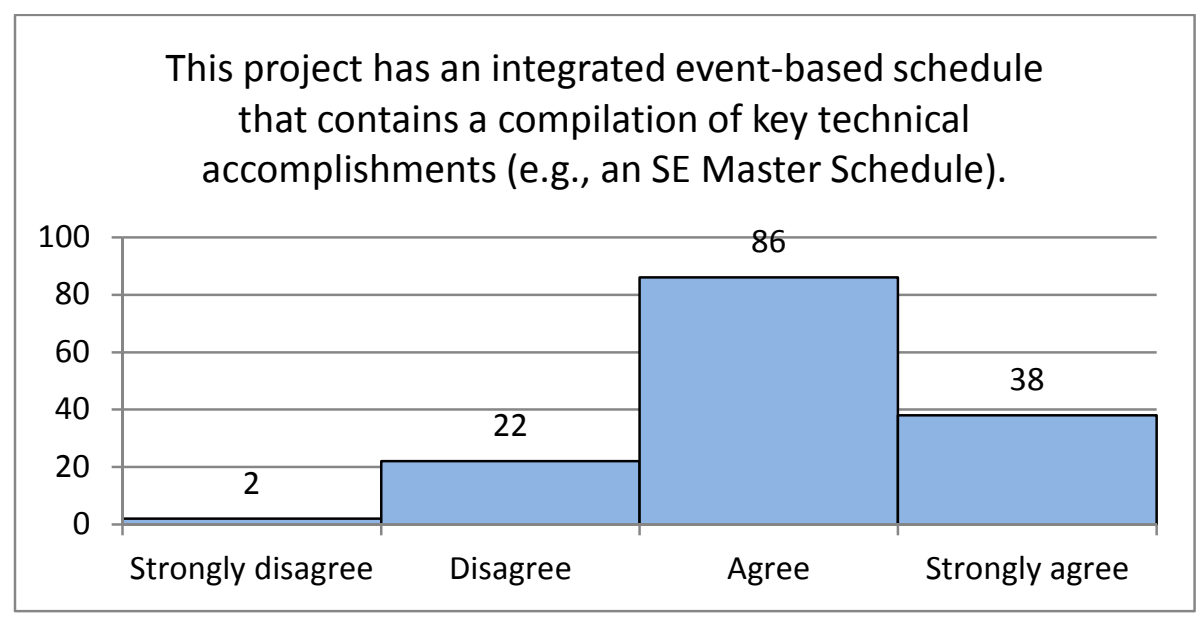

Figure 46: Question D.13 - Key Technical Accomplishments in the Schedule

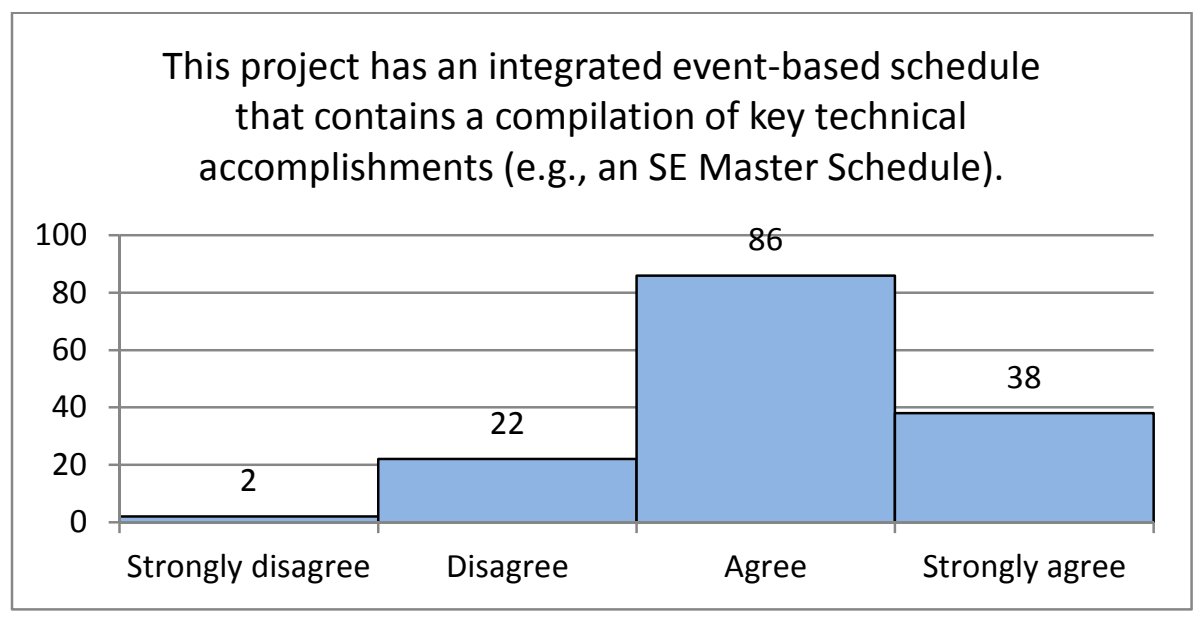

Figure 47: Question D.14 - Measurable Basis for the Schedule 


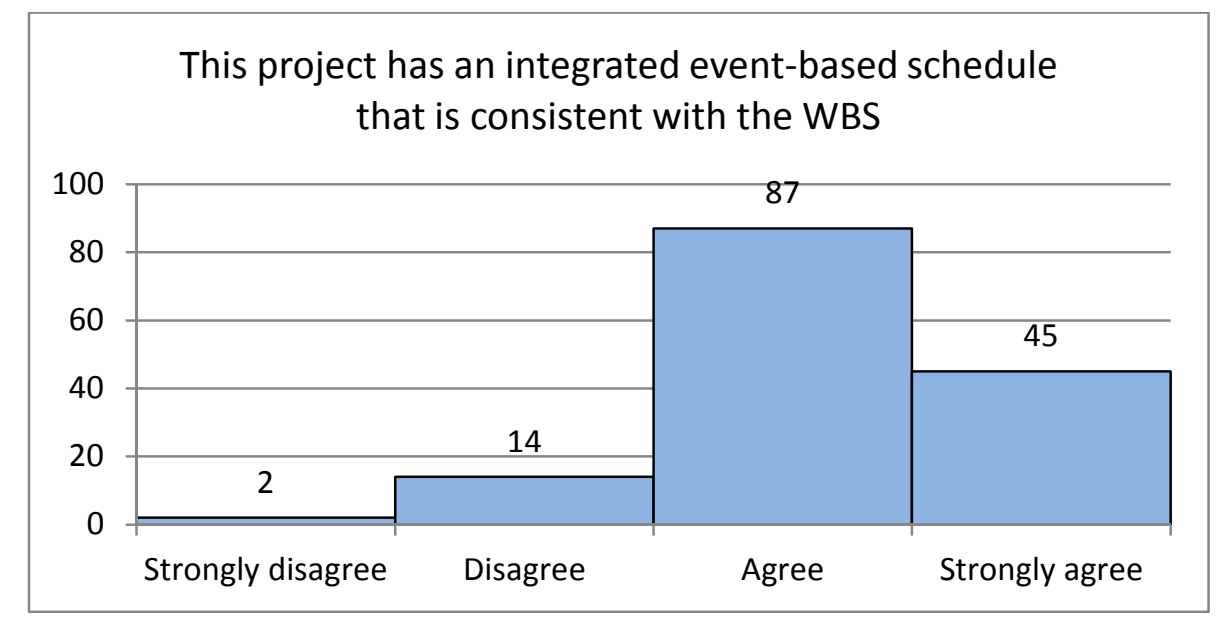

Figure 48: Question D.15 - The Schedule's Consistency with the WBS

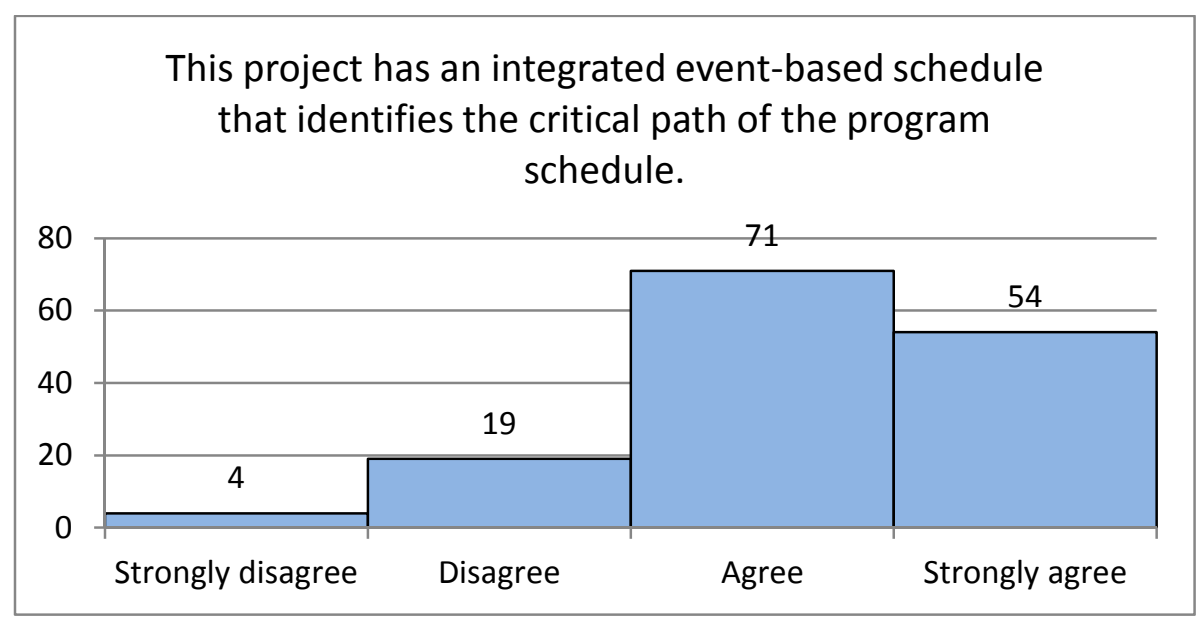

Figure 49: Question D.16 - Critical Path in the Schedule

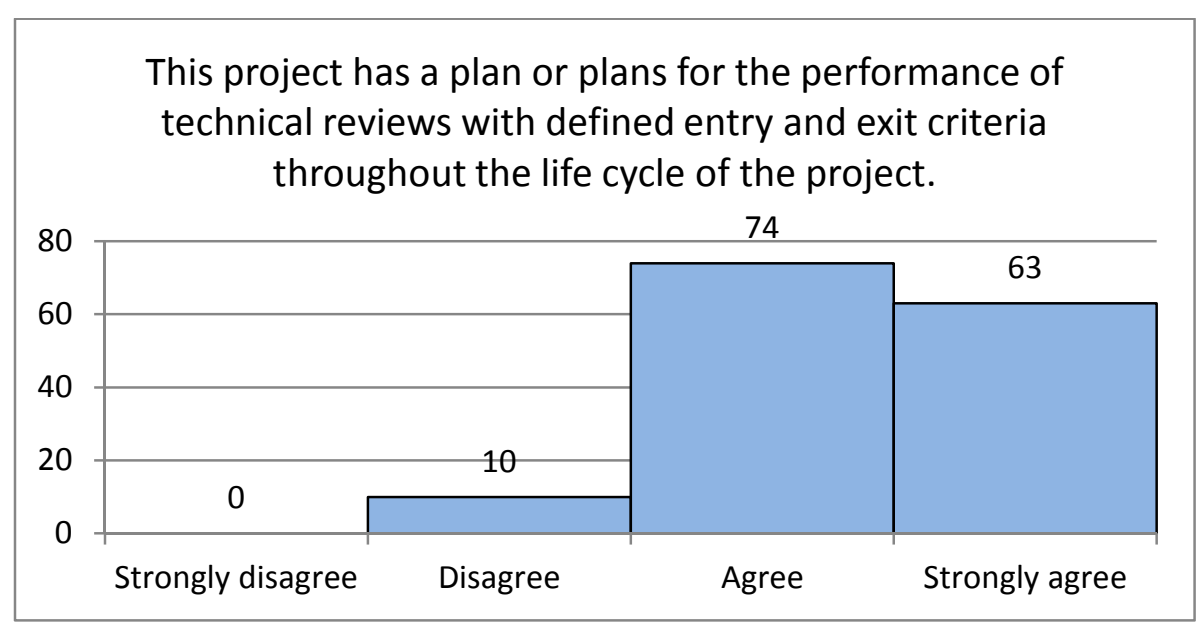

Figure 50: Question D.17 - Plan for Periodic Technical Reviews 


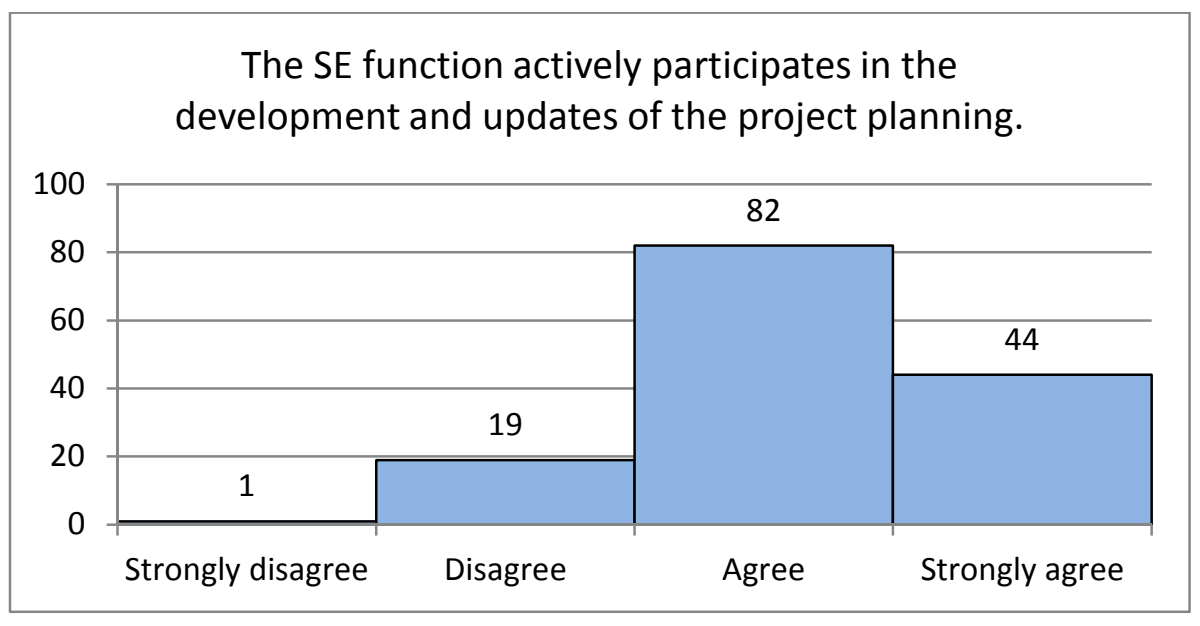

Figure 51: Question D.18 - SE involvement in Project Planning

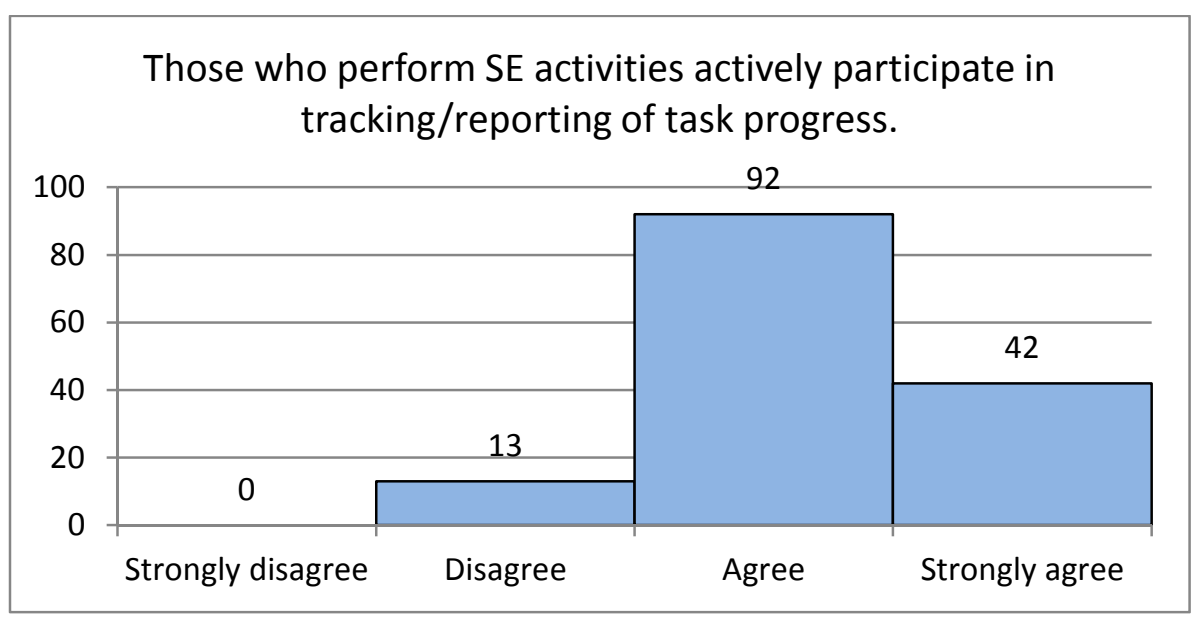

Figure 52: Question D.19 - SE Involvement in Tracking and Reporting Progress

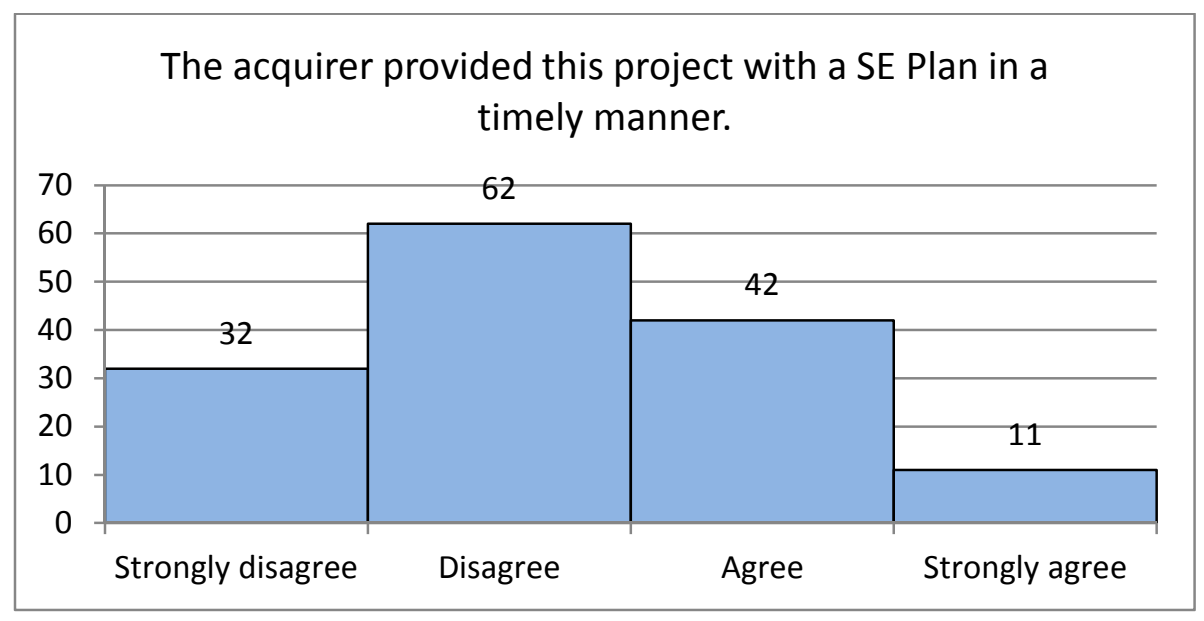

Figure 53: Question D.20 - Acquirer-Provided SE Plan 


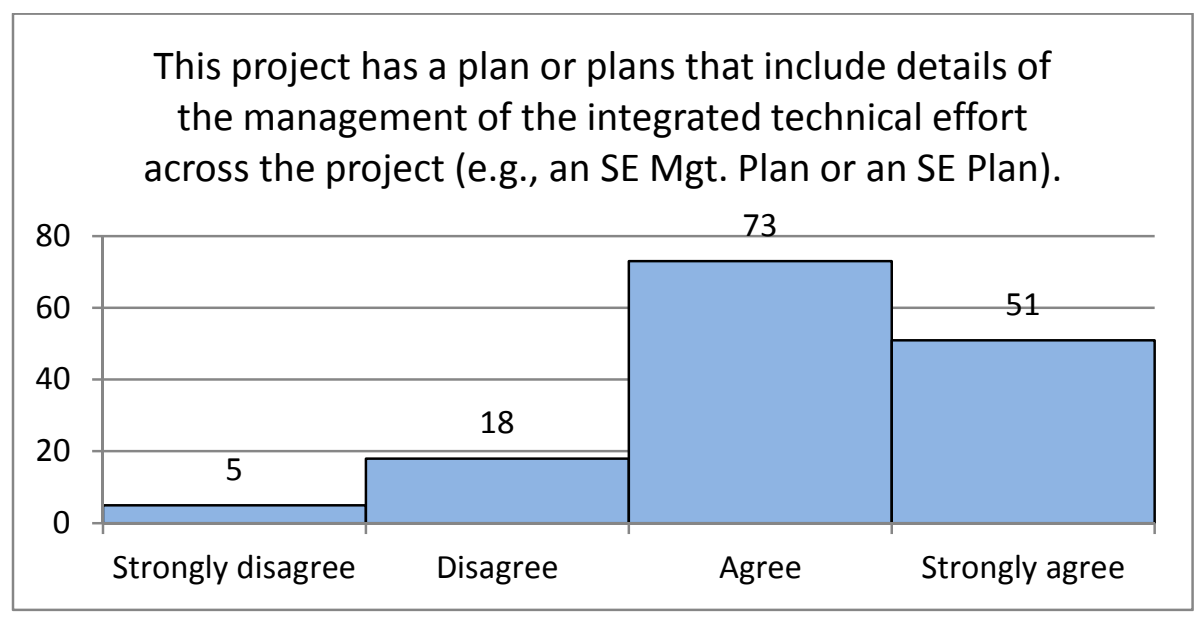

Figure 54: Question D.21 - Plan for Integrated Technical Effort

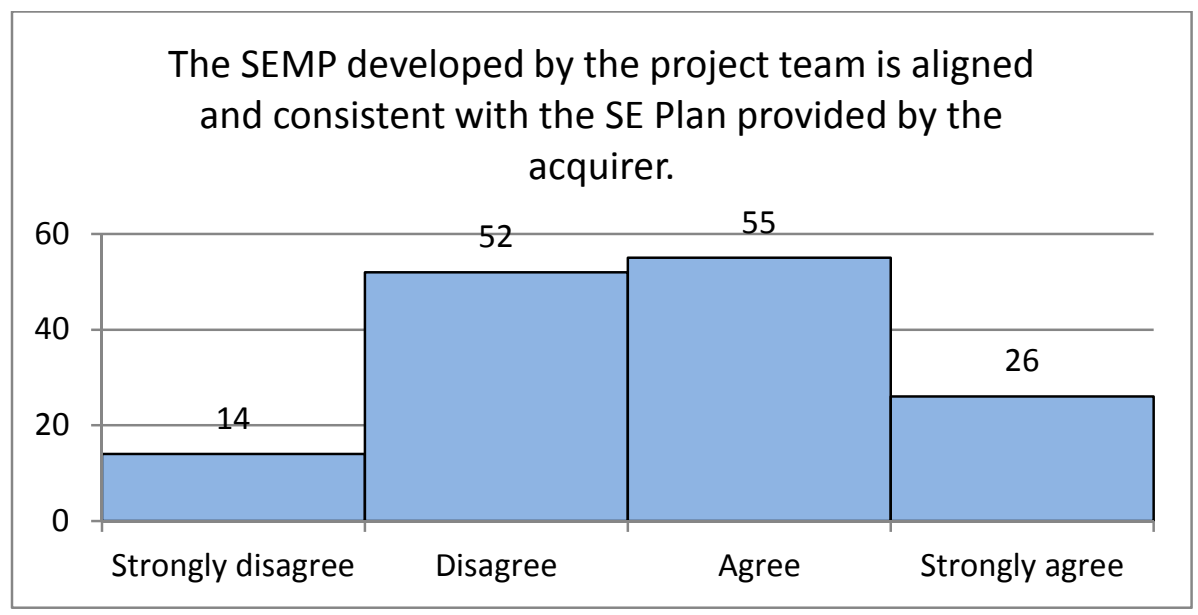

Figure 55: Question D.22 - SEMP Consistency with the Acquirer's SE Plan 


\section{Questionnaire Section E - Integrated Product Teams}

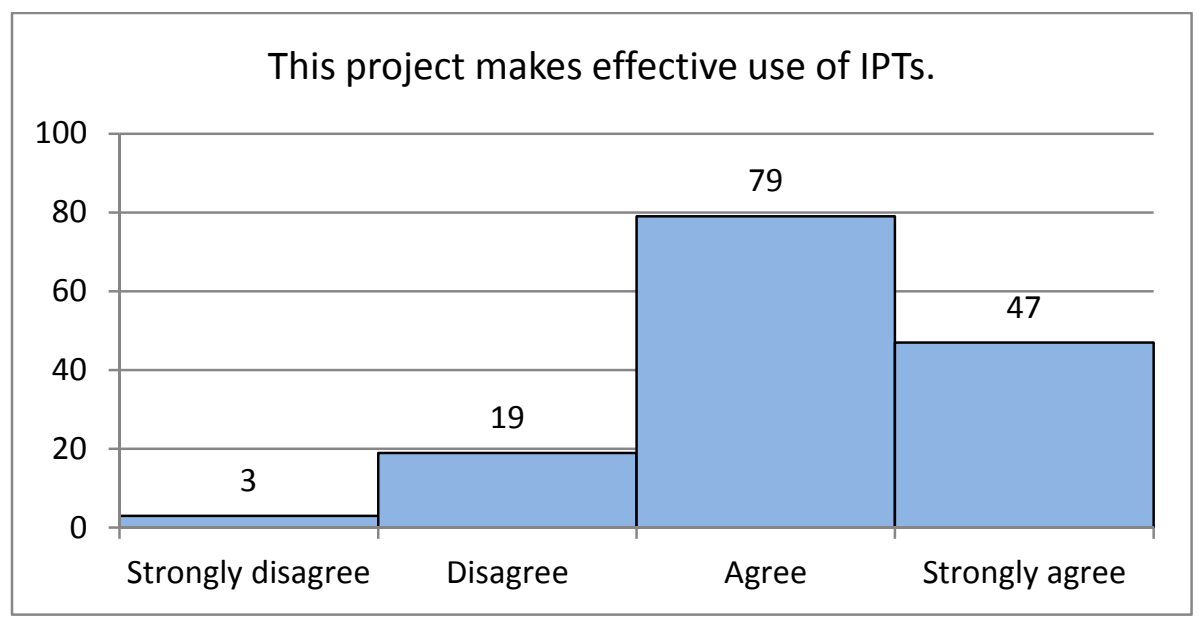

Figure 56: Question E.1 - Effectiveness of IPTS

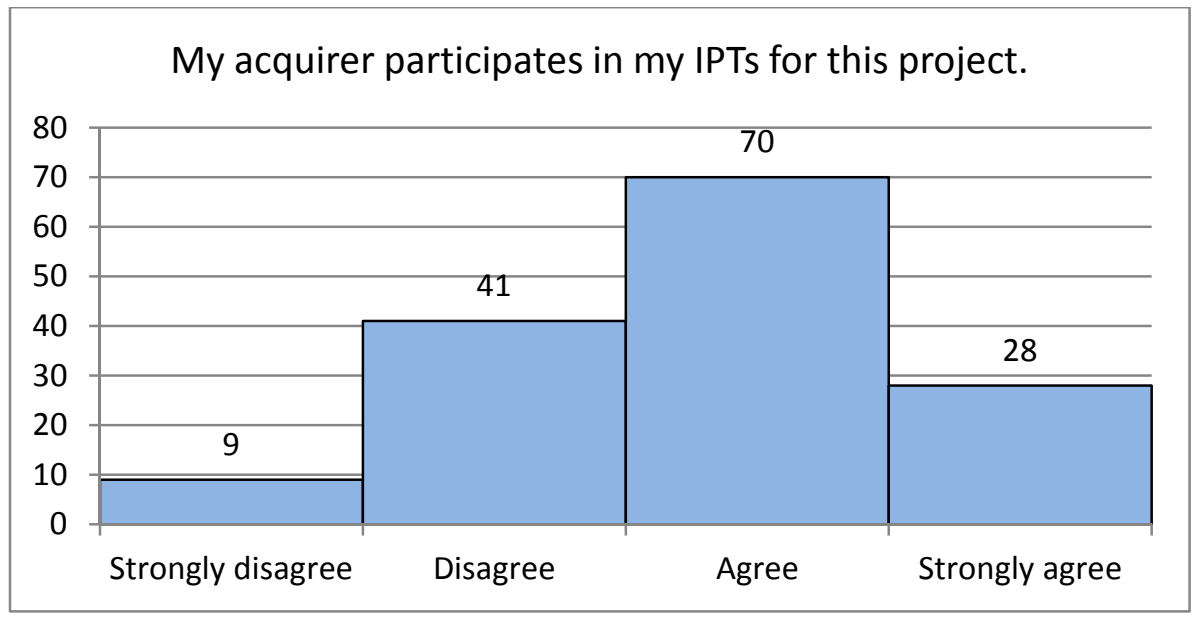

Figure 57: Question E.2 - Acquirer Participation in IPTS ${ }^{8}$ 


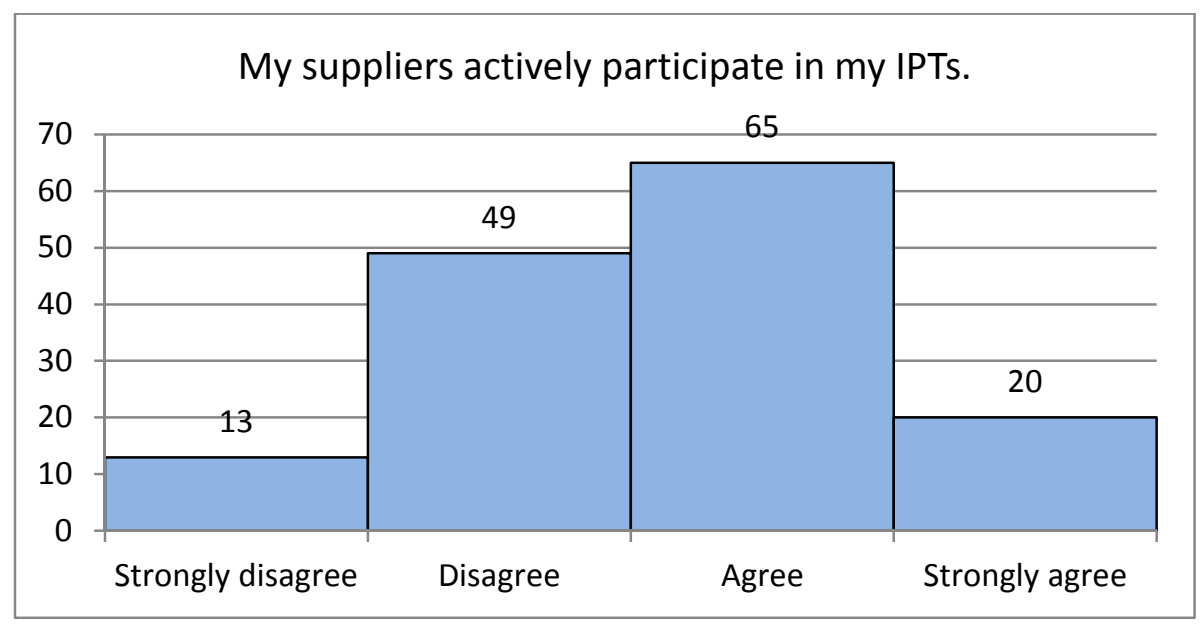

Figure 58: Question E.3 - Supplier Participation in IPTS

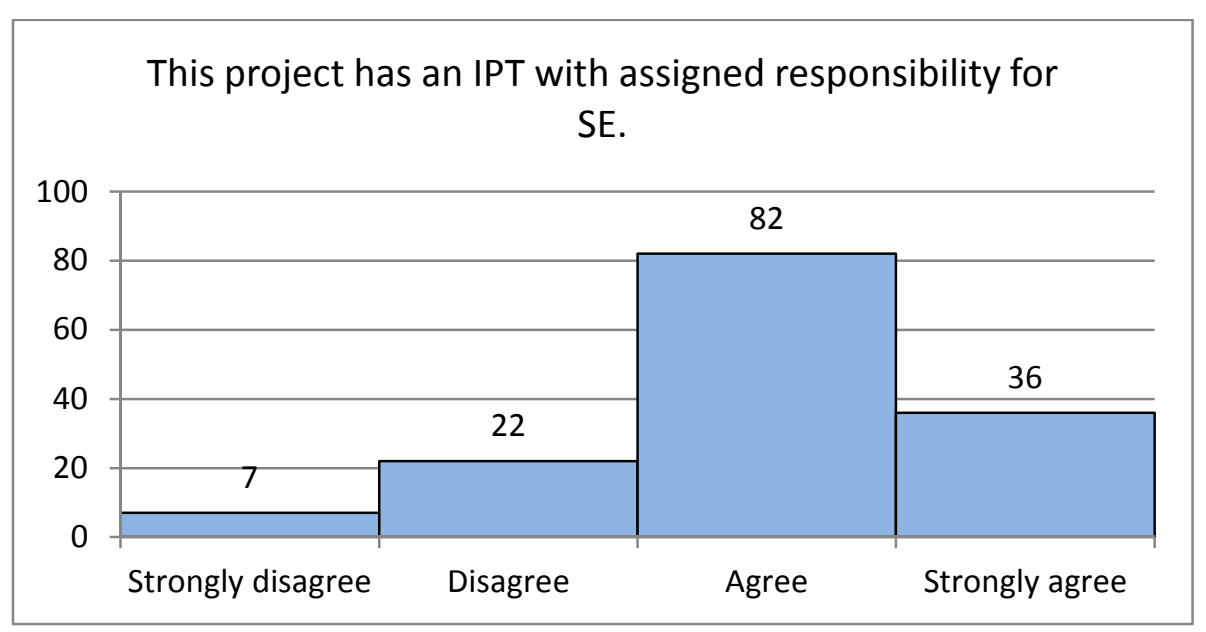

Figure 59: Question E.4 - IPT Responsibility for SE

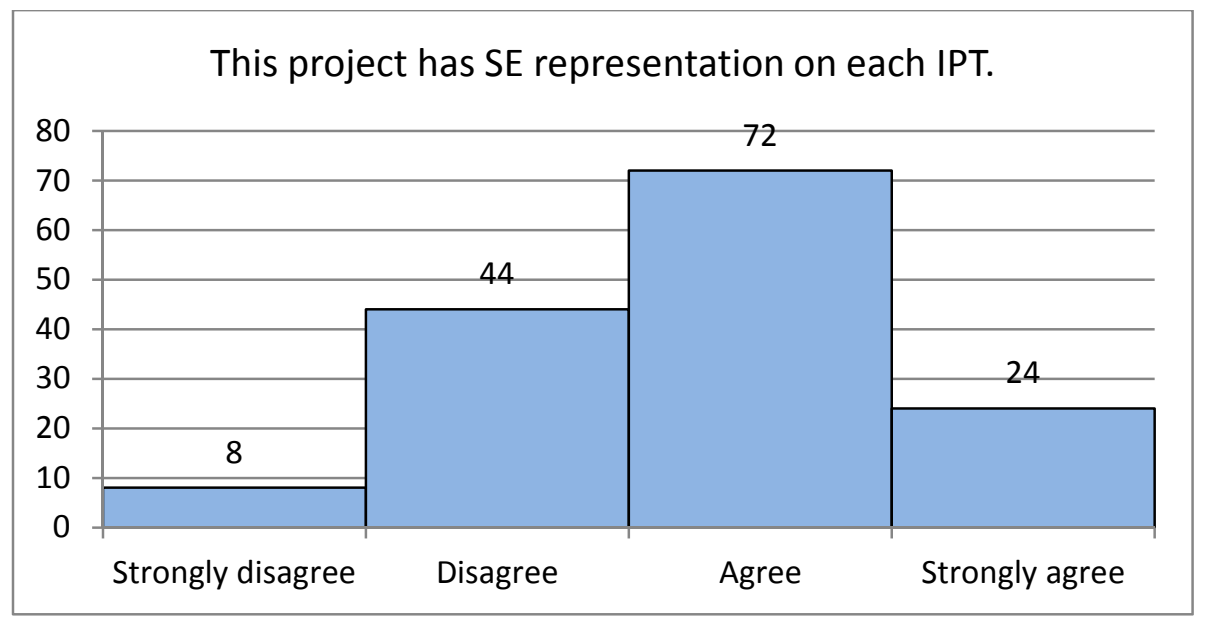

Figure 60: Question E.5 - SE Representation on IPTS 


\section{Questionnaire Section F - Risk Management}

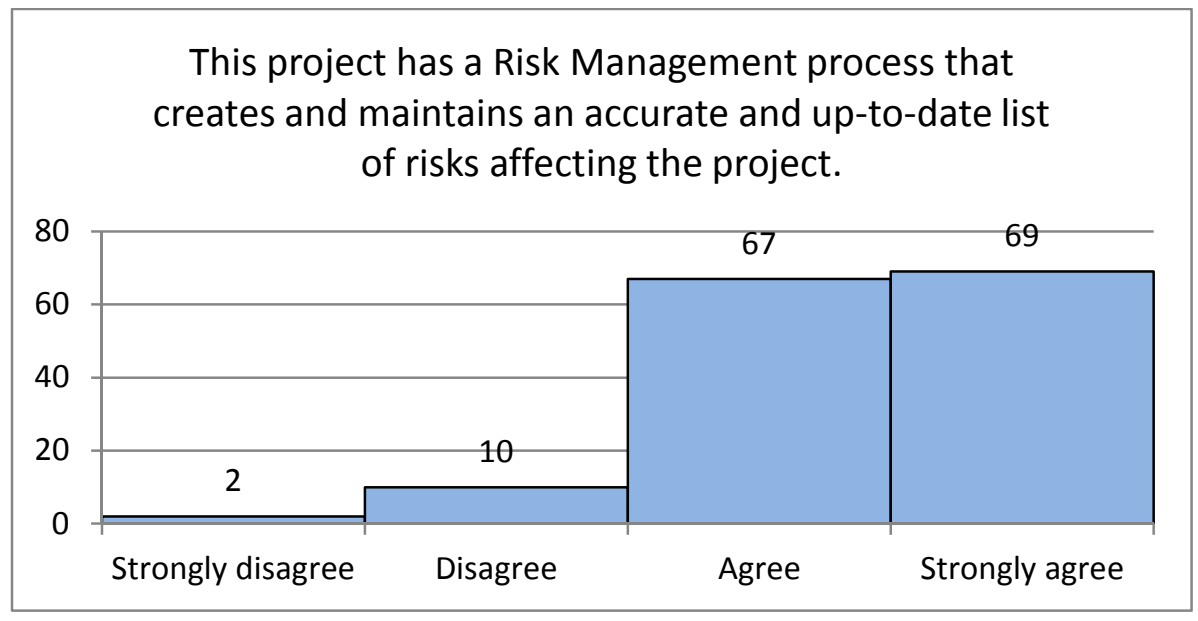

Figure 61: Question F.1 - List of project risks

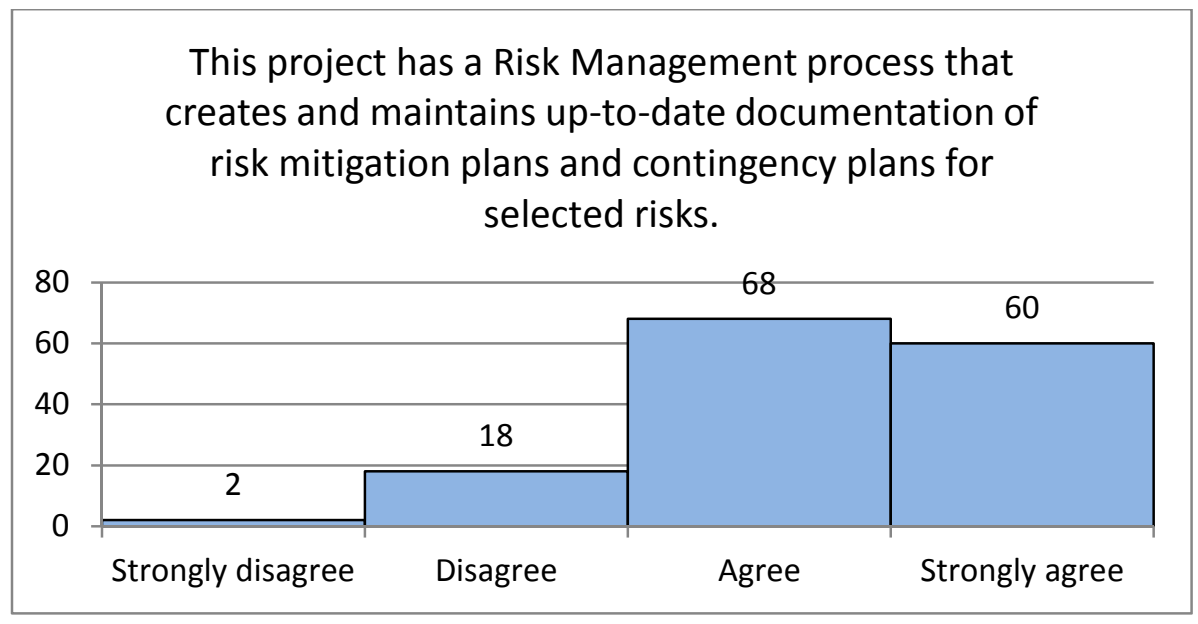

Figure 62: Question F.2 - Risk Management and Contingency Plans 


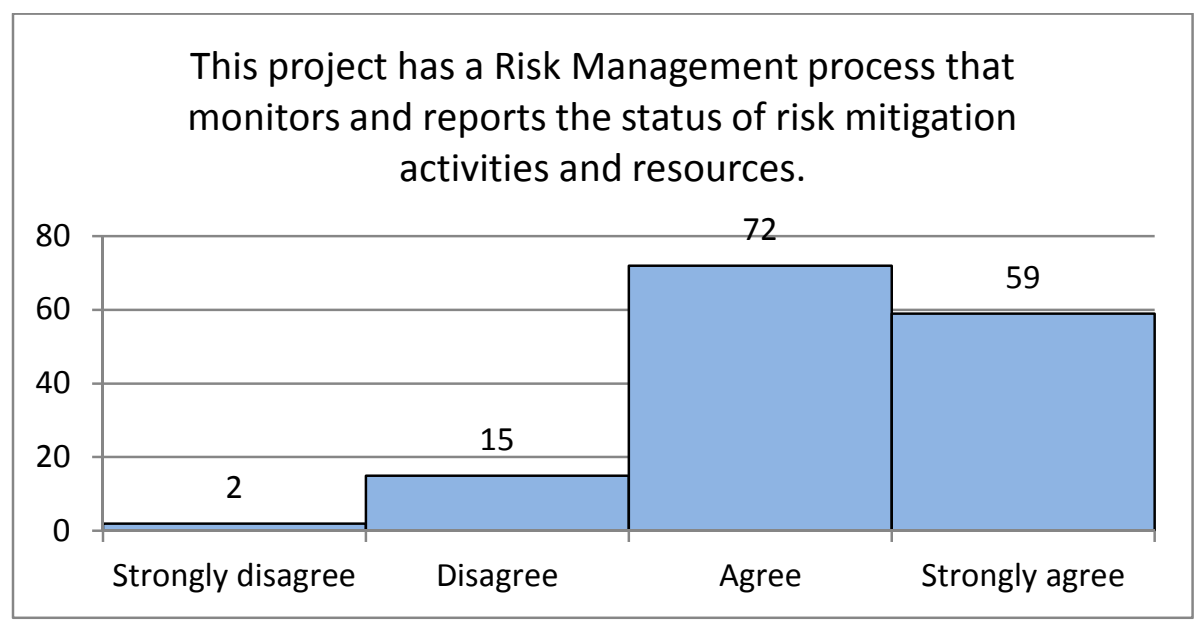

Figure 63: Question F.3 - Risk Mitigation Status and Resource Status Monitoring

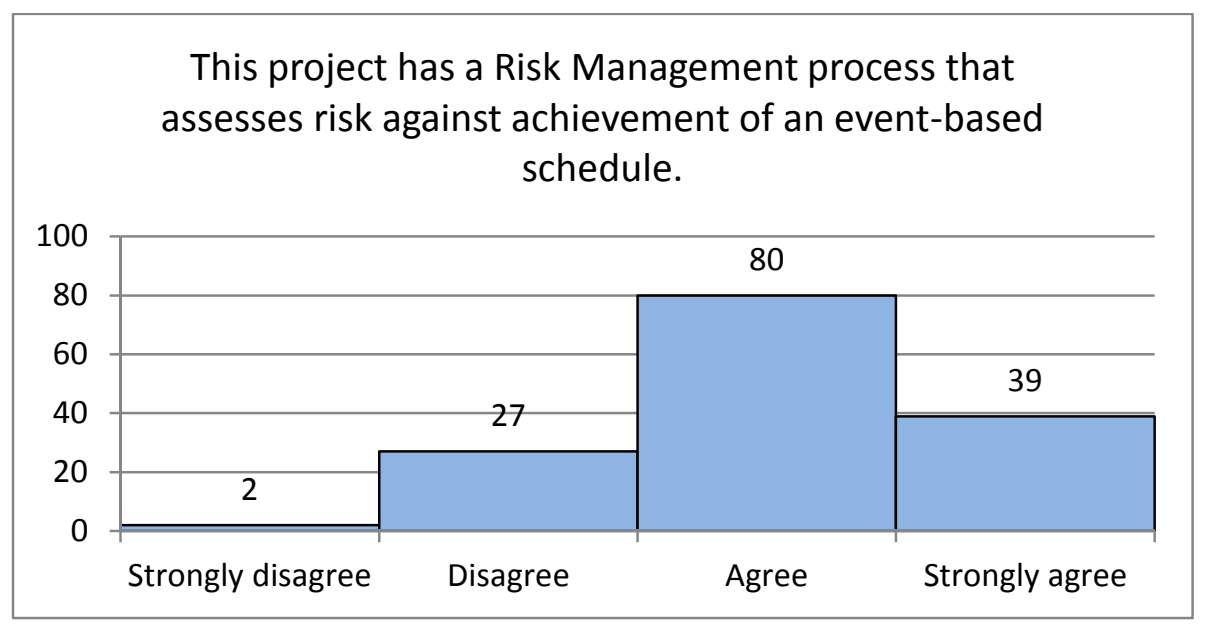

Figure 64: Question F.4 - Schedule Risk Assessment

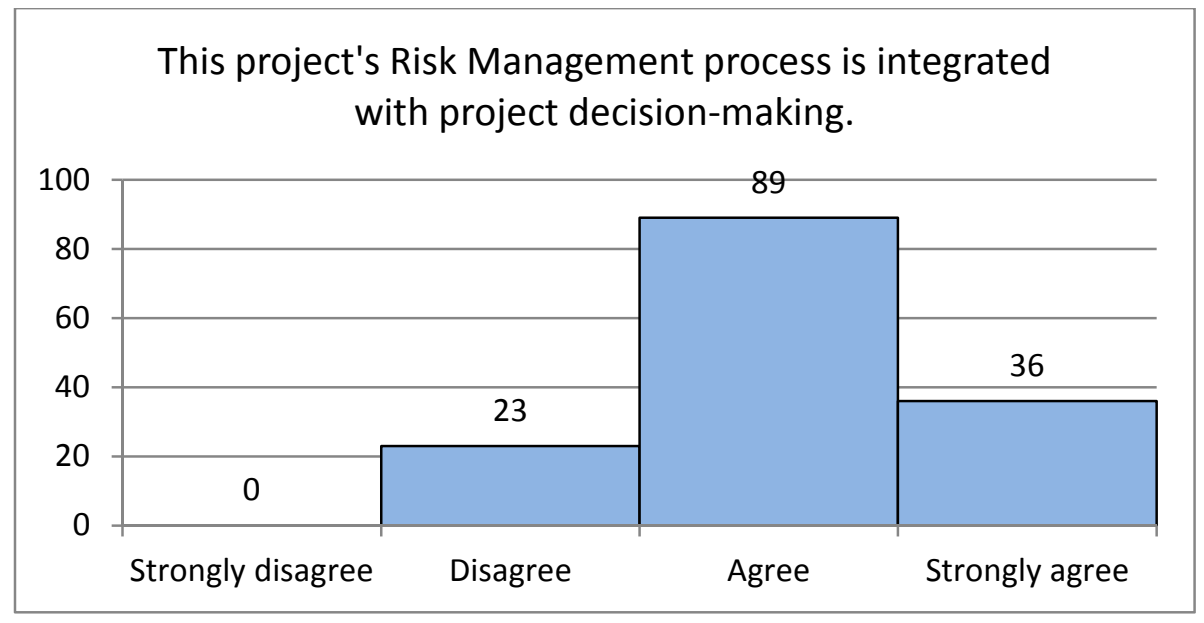

Figure 65: Question F.5 - Risk Management in Decision Making 


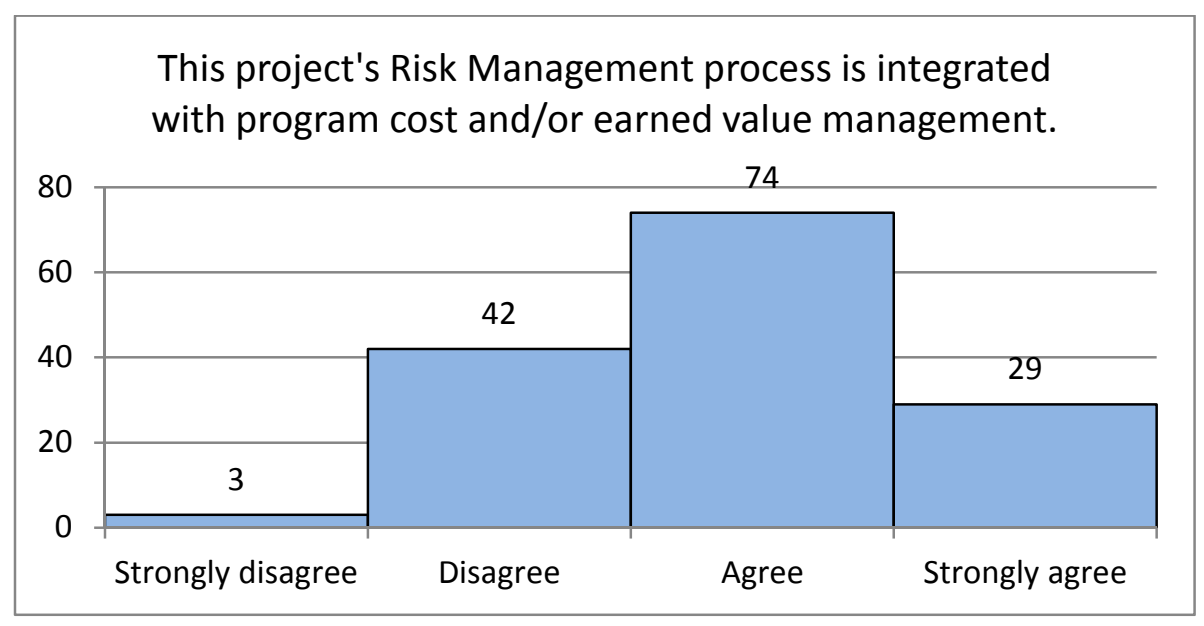

Figure 66: Question F.6 - Risk Management Integration with Cost Management

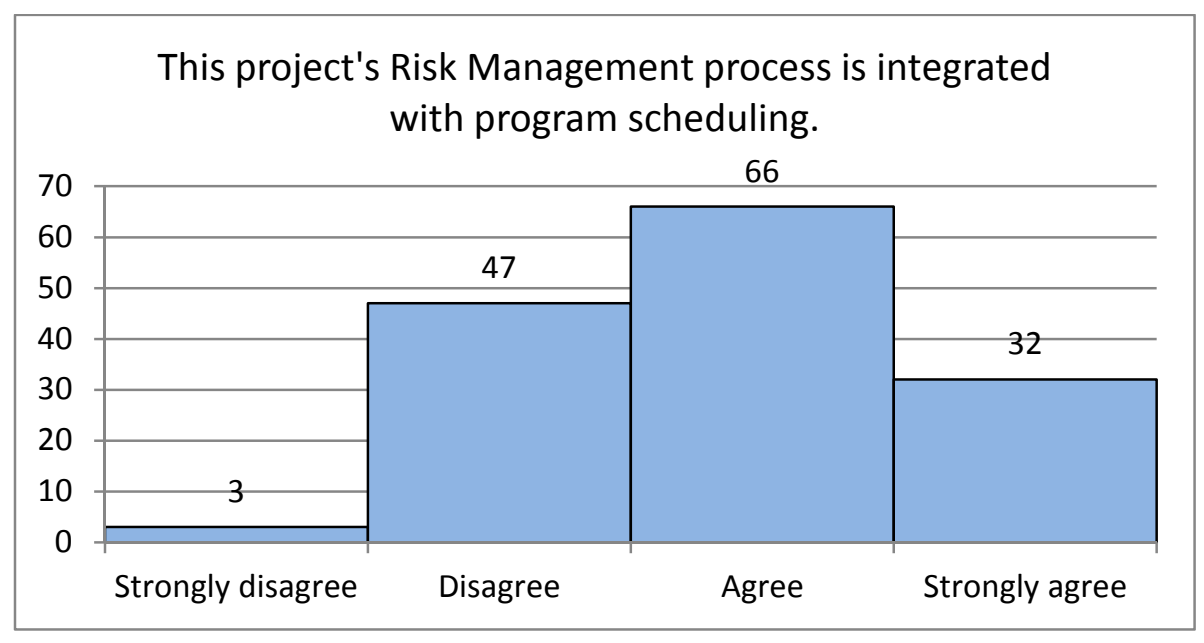

Figure 67: Question F.7 - Risk Management Integration with Program Scheduling

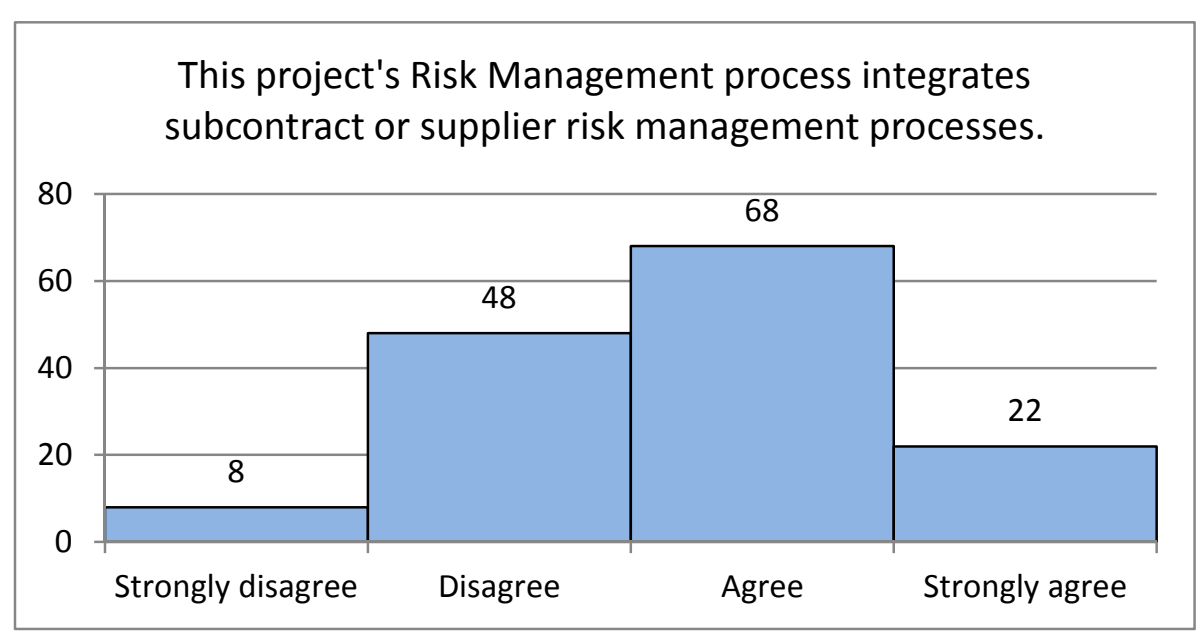

Figure 68: Question F.8 - Integration of Supplier Risk Management Processes 


\section{Questionnaire Section G - Requirements Development and Management}

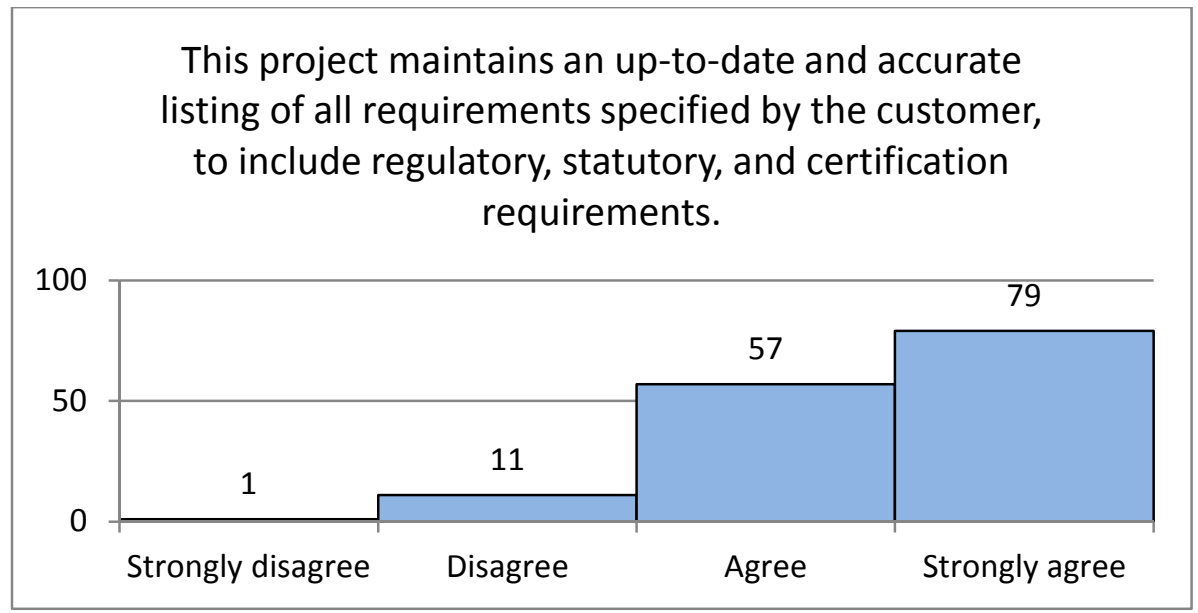

Figure 69: Question G.1 - Documentation of Customer Requirements

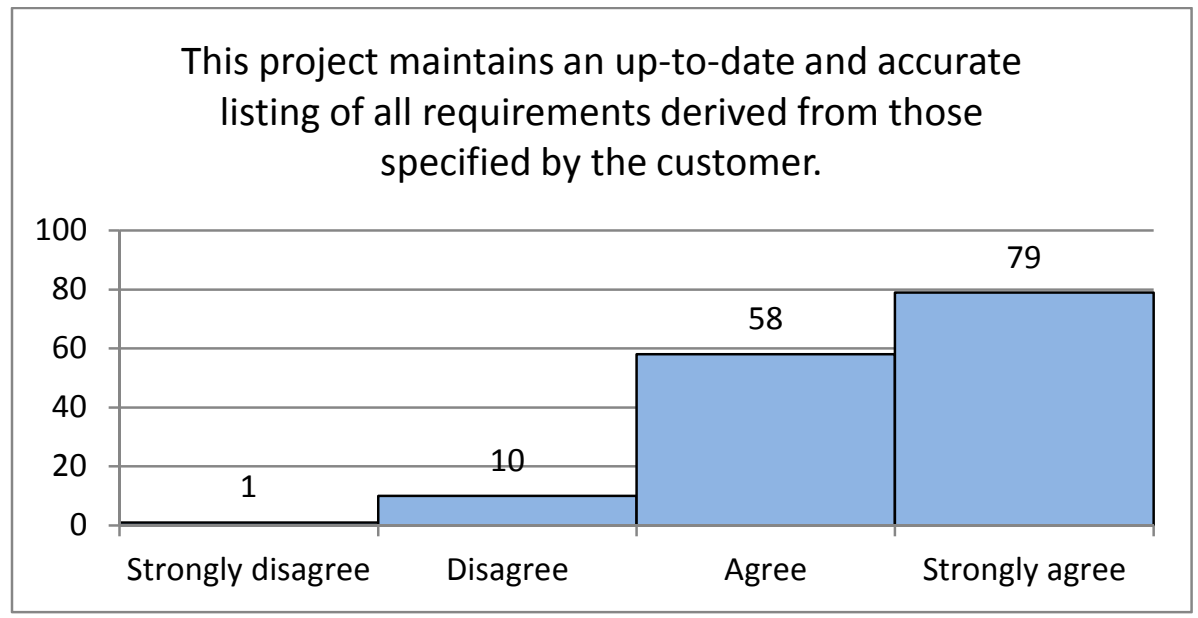

Figure 70: Question G.2 - Documentation of Derived Requirements 


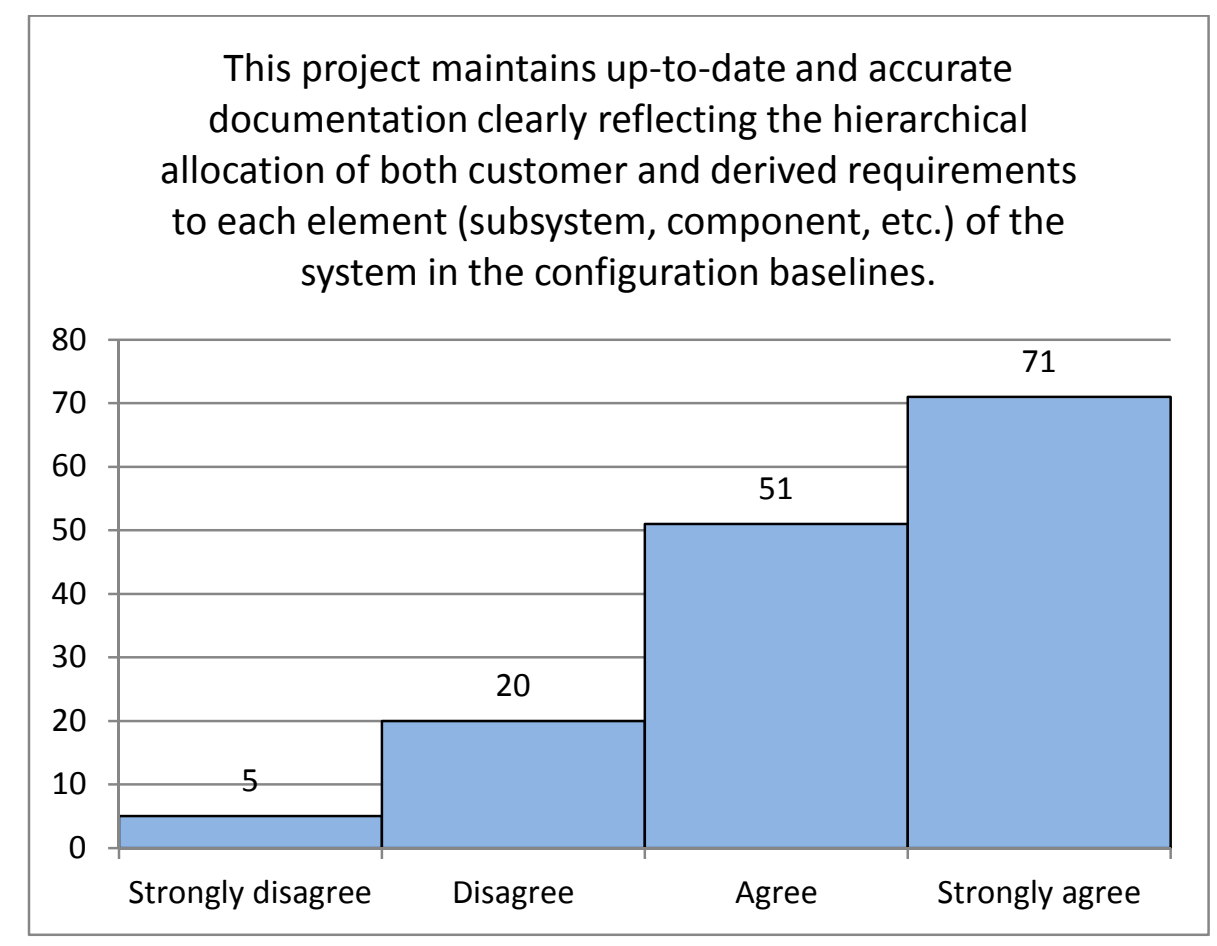

Figure 71: Question G.3 - Hierarchical Allocation of Requirements

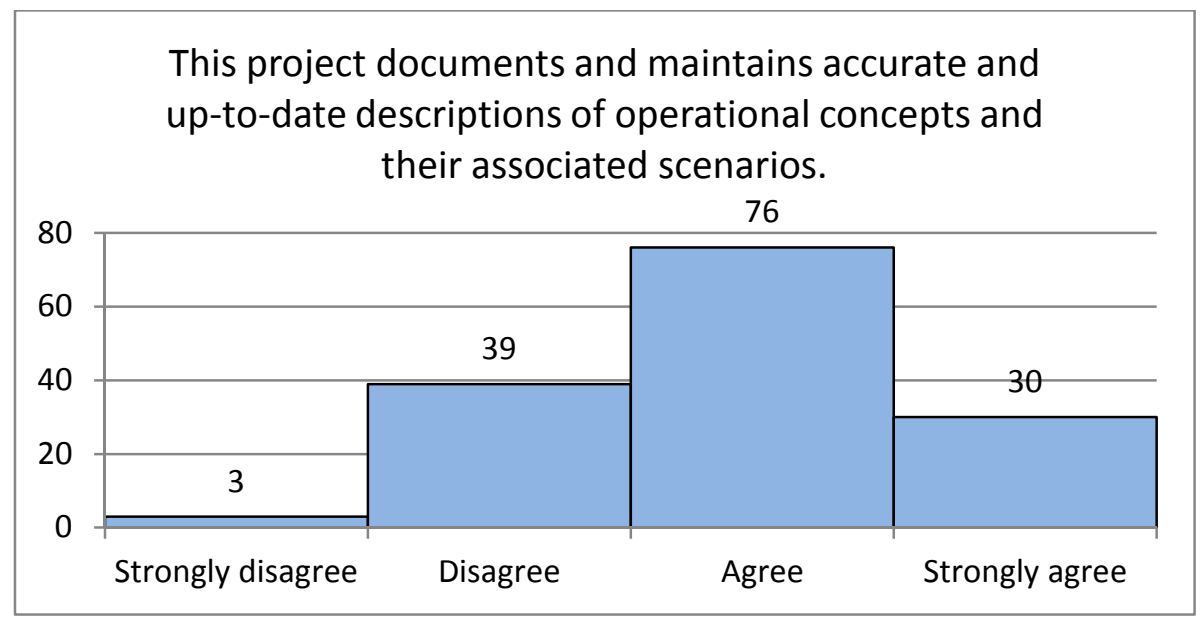

Figure 72: Question G.4 - Operational Concepts and Scenarios 


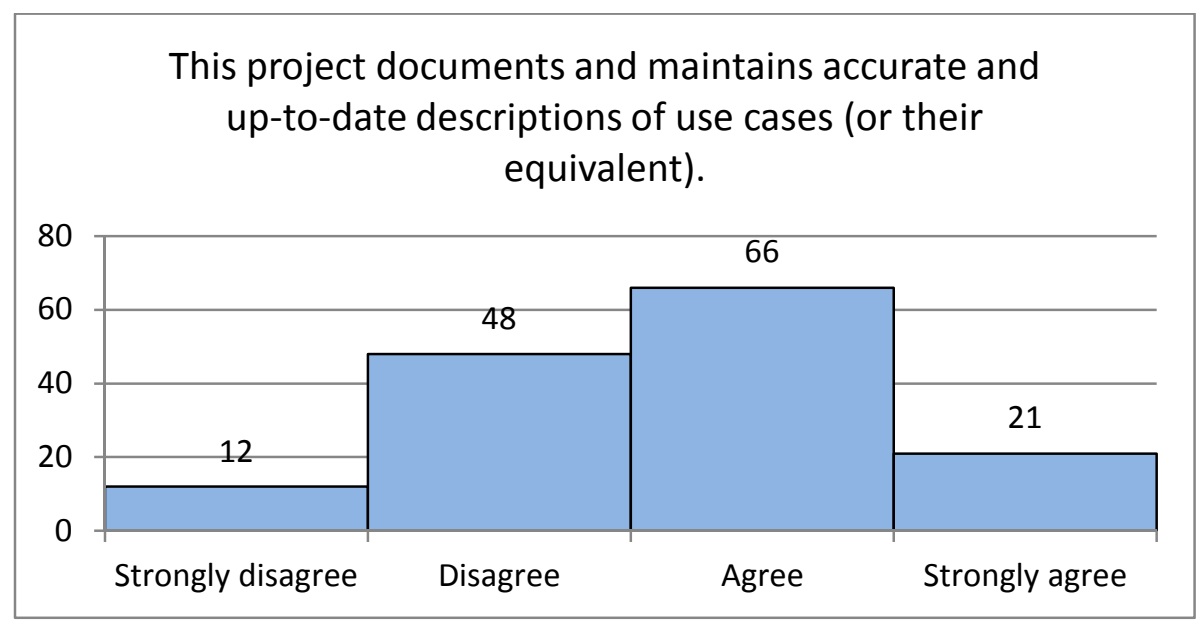

Figure 73: Question G.5 - Use Cases

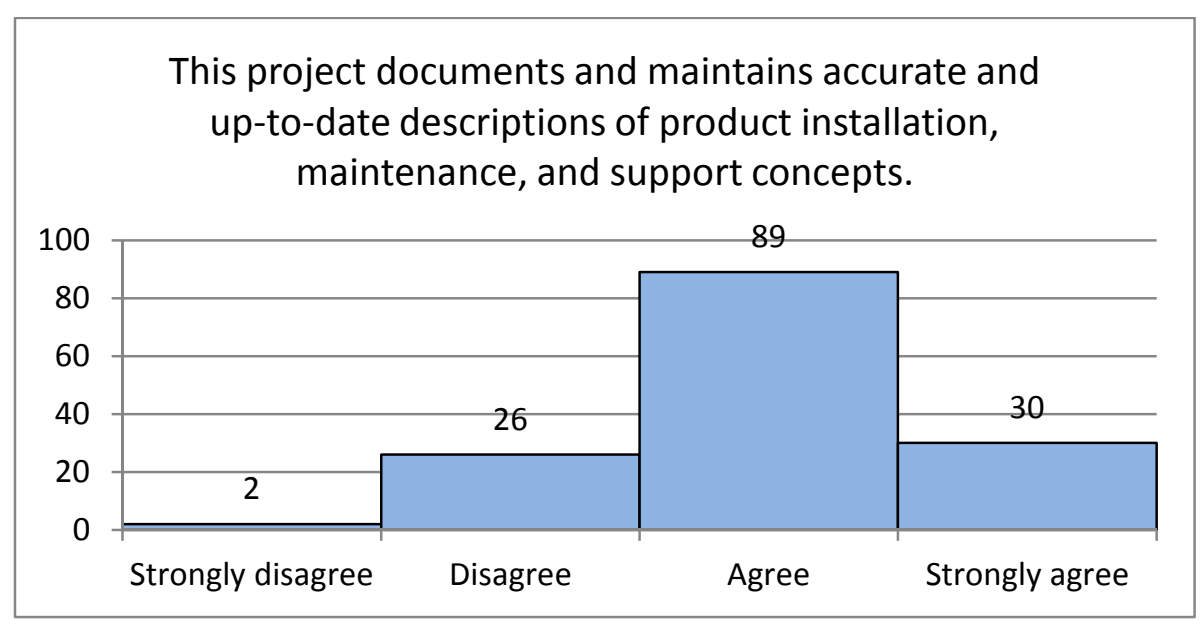

Figure 74: Question G.6 - Installation, Maintenance, and Support Concepts

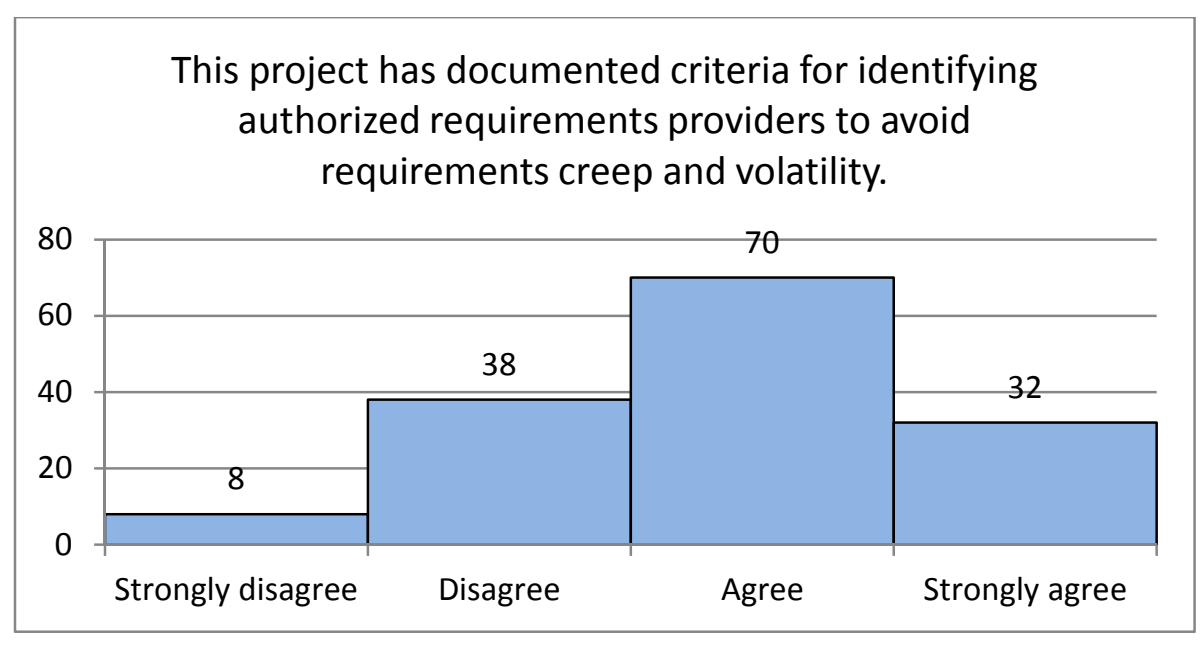

Figure 75: Question G.7 - Criteria for Authorizing Requirements Providers 


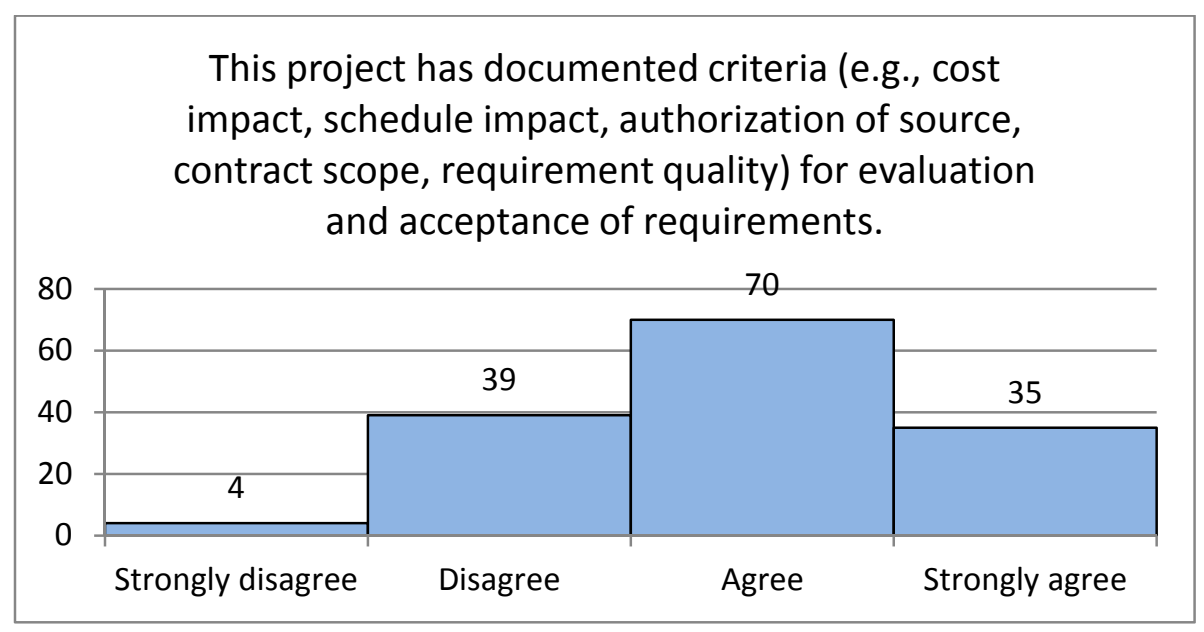

Figure 76: Question G.8 - Criteria for Accepting Requirements

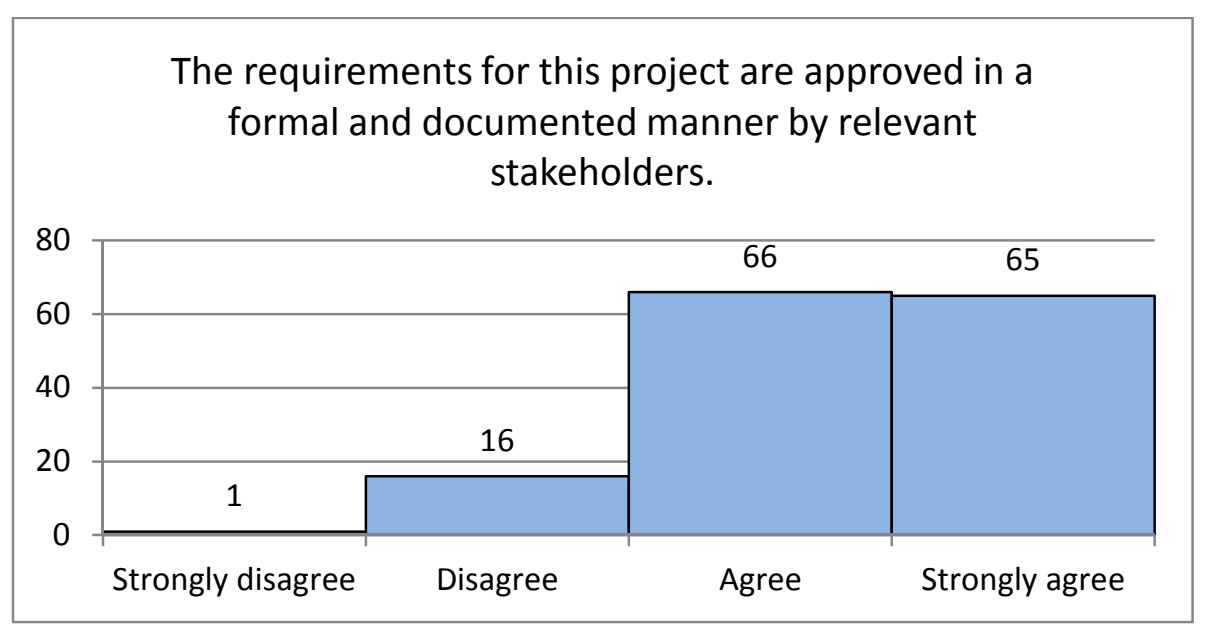

Figure 77: Question G.9 - Approval Process for Requirements

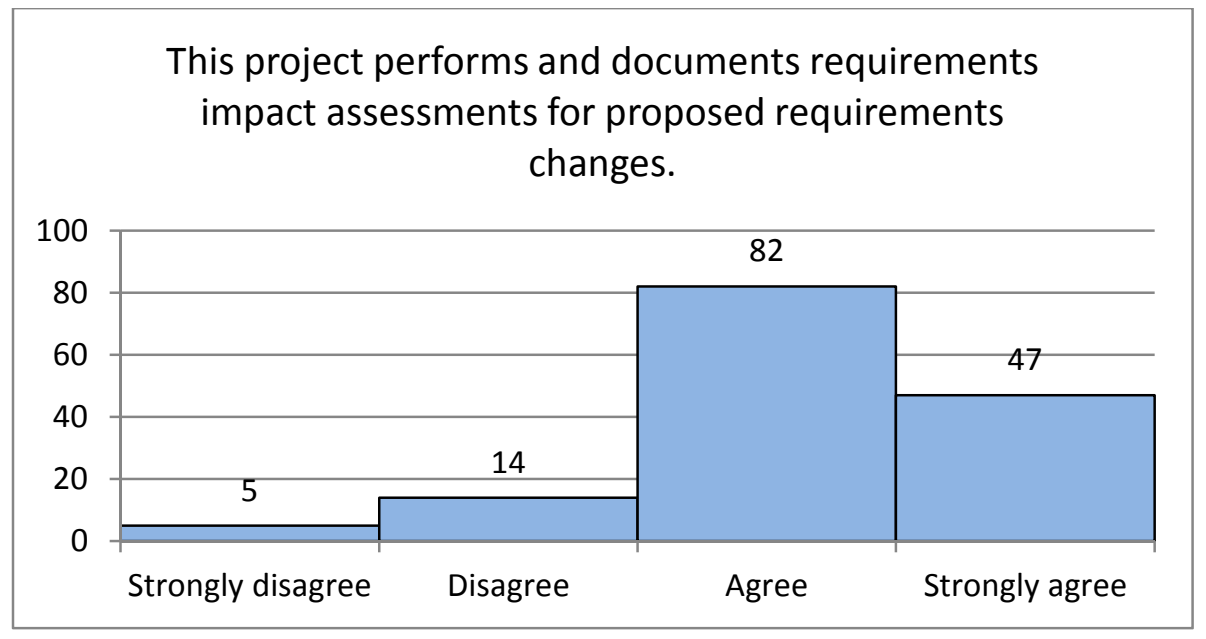

Figure 78: Question G.10 - Requirements Impact Assessments 


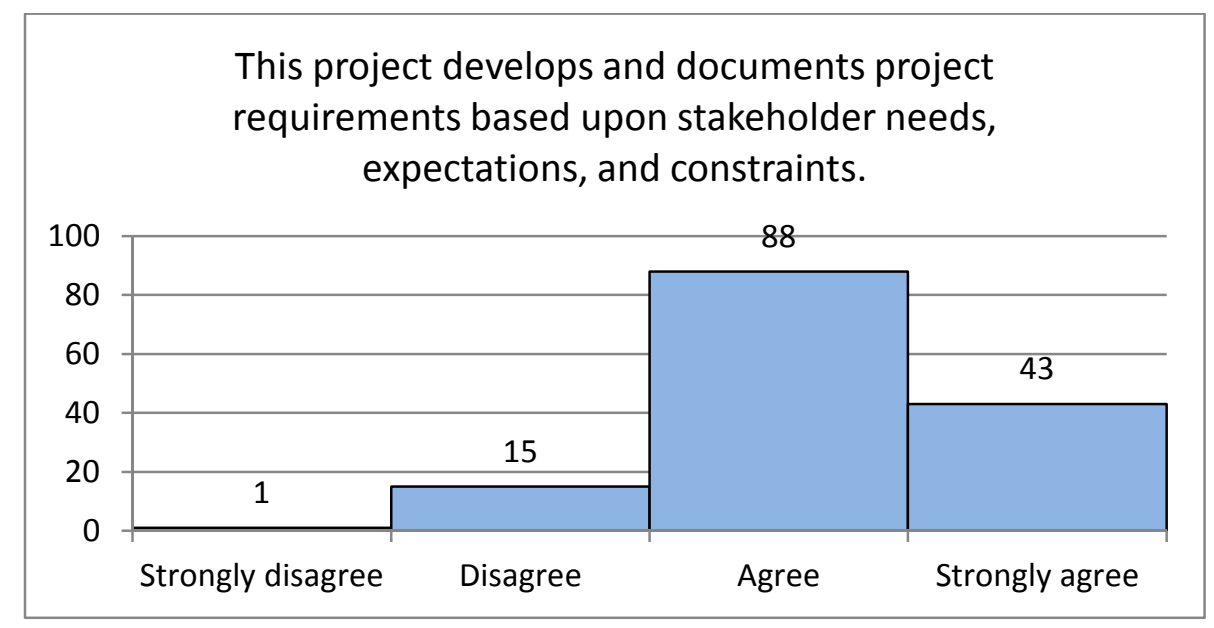

Figure 79: Question G.11 - Stakeholder-Based Requirements

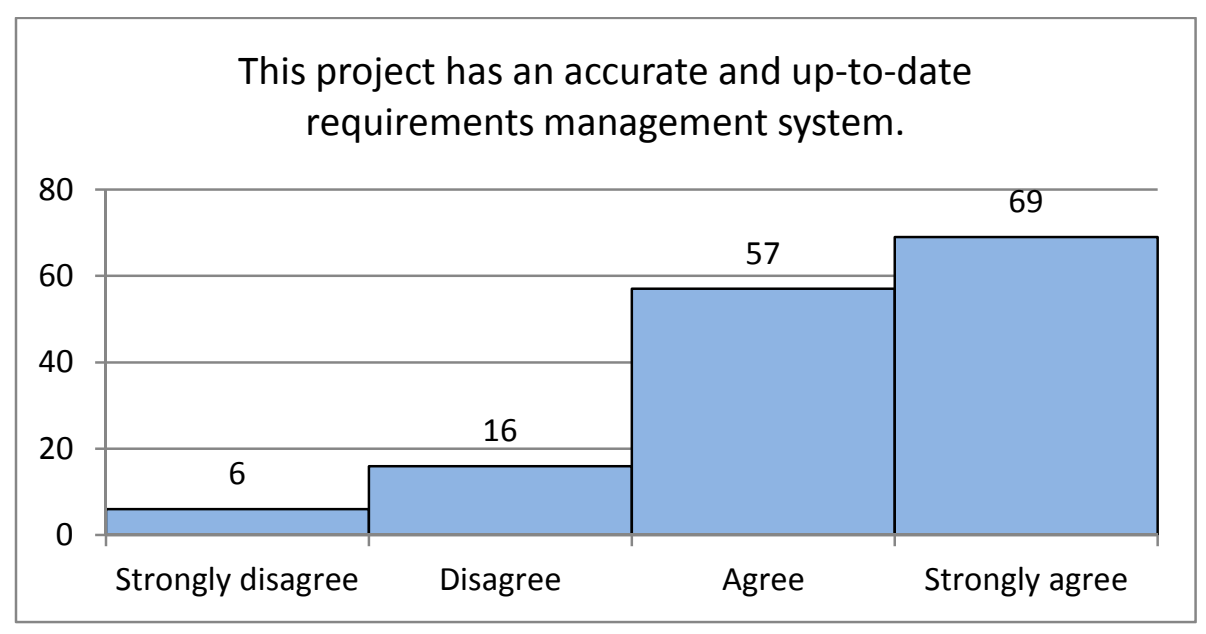

Figure 80: Question G.12 - Requirements Management System

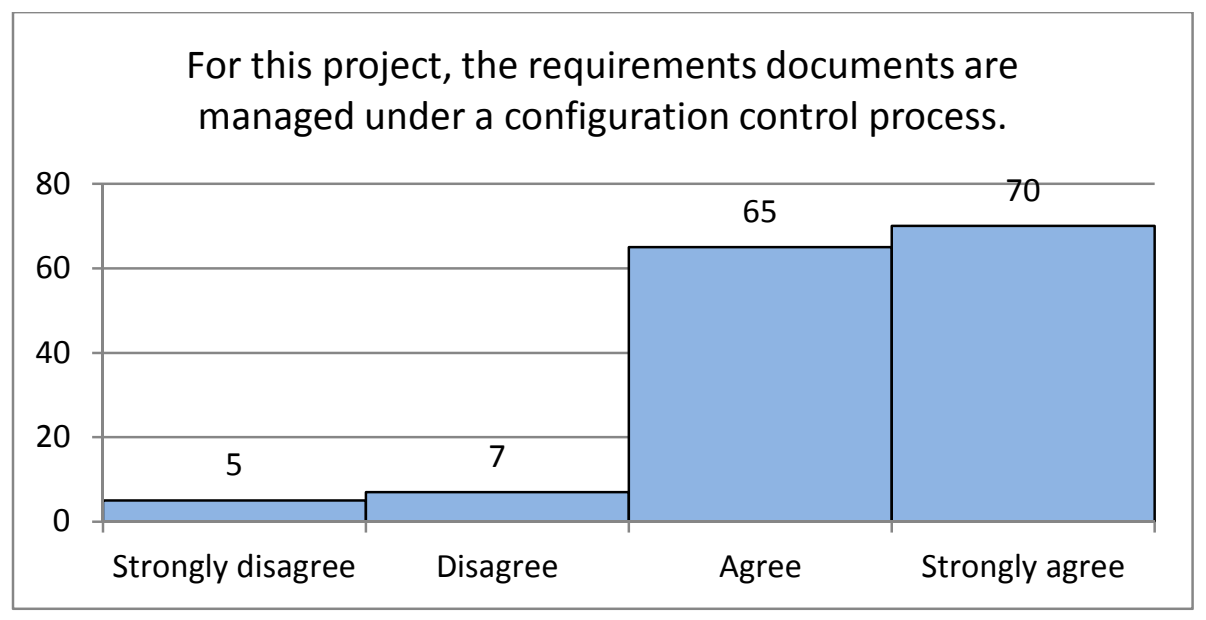

Figure 81: Question G.13 - Configuration Control of Requirements 


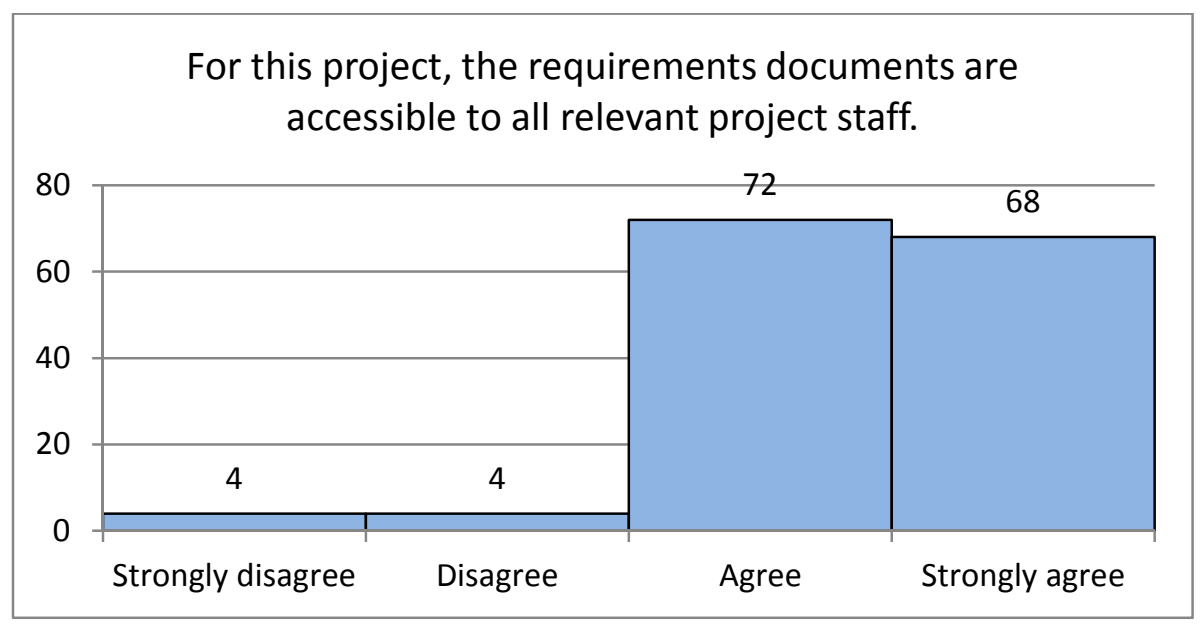

Figure 82: Question G.14 - Accessibility of Requirements 


\section{Questionnaire Section H - Trade Studies}

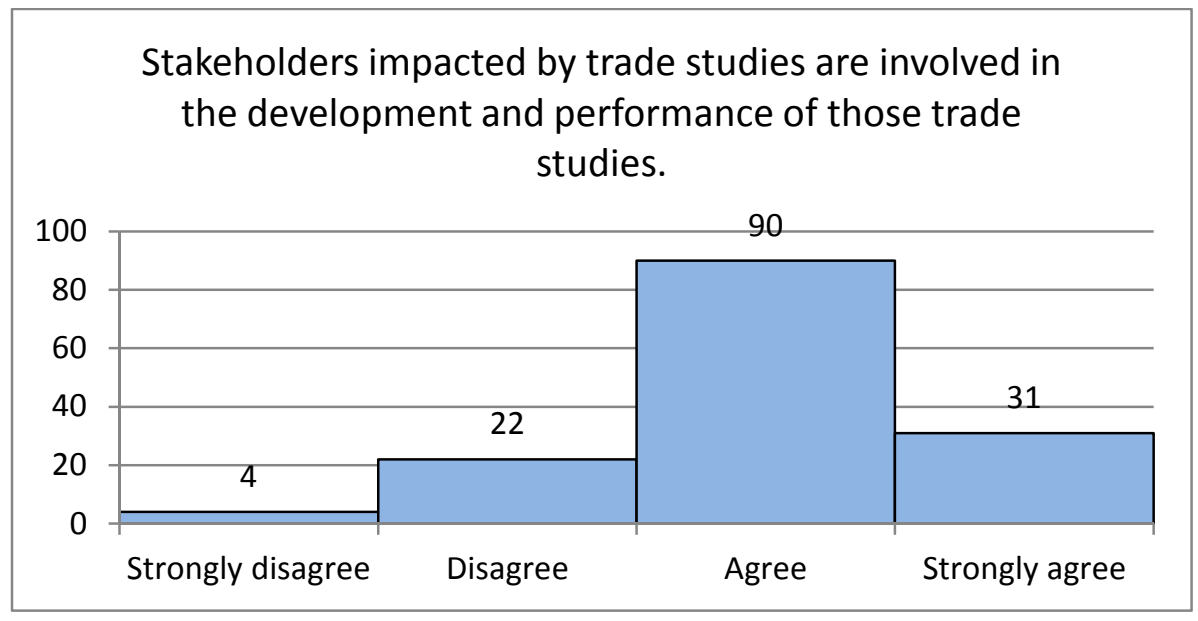

Figure 83: Question H.1 - Stakeholders Involvement in Trade Studies

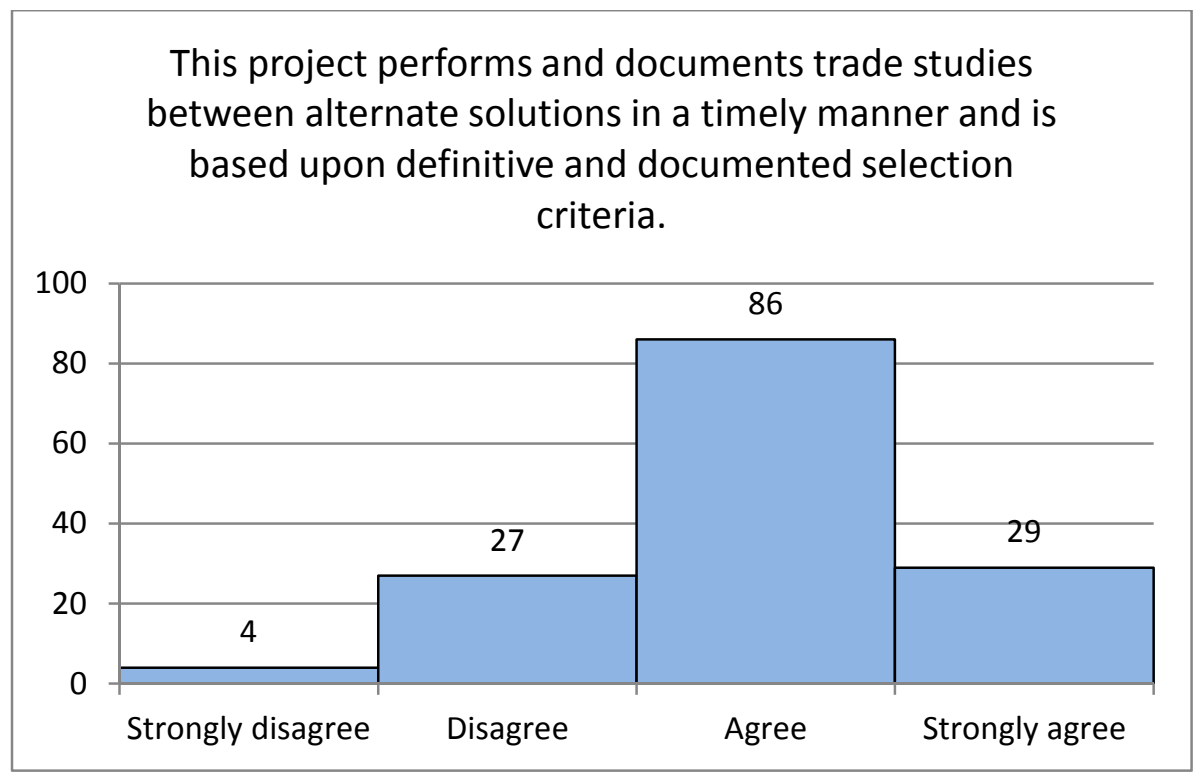

Figure 84: Question H.2 - Effectiveness of Trade Studies 


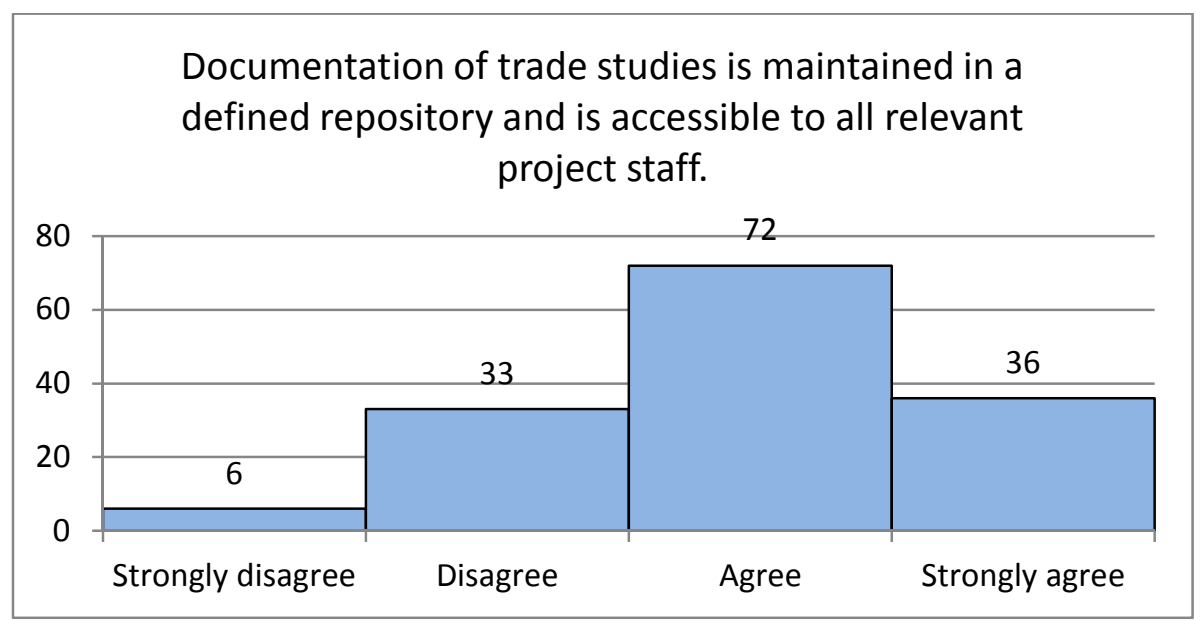

Figure 85: Question H.3 - Trade Study Documentation 


\section{Questionnaire Section I - Product Architecture}

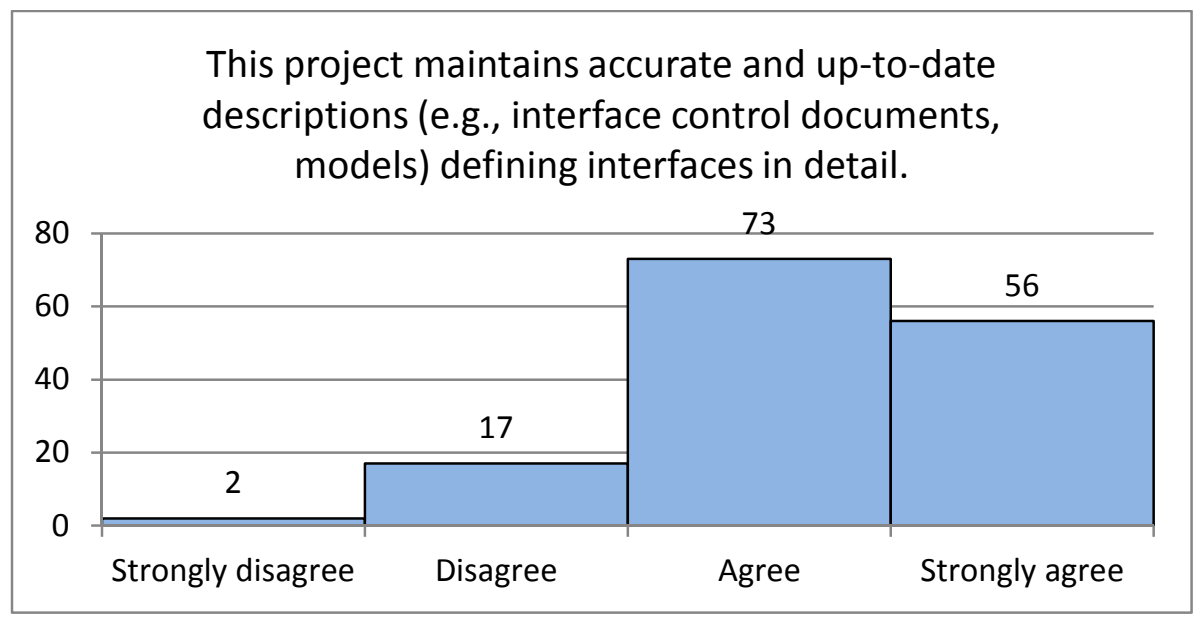

Figure 86: Question I.1 - Quality of Interface Descriptions

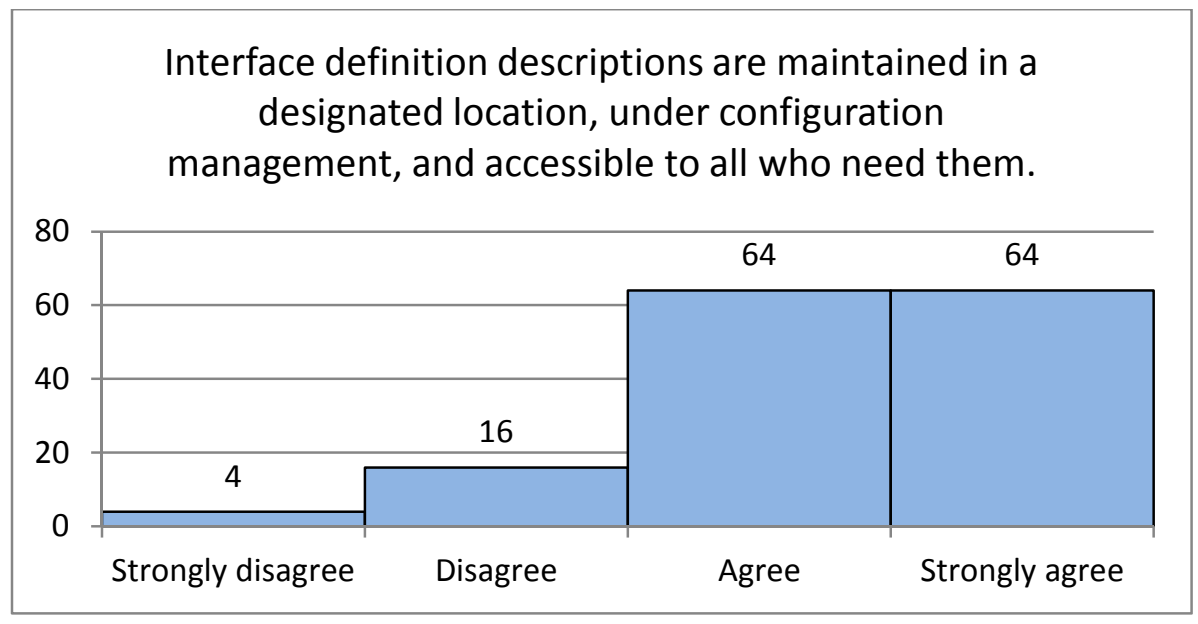

Figure 87: Question I.2 - Management of Interface Descriptions 


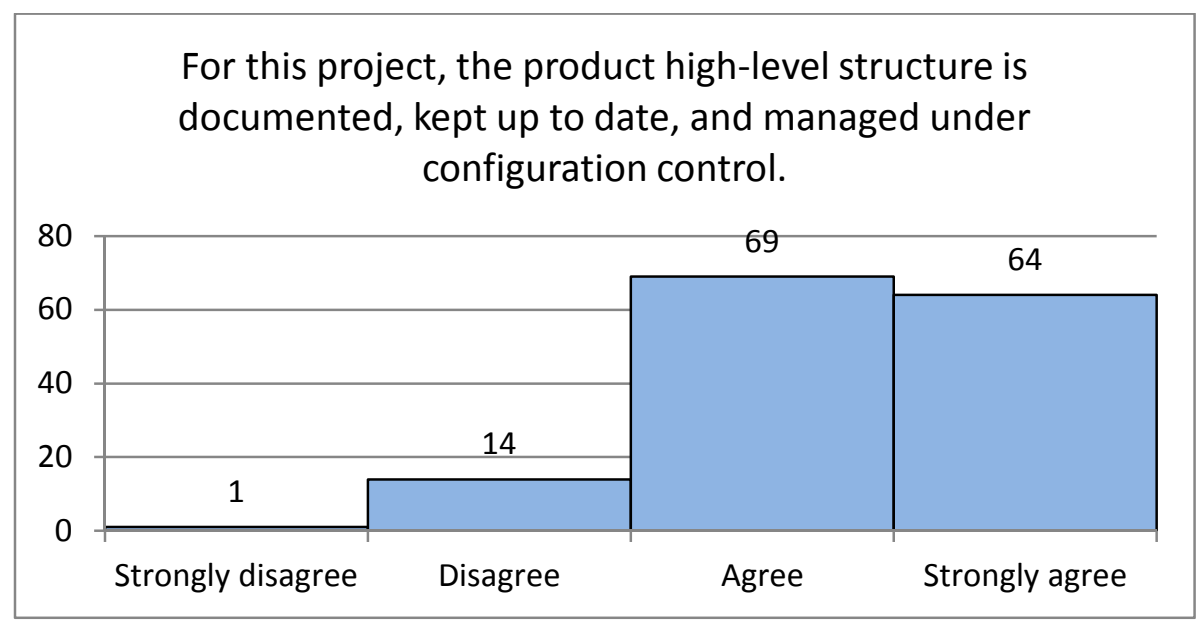

Figure 88: Question I.3 - Maintained Documentation of the Product Structure

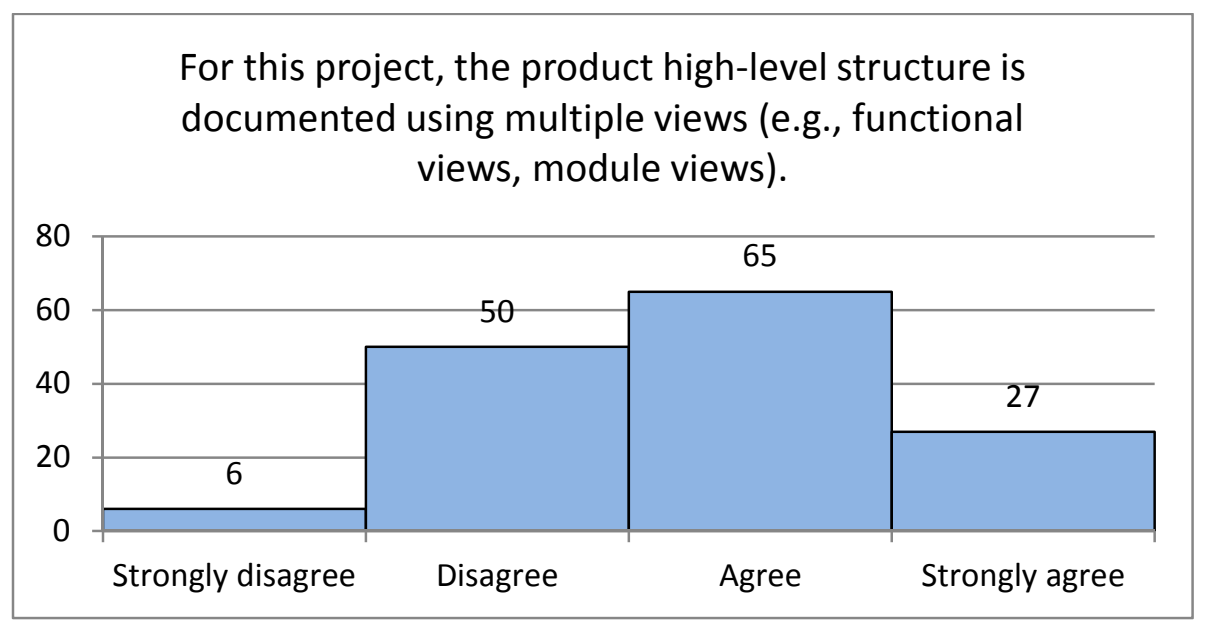

Figure 89: Question I.4 - Multiple Views of the Product Structure

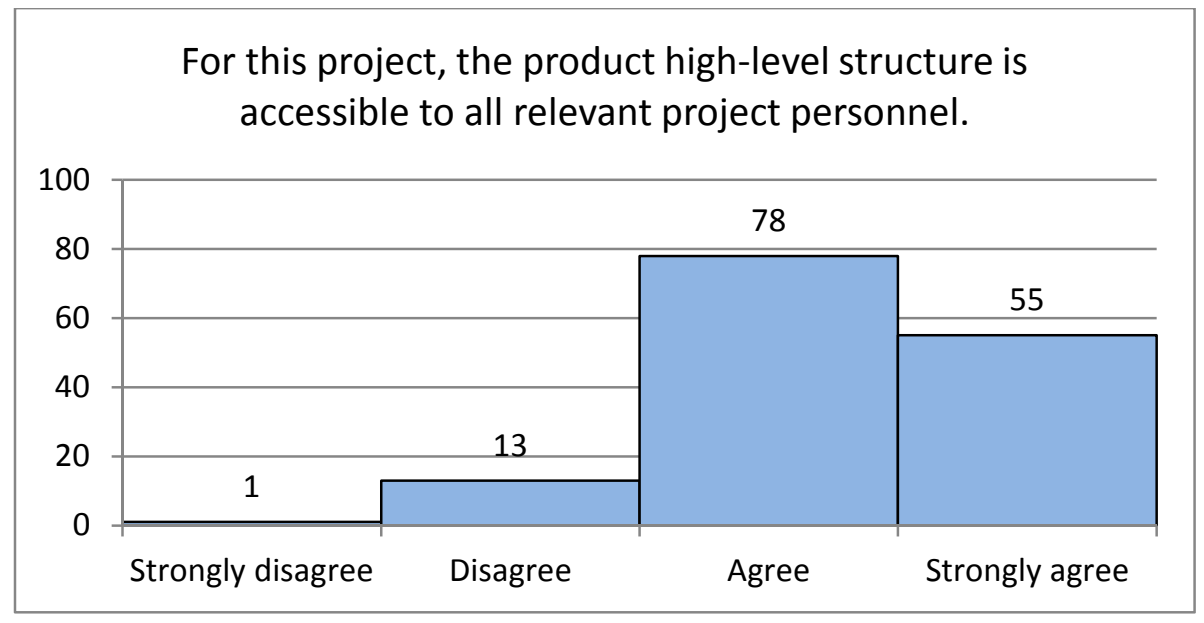

Figure 90: Question I.5 - Accessibility of Product Structure Documentation 


\section{Questionnaire Section J - Product Integration}

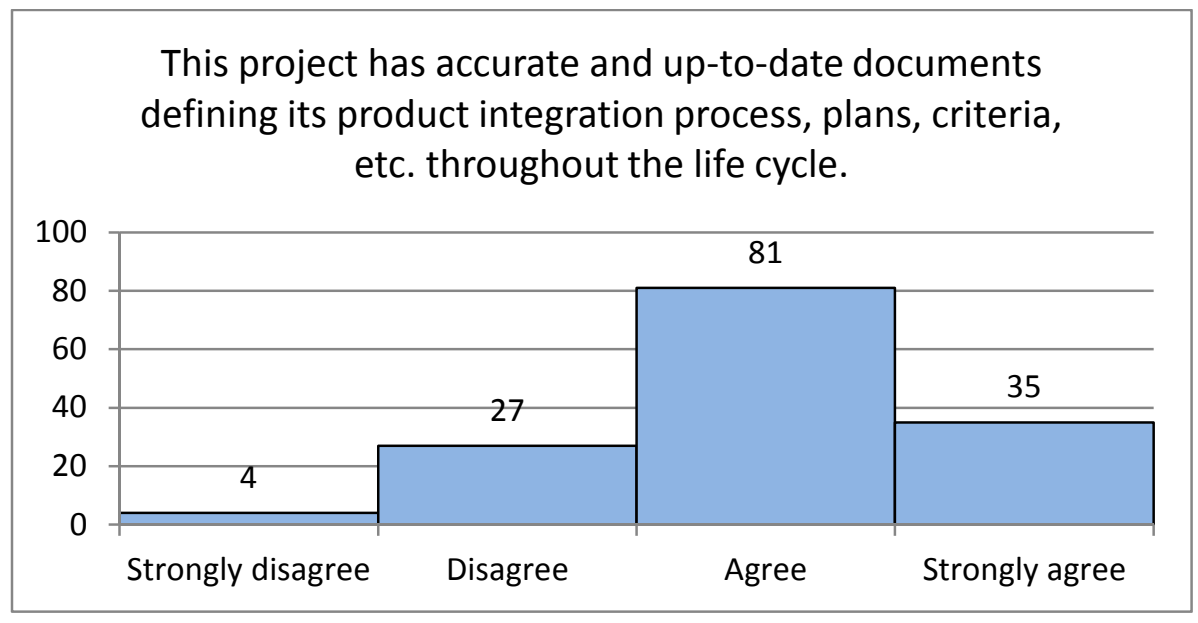

Figure 91: Question J.1 - Documented Product Integration Process 


\section{Questionnaire Section K - Verification}

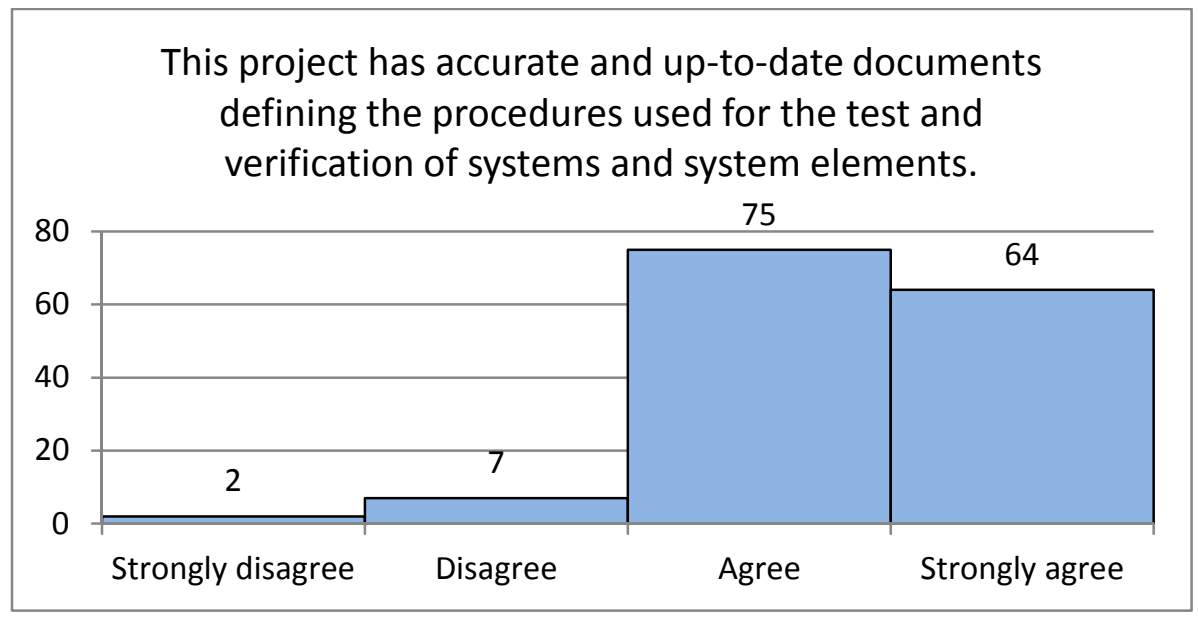

Figure 92: Question K.1 - Documented Verification Procedures

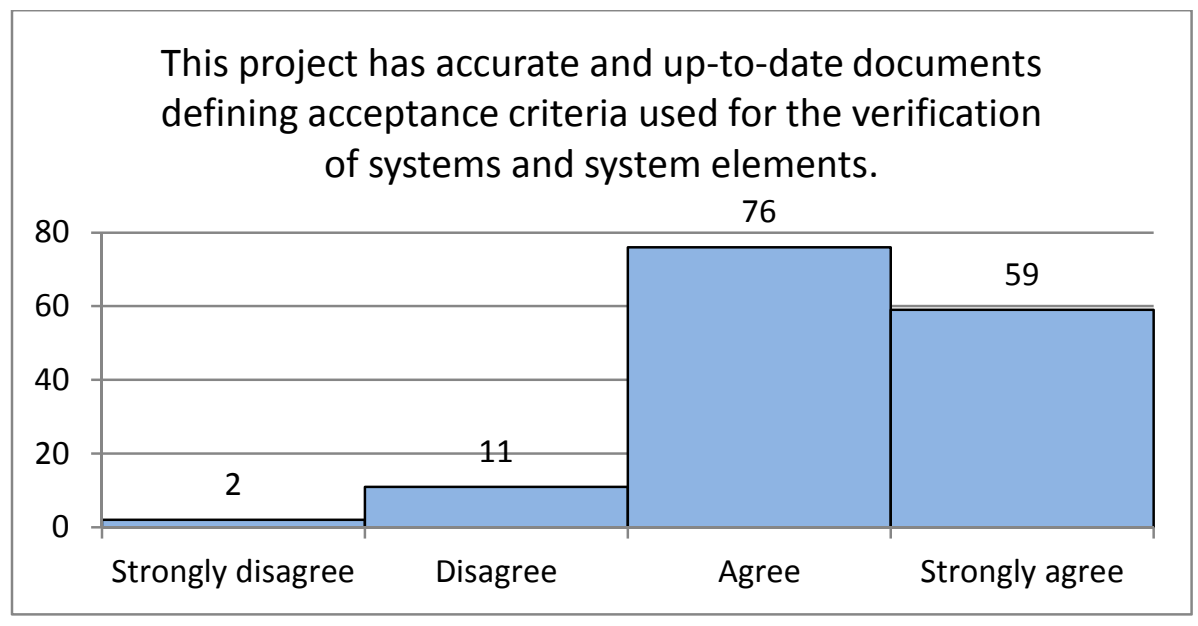

Figure 93: Question K.2 - Documented Acceptance Criteria for Verification 


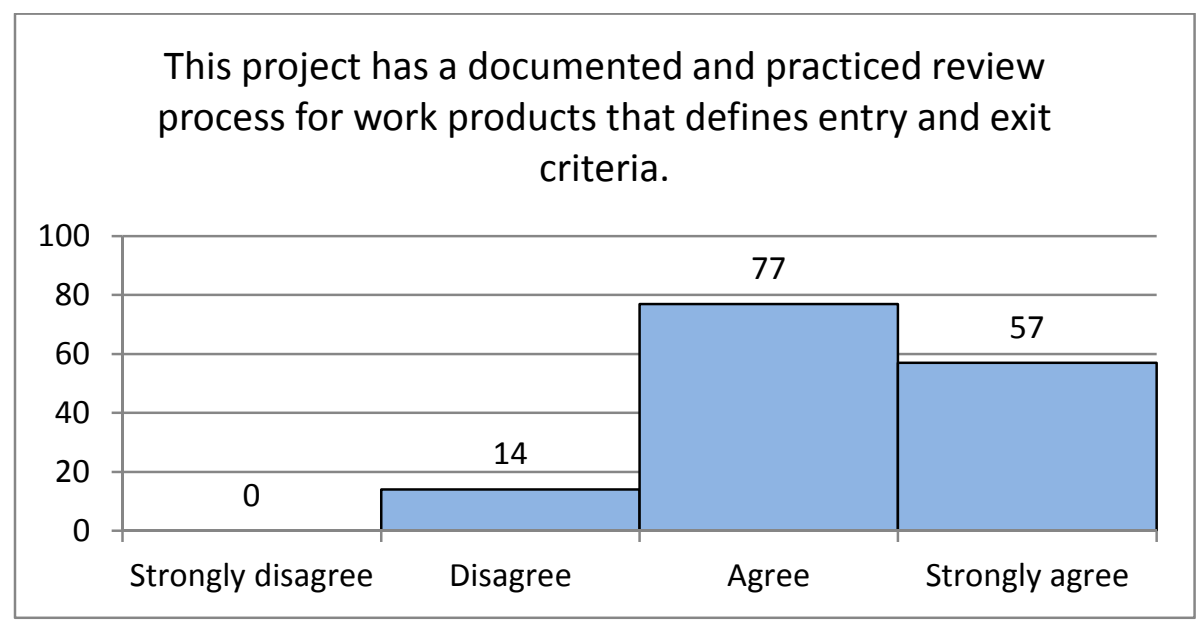

Figure 94: Question K.3 - Documented and Practiced Review Process

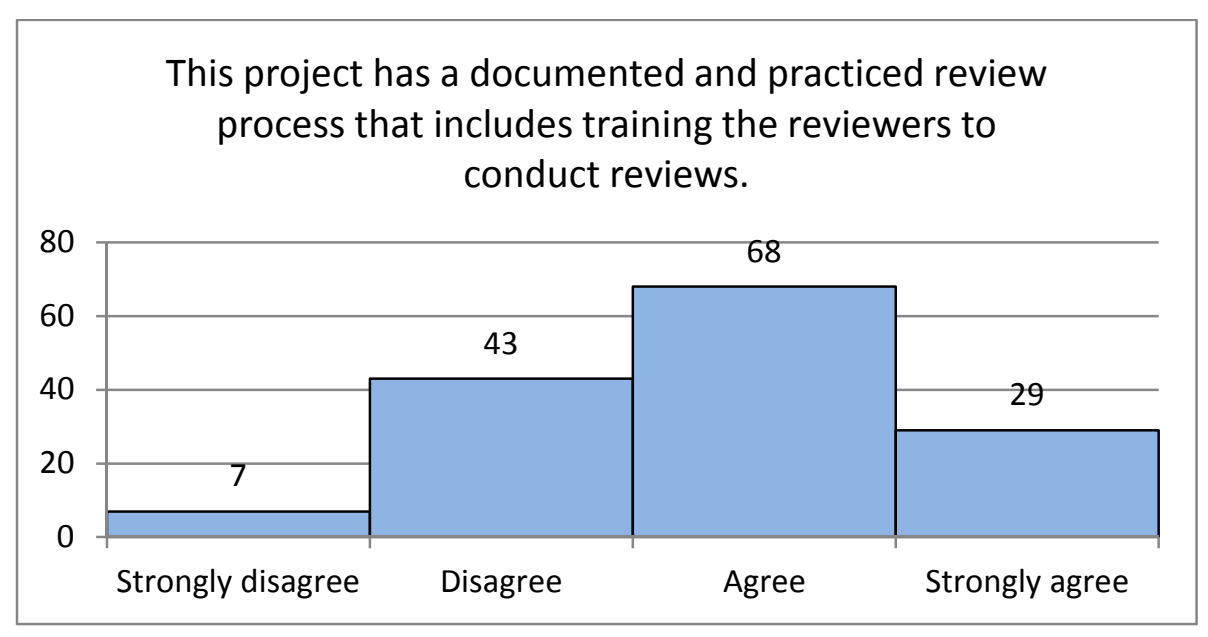

Figure 95: Question K.4 - Training for the Review Process

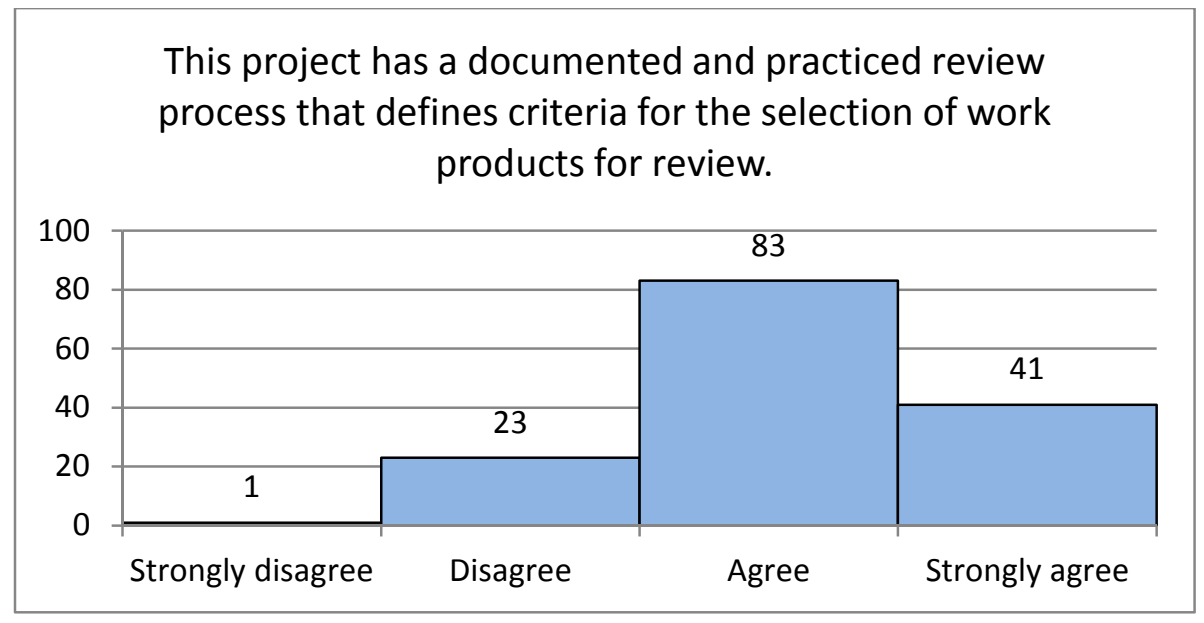

Figure 96: Question K.5 - Criteria for Selecting Work Products for Review 


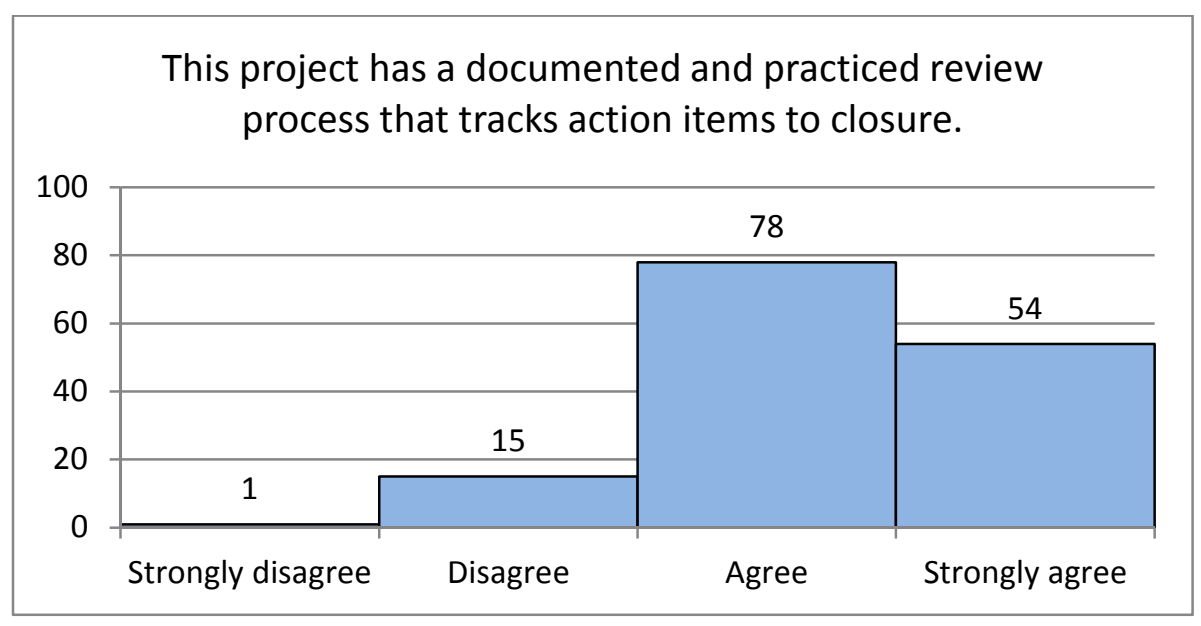

Figure 97: Question K.6 - Action Item Tracking

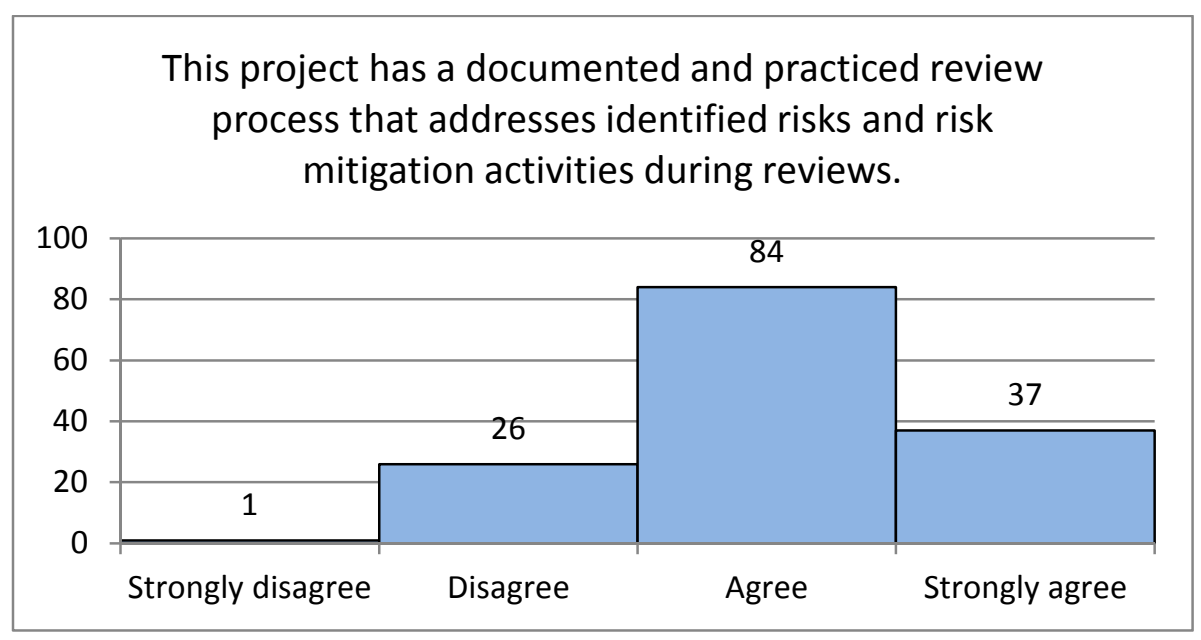

Figure 98: Question K.7 - Inclusion of Risk Management in the Review Process

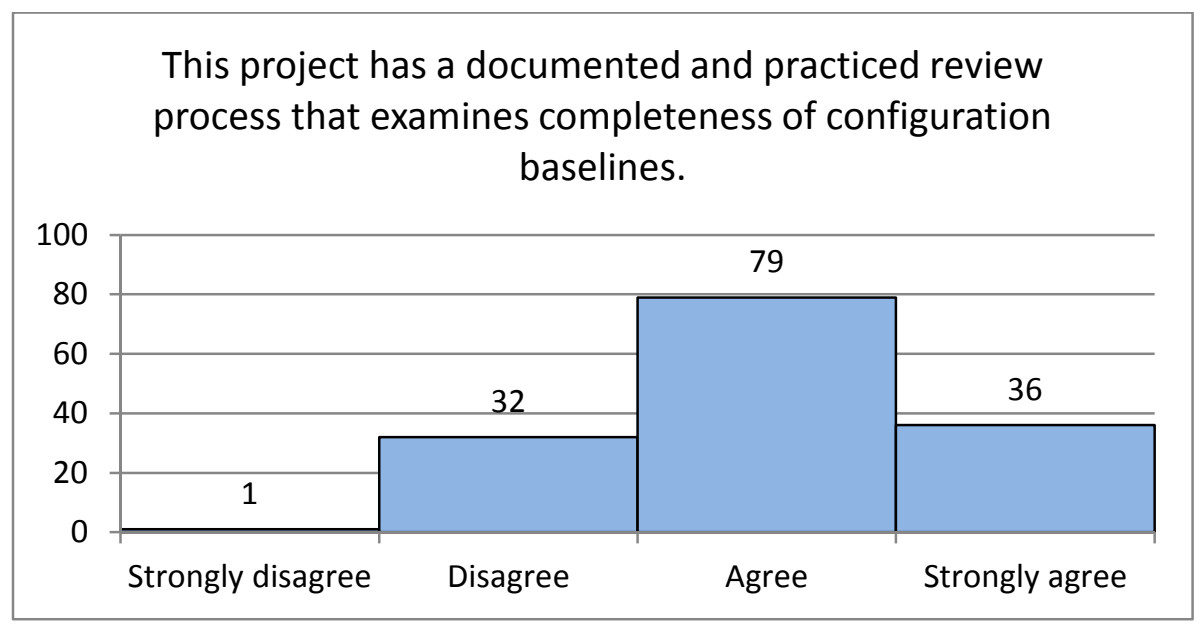

Figure 99: Question K.8 - Inclusion of Configuration Baselines in the Review Process 


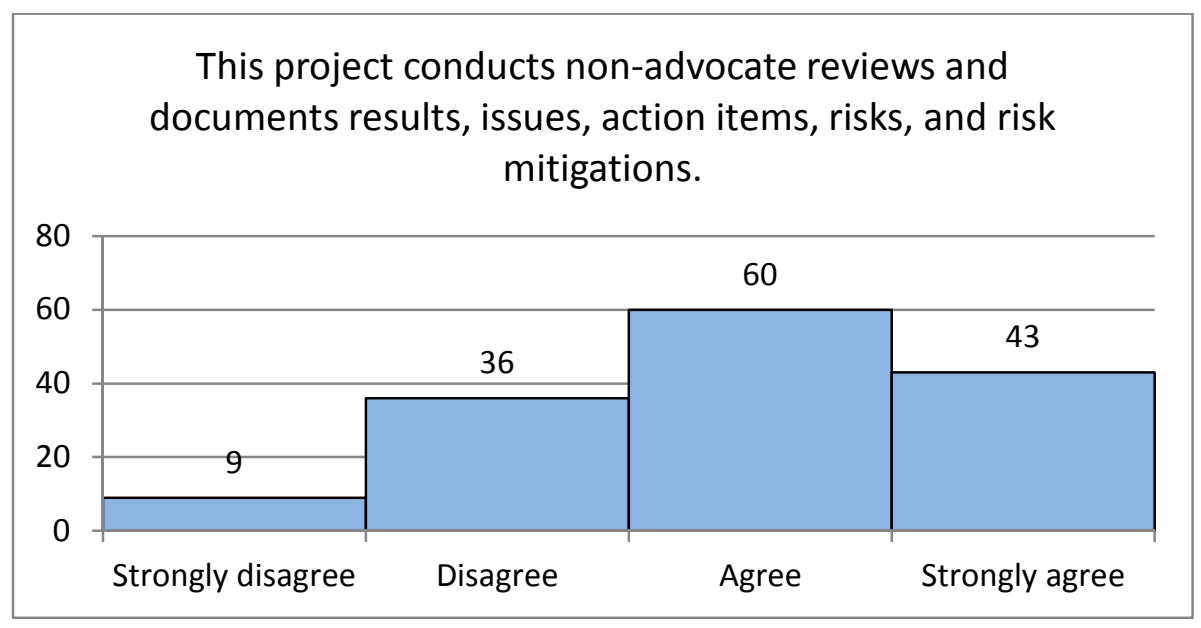

Figure 100: Question K.9 - Documentation of Review Results 


\section{Questionnaire Section L - Validation}

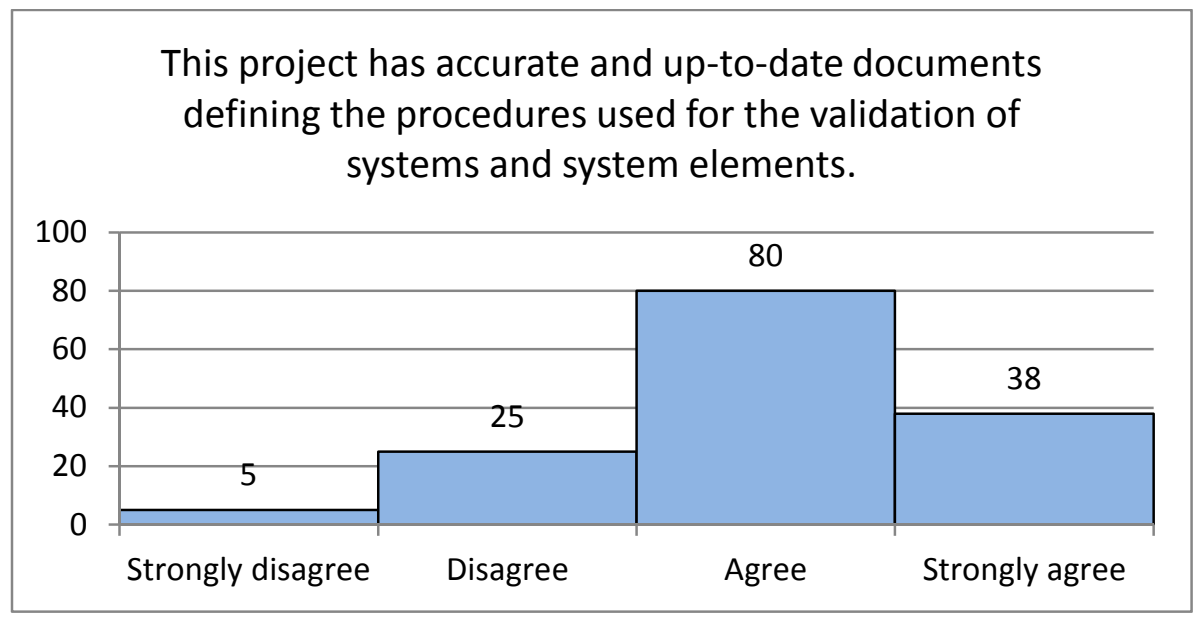

Figure 101: Question L.1 - Documented Validation Procedures

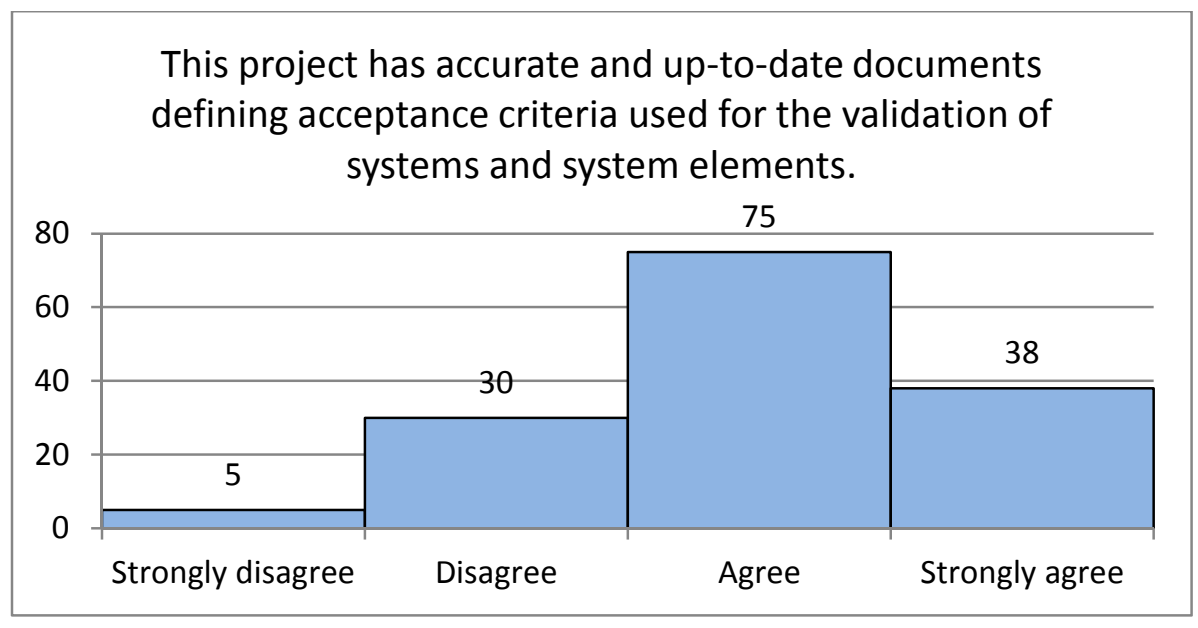

Figure 102: L.2 -- Documented Acceptance Criteria for Validation 


\section{Questionnaire Section M - Configuration Management}

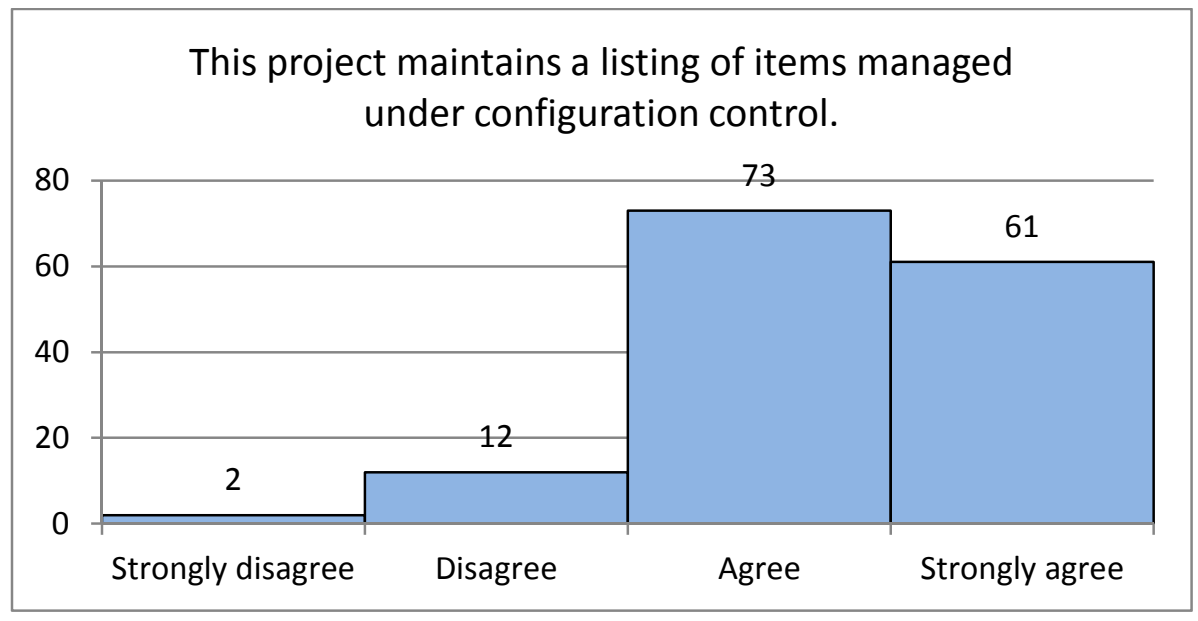

Figure 103: Question M.1 - Items Under Configuration Control

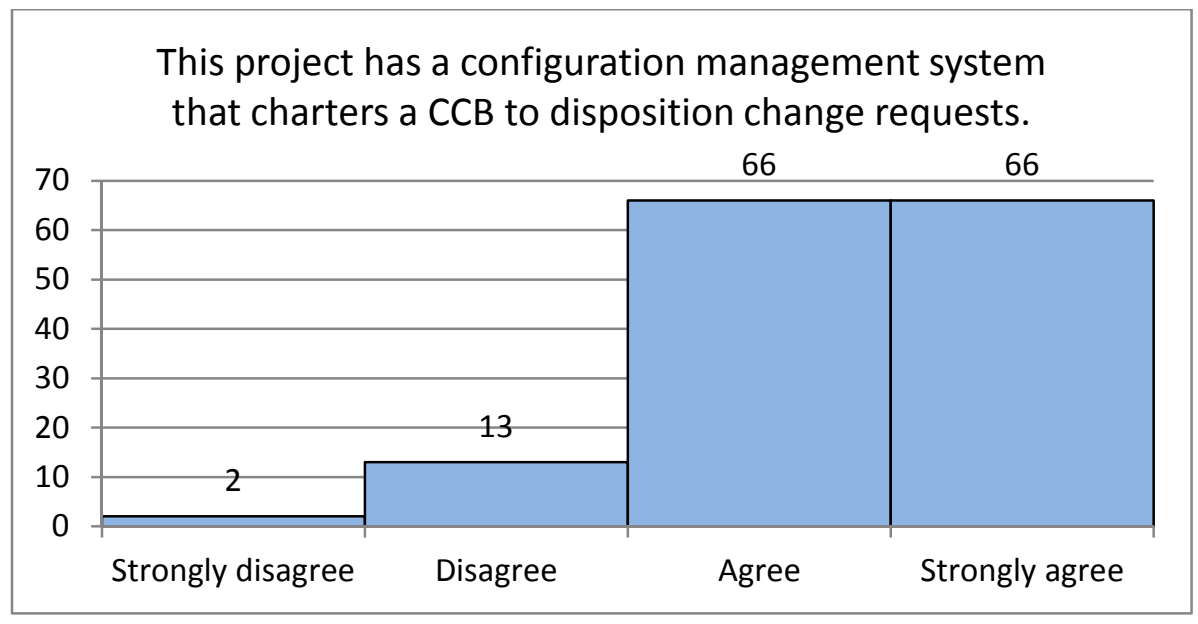

Figure 104: Question M.2 - Configuration Control Board 


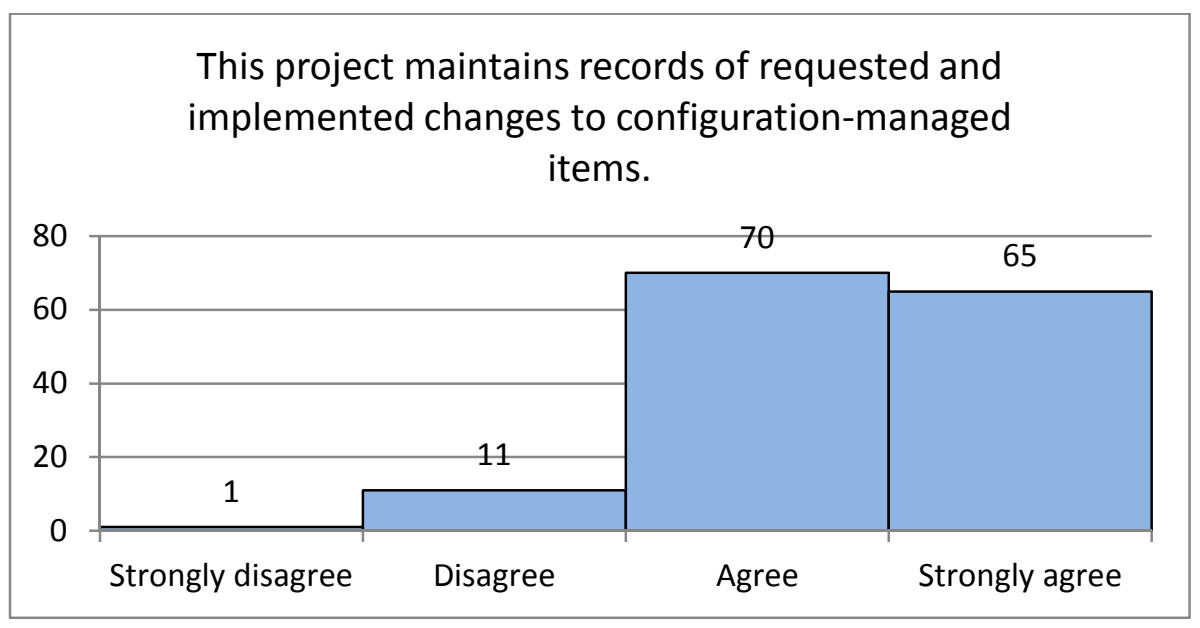

Figure 105: Question M.3 - Change Records

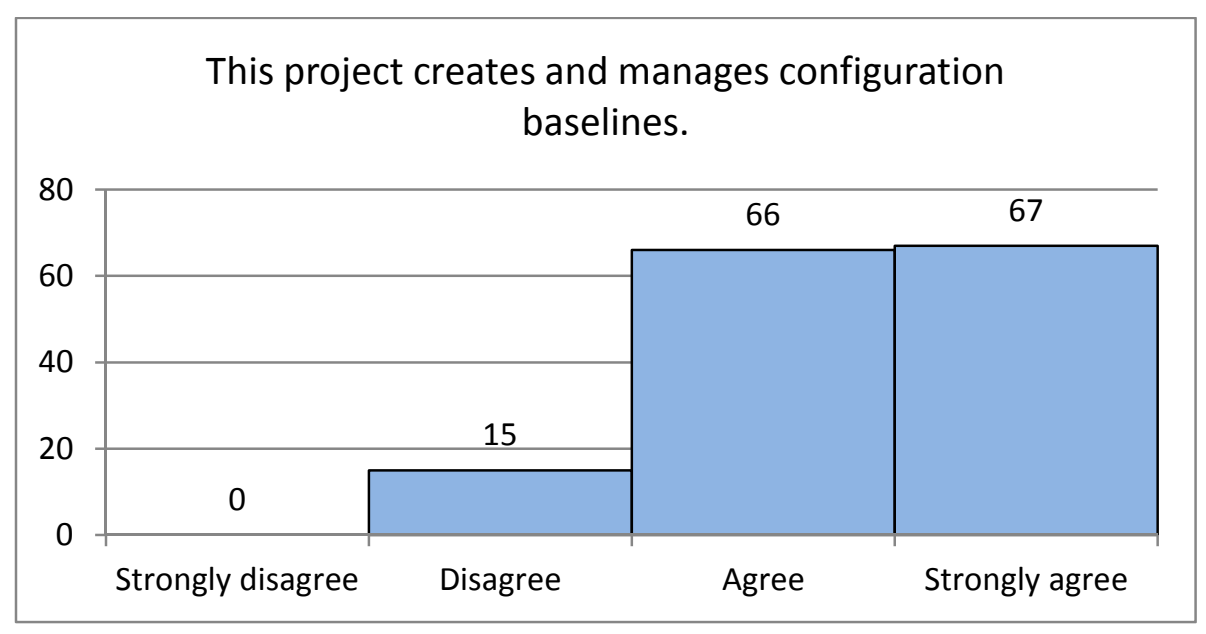

Figure 106: Question M.4 - Configuration Baselines 


\section{Questionnaire Section N - Project Performance}

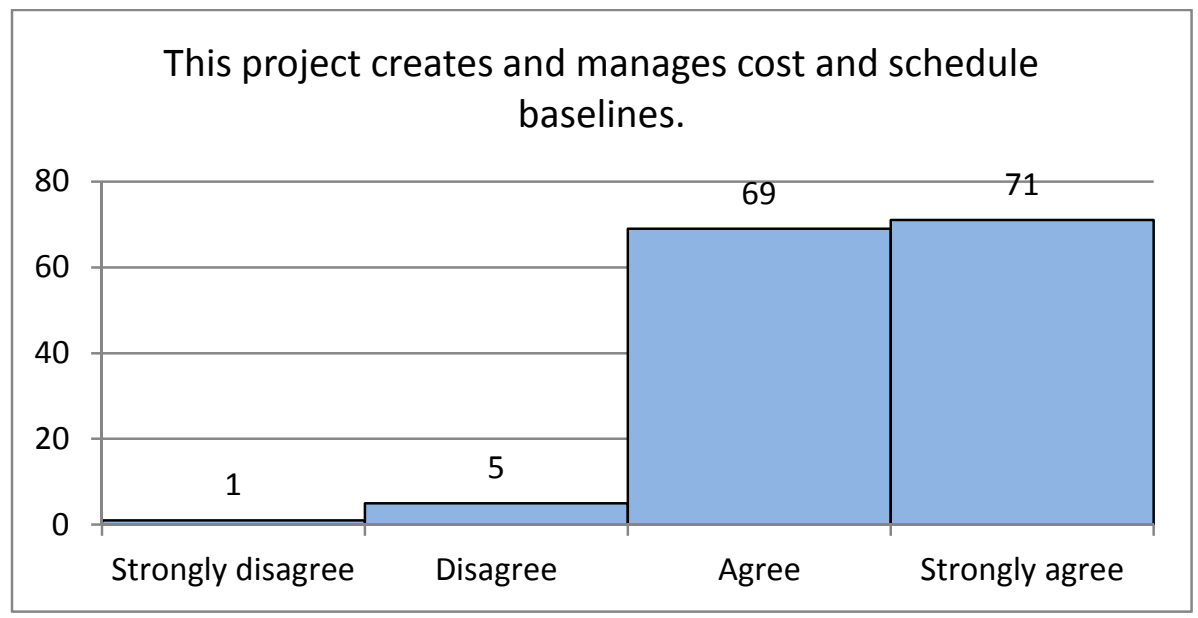

Figure 107: Question N.1 - Cost and Schedule Baselines

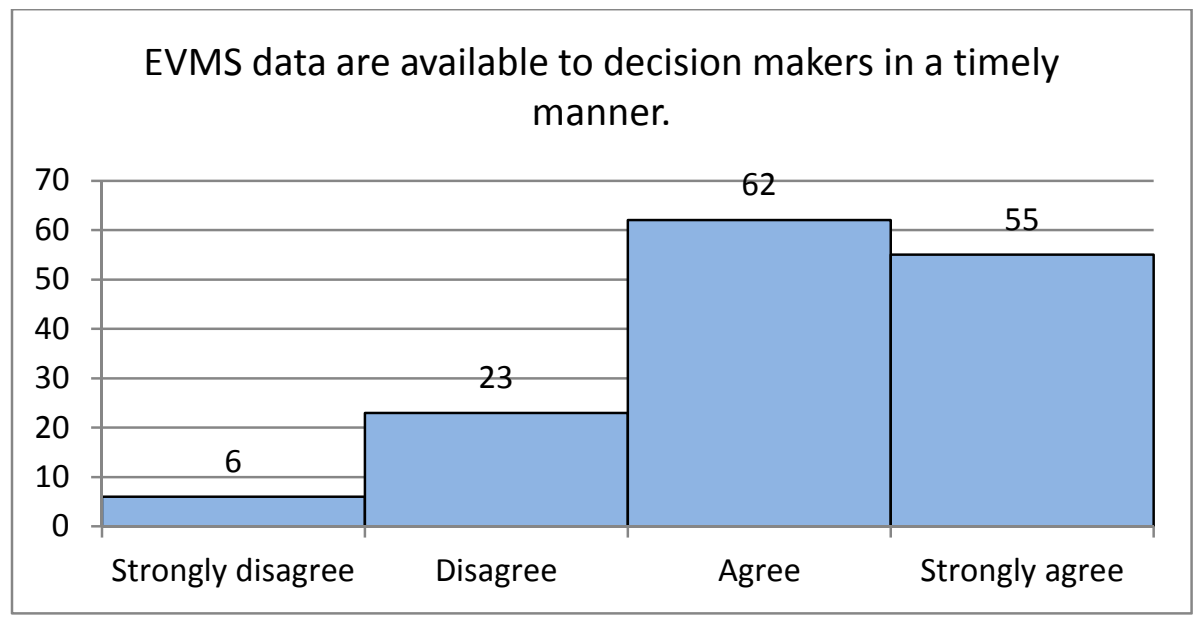

Figure 108: Question N.2 - Availability of EVMS ${ }^{9}$ Data

$9 \quad$ Earned Value Management System 


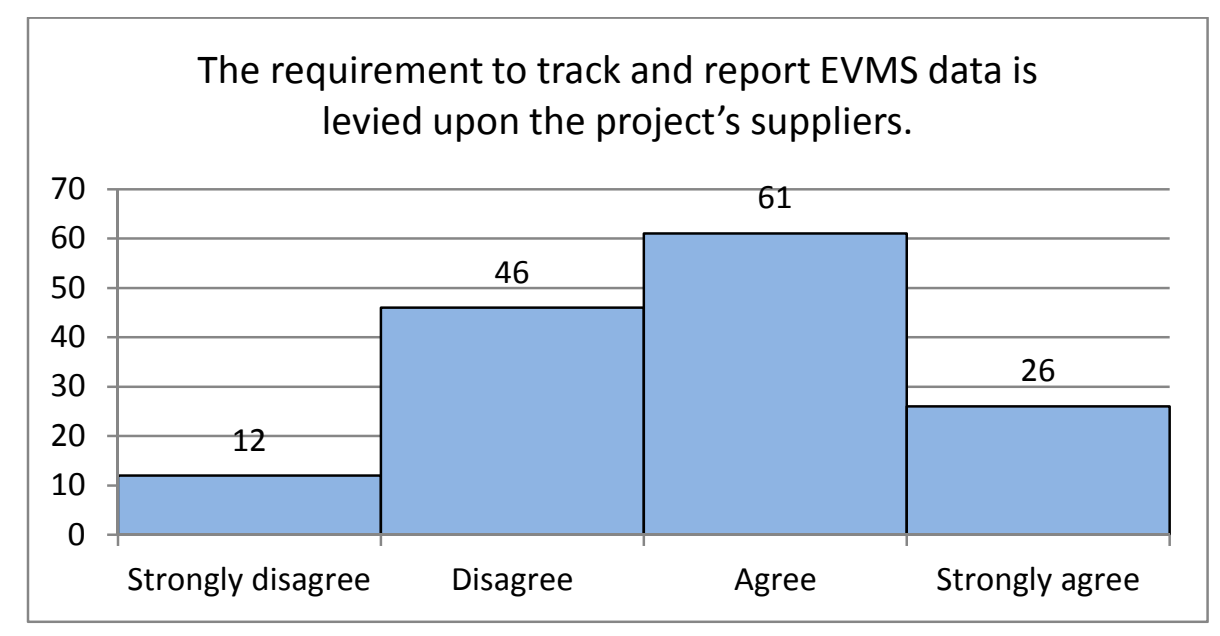

Figure 109: Question N.3 - Requirement for Suppliers to Track and Report EVMS Data

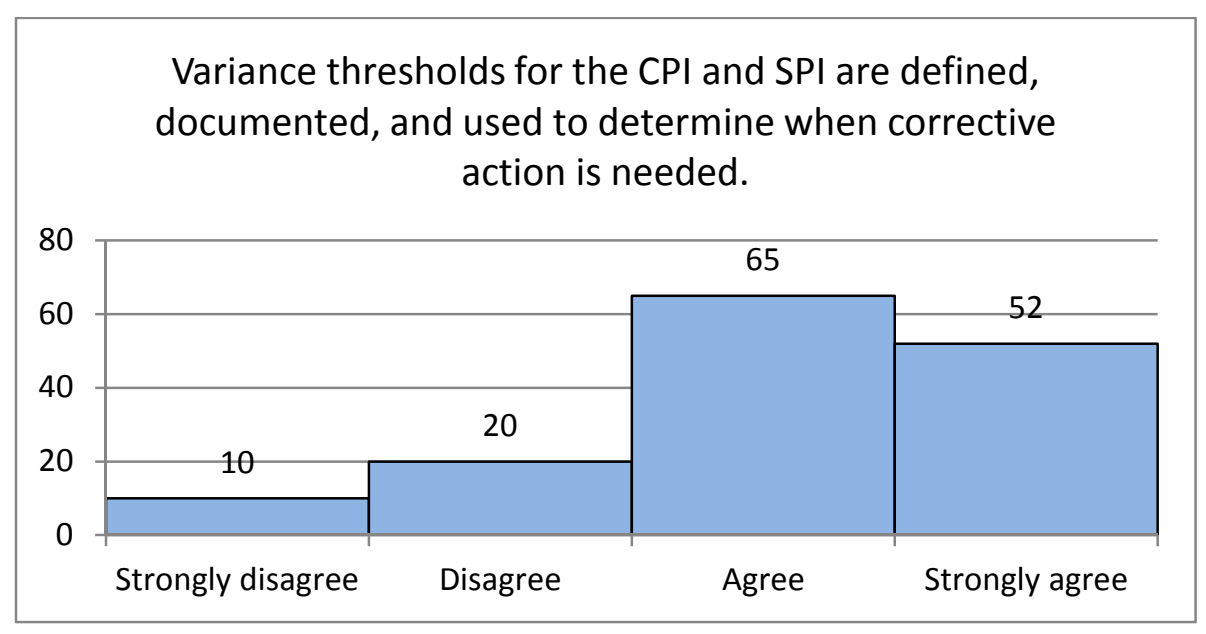

Figure 110: Question N.4 - Defined Variance Thresholds for CPI and SPI10

10 EVMS Cost Performance Index and Schedule Performance Index 


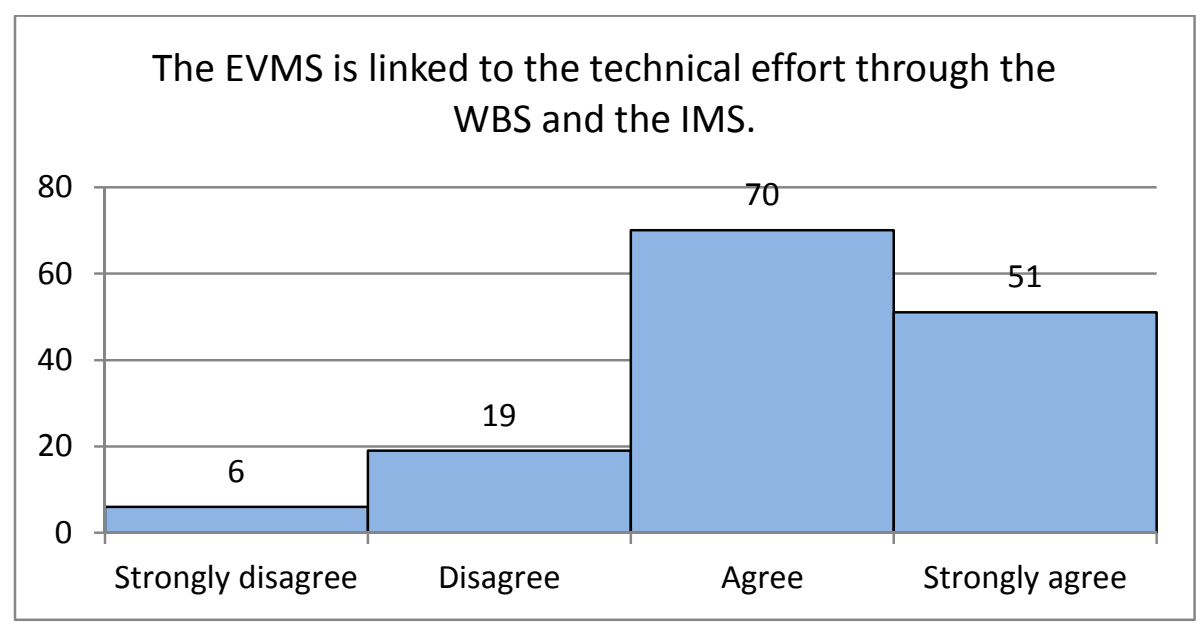

Figure 111: Question N.5 - EVMS Connections to the WBS and IMS ${ }^{11}$

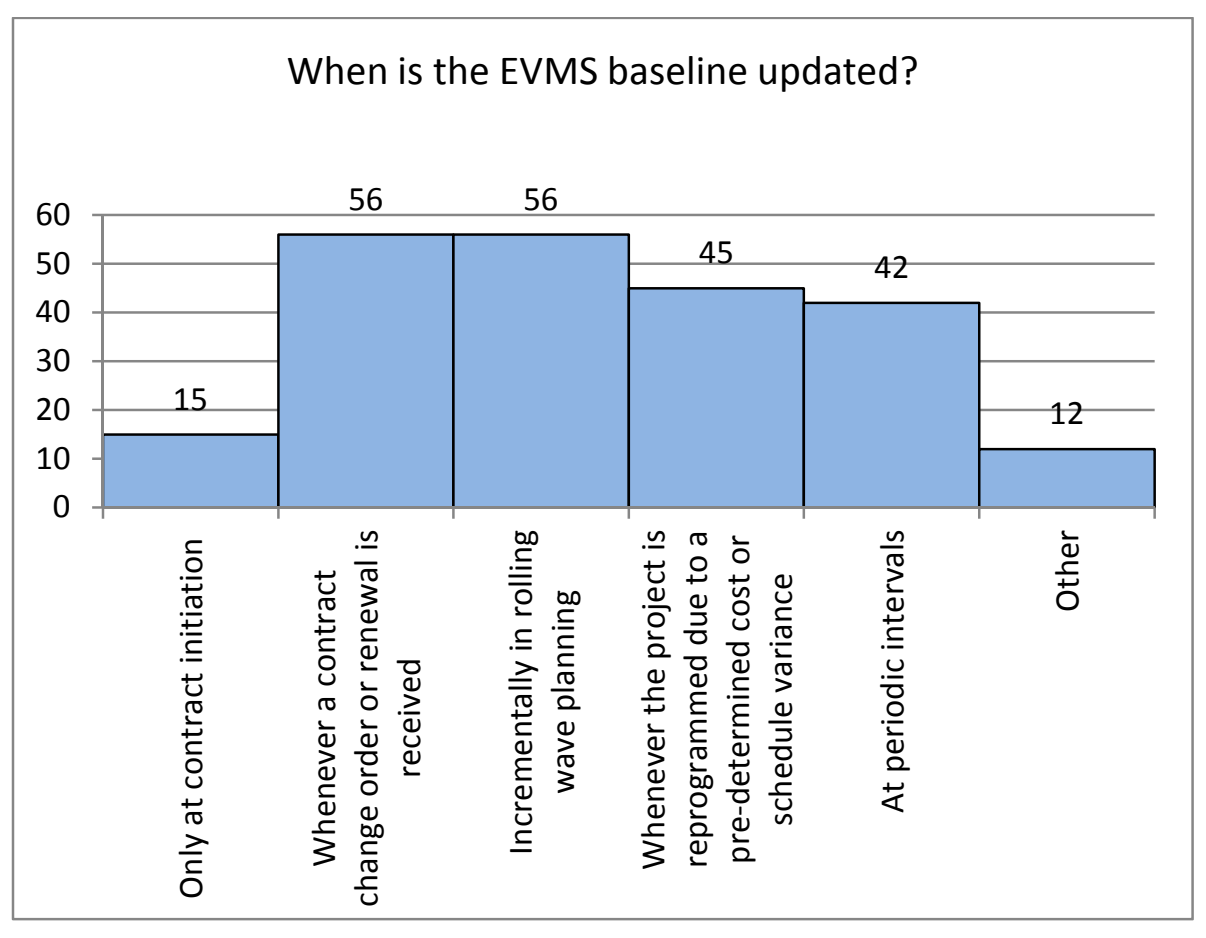

Figure 112: Question N.6 - Strategy for Updating the EVMS Baseline 


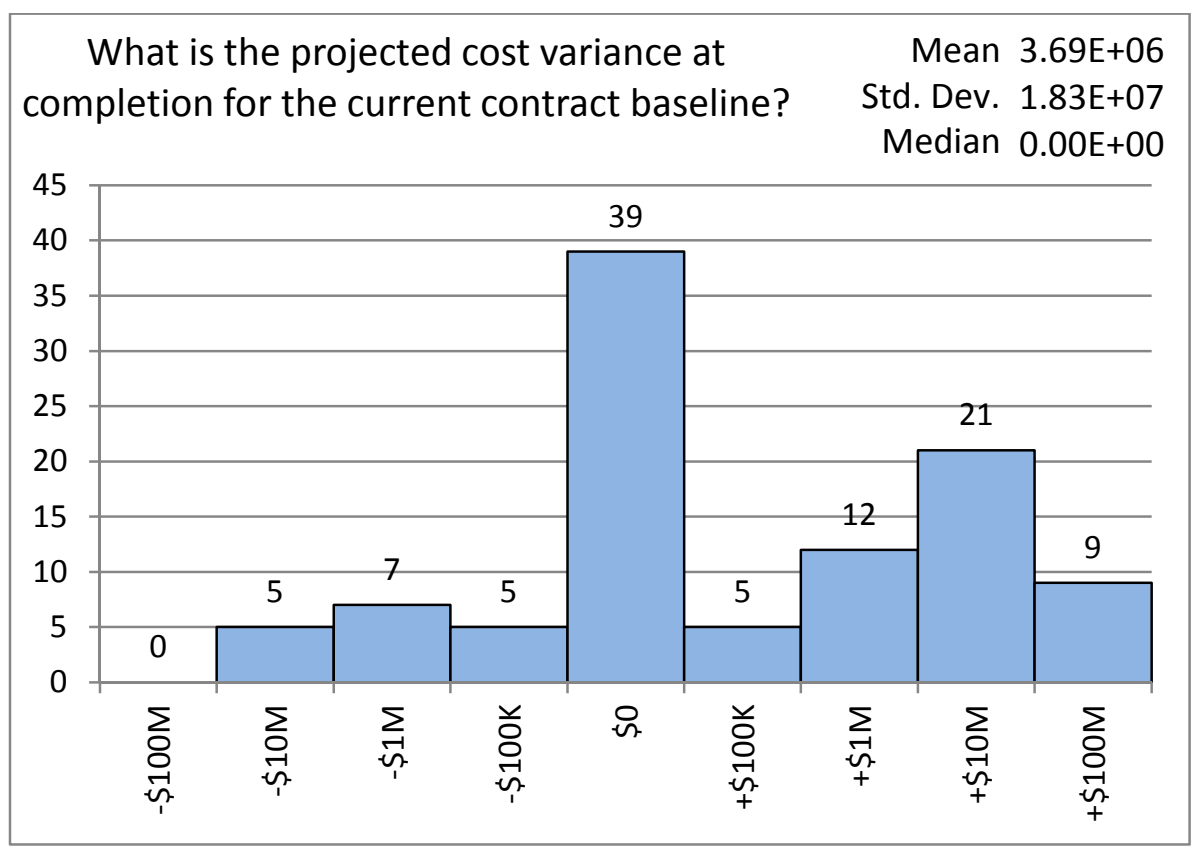

Figure 113: Question N.7 - Projected Cost Variance

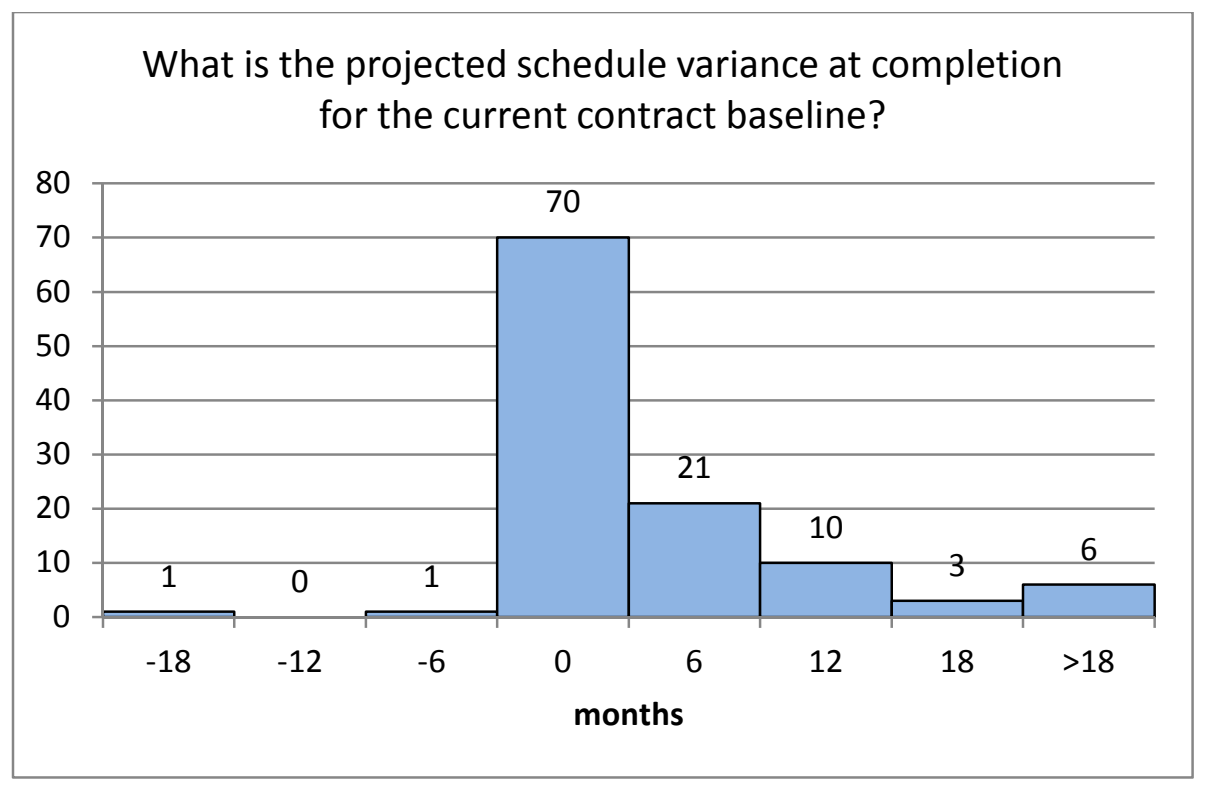

Figure 114: Question N.8 - Projected Schedule Variance 


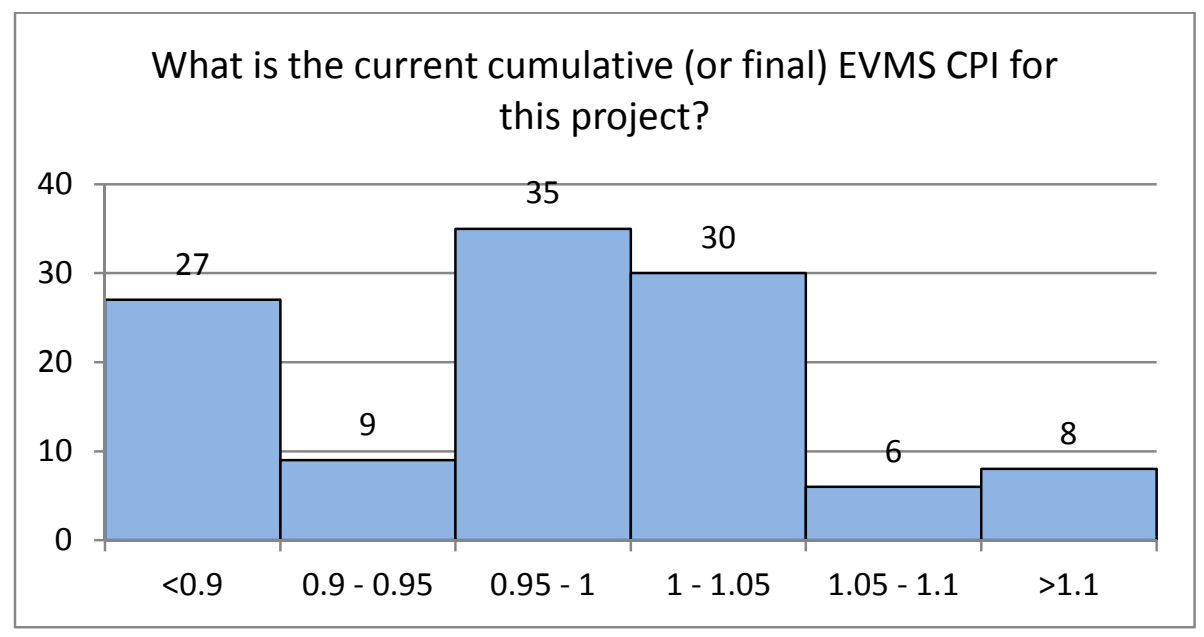

Figure 115: Question N.9 - Current EVMS CPI ${ }^{12}$

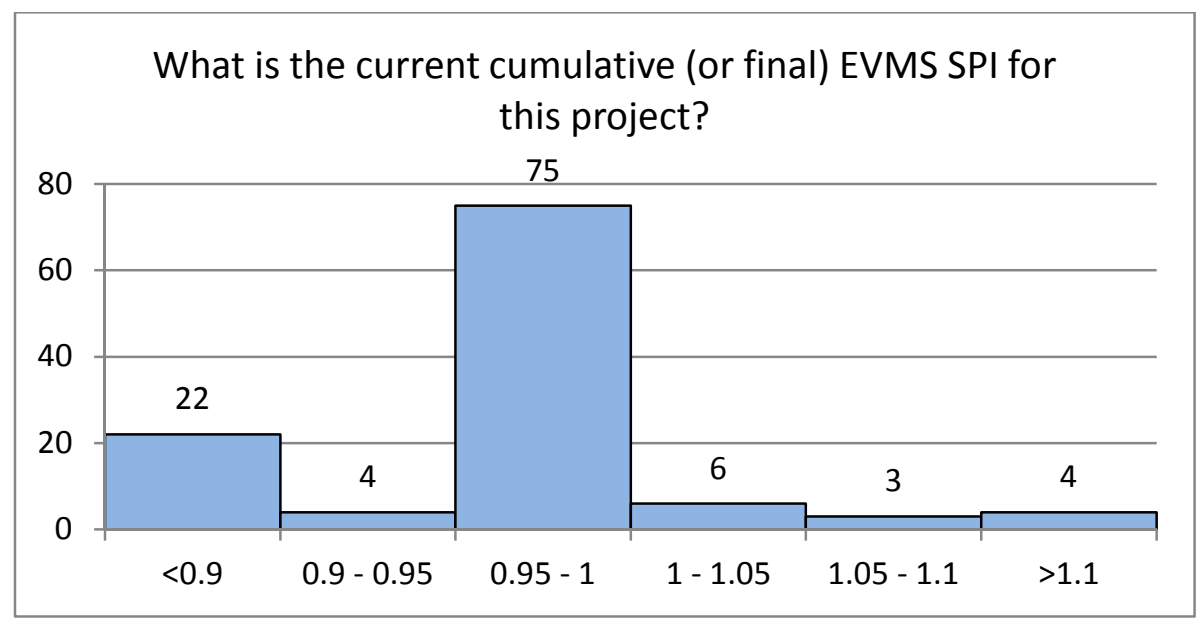

Figure 116: Question N.10 - Current EVMS SPI 13

\footnotetext{
12 EVMS Cost Performance Index

13 EVMS Schedule Performance Index
} 


\section{Questionnaire Section O - Other Performance Measures}

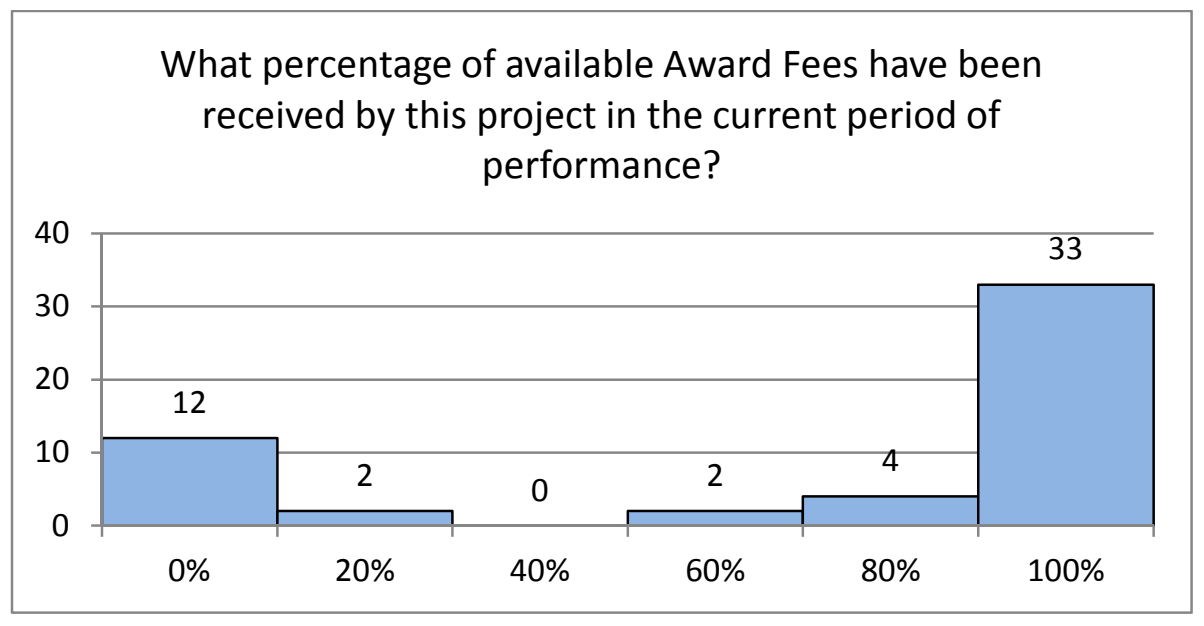

Figure 117: Question O.1 - Percentage of Award Fees Collected in the Current Period

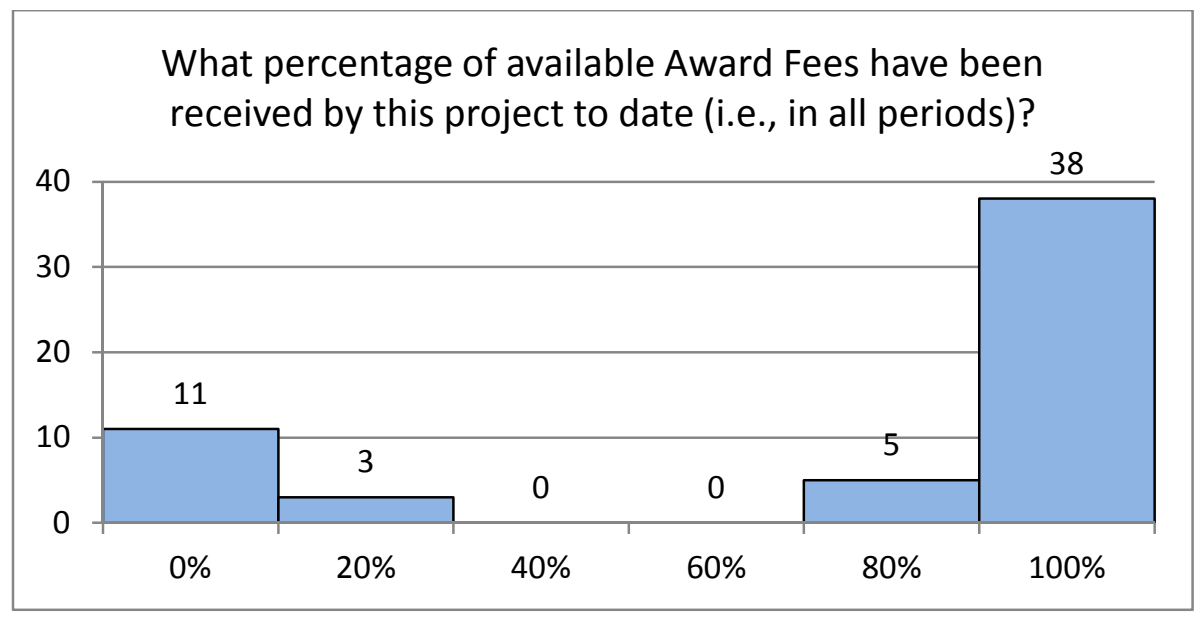

Figure 118: Question 0.2 - Percentage of Award Fees Collected During the Whole Project 


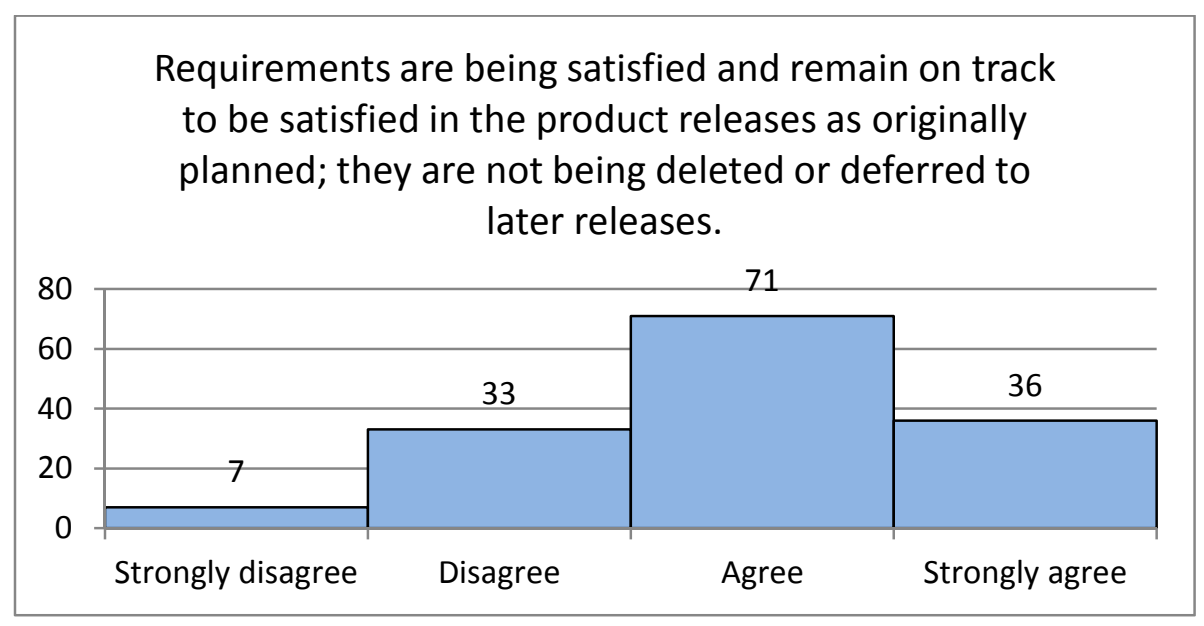

Figure 119: Question 0.3 - Satisfaction of Requirements

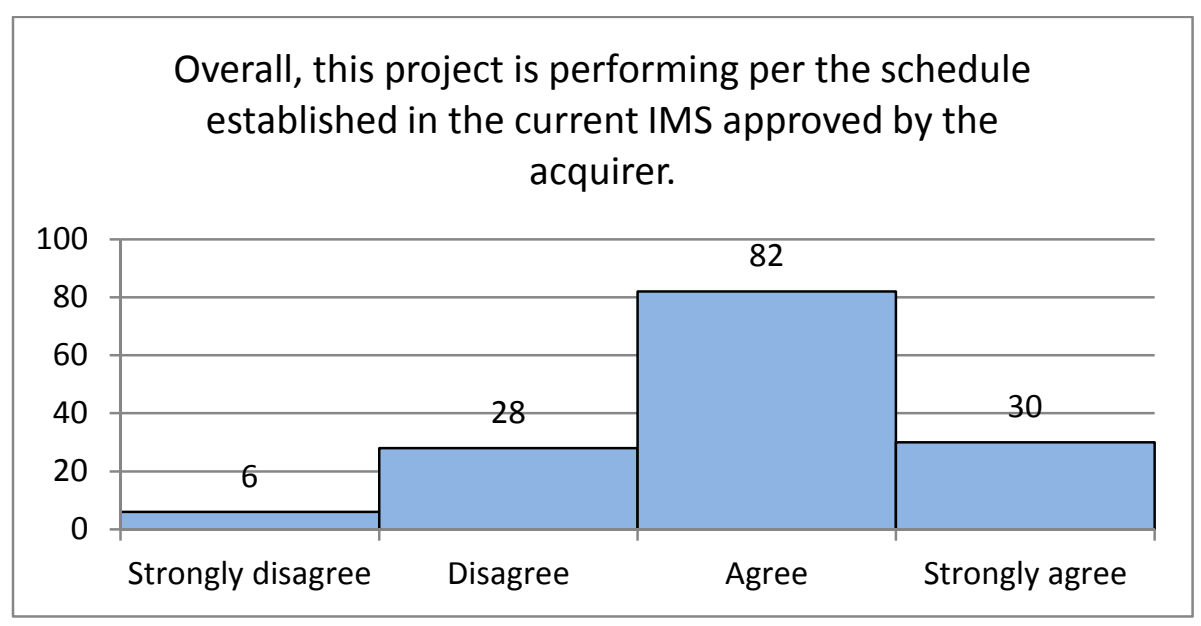

Figure 120: Question O.4 - Compliance with Approved Schedule

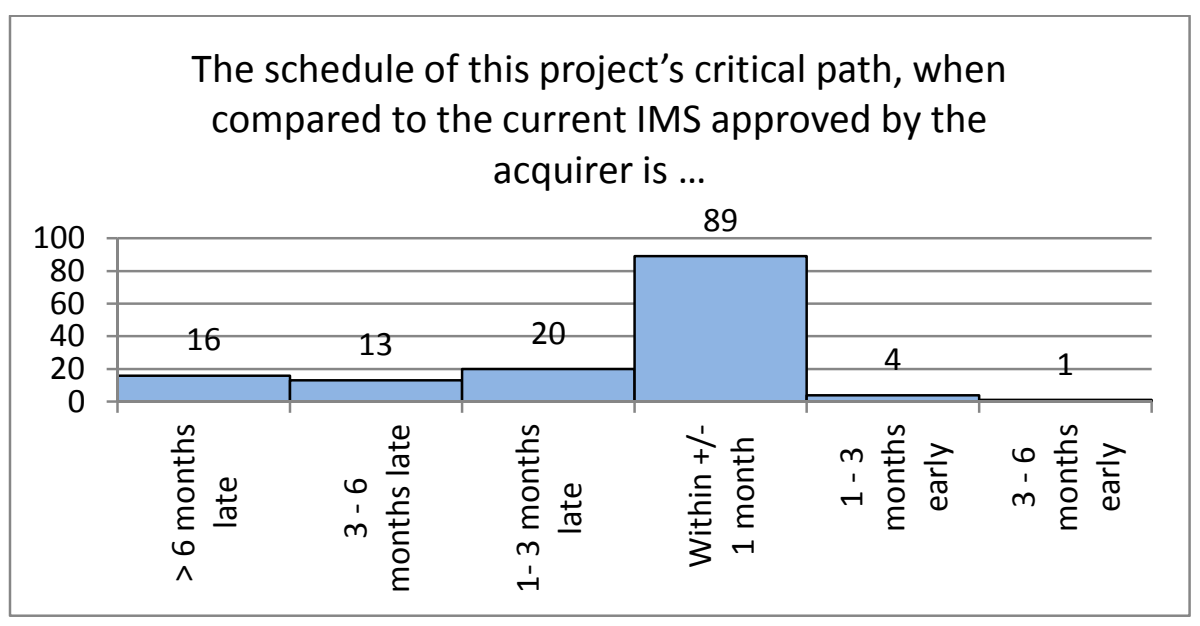

Figure 121: Question O.5 - Current Schedule Variance 


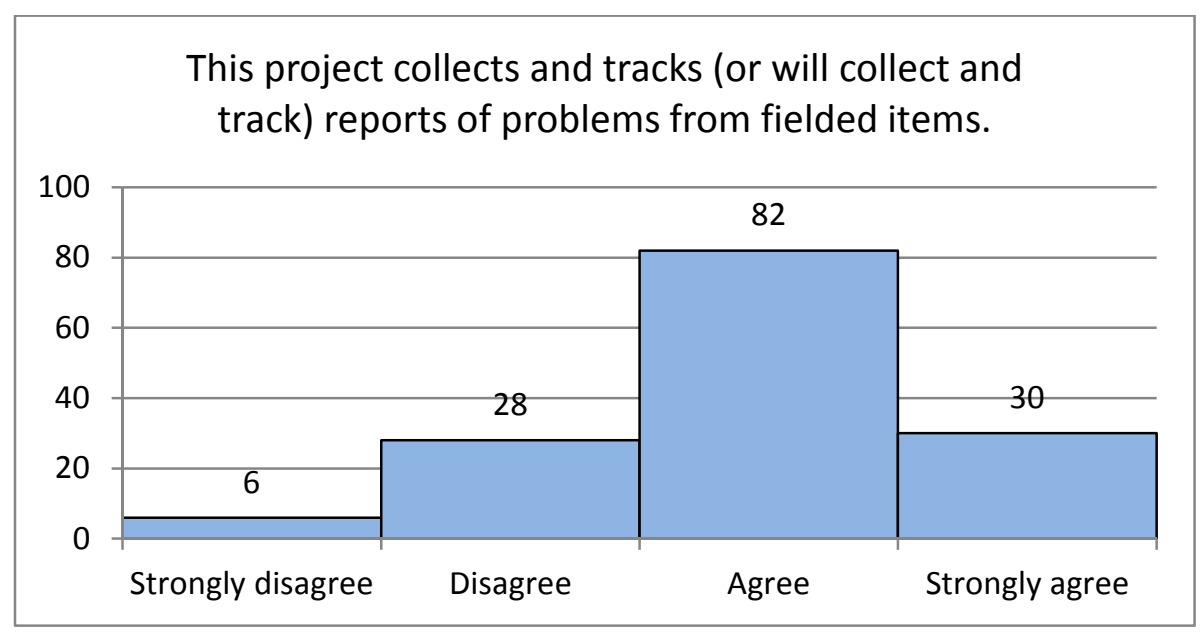

Figure 122: Question O.6 - Post-fielding Problem Tracking

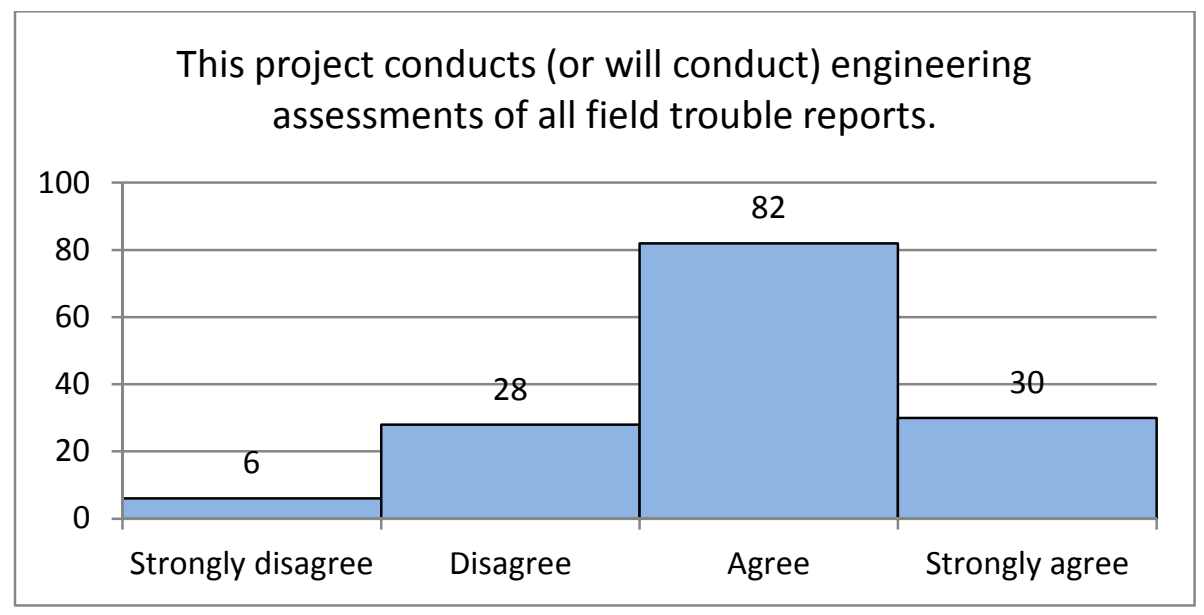

Figure 123: Question O.7 - Engineering Assessments of Problems

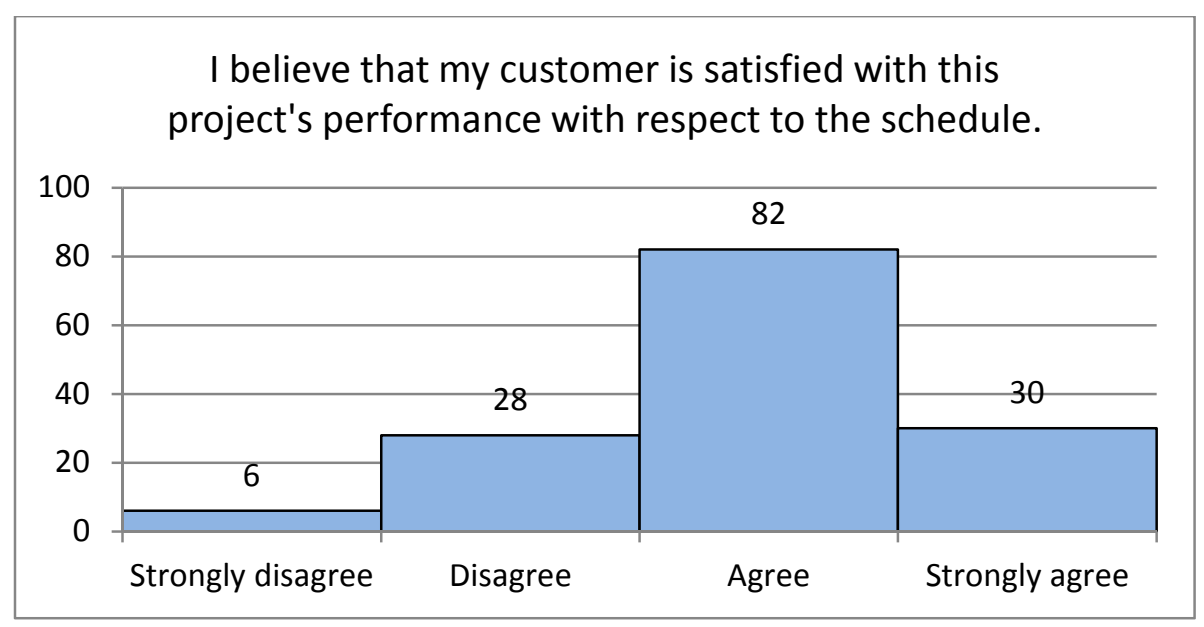

Figure 124: Question 0.8 - Customer Satisfaction with Schedule 


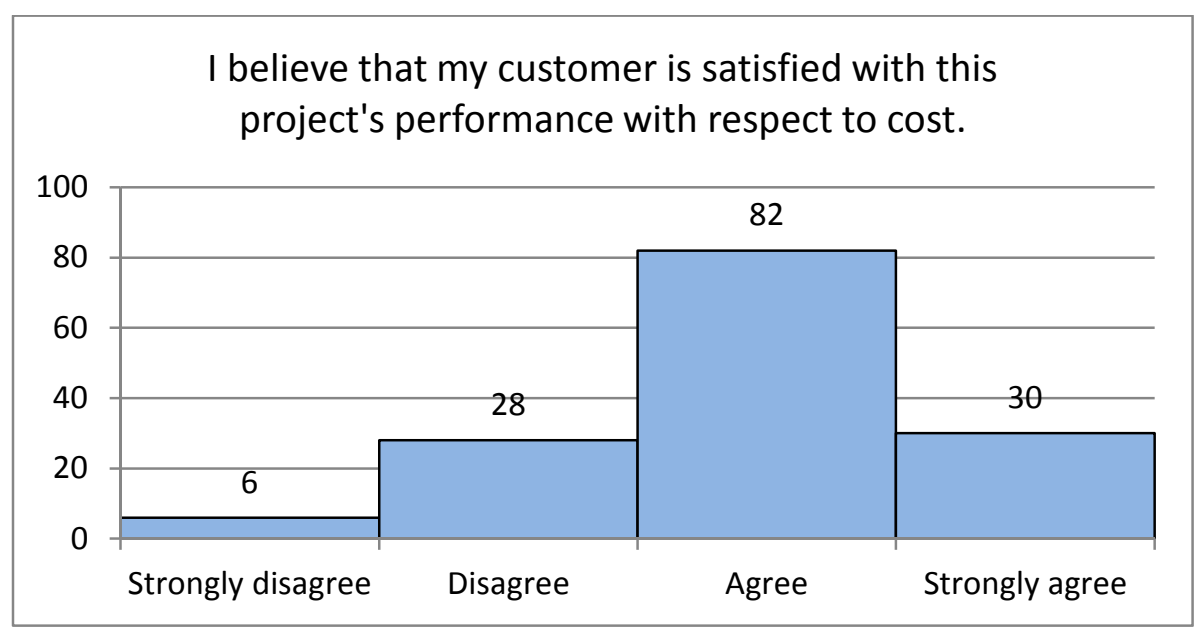

Figure 125: Question 0.9 - Customer Satisfaction with Cost

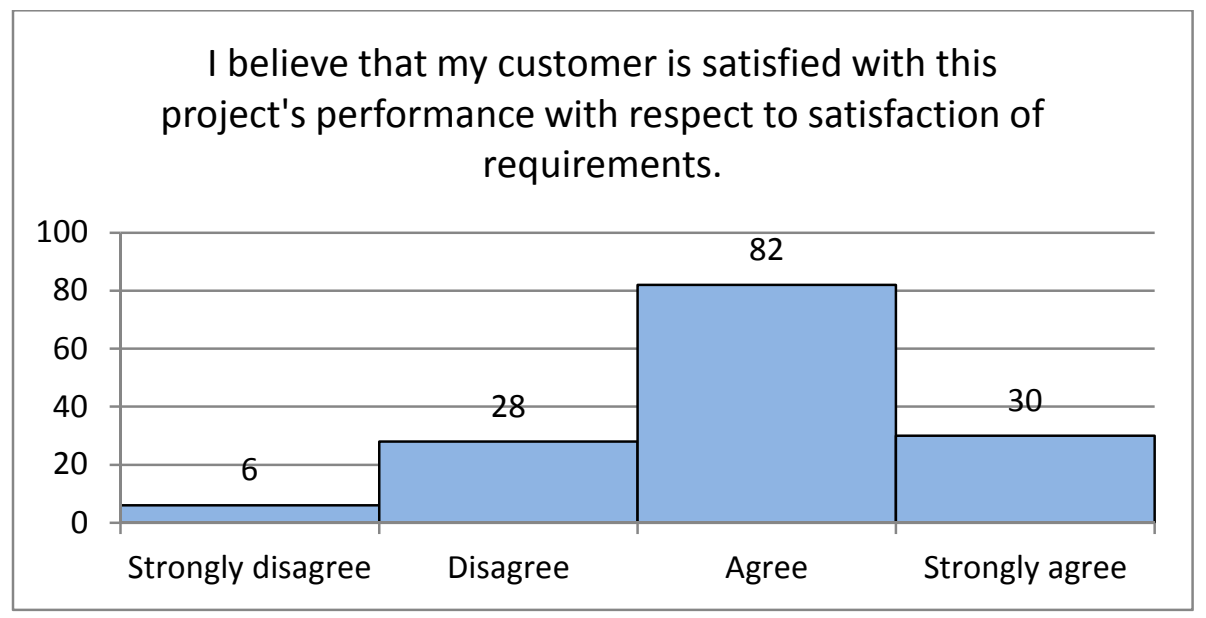

Figure 126: Question 0.10 - Customer Satisfaction with Compliance to Requirements 
Table 7: $\quad$ Question 0.11 - Other Useful Performance Indicators

\begin{tabular}{l} 
O.11 $\begin{array}{l}\text { What performance indicators (beyond cost and schedule) have been particularly useful for manag- } \\
\text { ing your project? }\end{array}$ \\
\hline Technical Performance Metrics (TPMs) \\
\hline KPP $^{14}$ metrics (\% satisfied, margins) \\
\hline EVMS metrics (CPI, SPI, ECTC) ${ }^{15}$ \\
\hline Requirements metrics (volatility, closure, satisfaction, trends, derived requirements count) \\
\hline Customer feedback (comments, complaints, report cards) \\
\hline Problem and Trouble Reports (issue count, time to resolution) \\
\hline Test metrics (\% of tests passed, test defects, time to defect correction) \\
\hline Risk metrics (expected cost of risk, mitigation status) \\
\hline Milestone metrics (inchstone progress, milestone accomplishment) \\
\hline Award fee metrics \\
\hline Review metrics (peer review status, design reviews completed) \\
\hline Software metrics (progress, change rate, code growth, defect resolution rate) \\
\hline Work product metrics (acceptance rate, rejected CDRLs, time to correct defect) \\
\hline Subcontractor progress metrics \\
\hline
\end{tabular}

\footnotetext{
14 key performance parameter

15 estimated cost to complete
} 
Table 8: Question 0.12 - Other Desired Information That Was Unavailable to the Project

0.12 What other kinds of performance-related information would have been helpful for your project or program, but was unavailable?

Software licensing delivery \& tracking

Formal debriefs from product user

Cost and effort estimating parametrics earlier in the program

Realistic award fee scores based on performance within our control

More timely cost data - delays getting baseline established

Test progress vs. plan

Customer-provided metrics in cost, schedule, risk management

Capture of performance statistics on unit-level builds to help establish statistical performance acceptance criteria

Participation in the design and integration process, interaction with vendors and customers

Subject matter experts to monitor supplier development

$\mathrm{TPMs}^{16}, \mathrm{KPPS}$

Trend data for getting work accomplished

System maturity

User evaluations

Initial stakeholder feedback early in the contract

Specifics on CONOPs and/or mission scenarios from the user.

Personnel performance

Better defined technical performance requirements

Number of active users, project site usage statistics

Automated drawing tree fault checking

Greater insight into what the customer hears from the agencies they serve

TPMs from associated subcontractors were not shared with us by the customer but would have been helpful in identifying weak or risky areas.

Visibility into the actual impact of meeting requirements on end item system performance. Several tough requirements were not actually necessary to meet overall system performance.

End user system's performance

Requirements and management of business case assumptions

EVMS

Better status and performance info from subcontractor

Number of issues with requirements

Requirements S-curves.

16 technical performance measures 
Table 9: Question 0.13 - Other SE Effectiveness Indicators Currently Used

0.13 What indicators do you use in your project or organization to determine Systems Engineering effectiveness?

Requirements measures (count, volatility, closure of TBDs, traceability, waivers, satisfaction, burndown, hours spent per requirement)

Risk measures (burndown)

Project measures (EVMS, product and $\mathrm{CDRL}^{17}$ delivery date variance, milestone completion variance, IMS/IMP variance, cost variance, schedule variance, critical path variance, award fee criteria satisfaction, headcount)

Technical measures (Technical Performance Measures [TPMs])

Test measures (verification plan variance, inspection reports, defect detection profiles, work product inspections, $\mathrm{QA}^{18}$ assessments, discrepancy report data, rework measures)

Customer measures (customer comments, work product acceptance / rejection data, formal and informal customer satisfaction inquiries, customer evaluation of SE efforts)

Process measures (SE best practices reviews, PM best practice reviews, process application audits, CMMI assessments)

Review measures (peer review status, customer review status [e.g., SRR, PDR], action item closures)

\section{Table 10: Question 0.14 - Other SE Effectiveness Indicators}

\subsection{What indicators of Systems Engineering effectiveness are regularly reviewed across projects by} higher level management?

Requirements measures (count, volatility, closure of TBDs, maturity, traceability, defects, satisfaction, traceability) Project measures (EVMS, IMS/IMP variance, milestone completion variance, cost variance, schedule variance, product and CDRL delivery variance, \%-complete, affordability, headcount)

Technical measures (Technical performance measures [TPMSs], Key performance parameters [KPPs])

Risk measures (burndown)

Customer satisfaction measures (customer feedback, customer comments, work product acceptance / rejection data)

Process measures (Process Deviations, SE health assessment, compliance with SE processes, process audits) Review measures (customer reviews [SRR, PDR, CDR $]^{19}$ completed, SE peer reviews conducted, SE peer review effectiveness, action item closure)

Test measures (inspection metrics, work product inspection defects, verification status, rework measures)

\footnotetext{
17 contract data requirements list

18 quality assurance

19 system requirements review, preliminary design review, and critical design review
} 


\section{Questionnaire Section P - Conclusion}

\section{Table 11: Question P.1 - Other SE Comments About the Project or the Survey}

\section{P.1 Is there anything else that you would like to tell us about your project or this survey?}

The 4 levels of choice are too limiting; there is no ability to enter a "because" qualifier for a 4-level choice; there is no section on "customer-driven requirements churn: my company evaluates requirements changes (now 56\%) and (lately) provides cost/sch.

Referenced project is huge, multi-billion, multi-location, multi-agency, multi-nation contract. A Joint Services / Joint Country program like this has no precedence. Schedule variances are due to 1) changing technology, 2) aggressive schedule.

This project used a concurrent engineering approach, which proved to be a differentiator between our success vs. other programs that did not fare as well.

Schedule delay currently experienced is largely due to slips in production (root cause labor skill and capacity shortfalls) rather than slips caused by design and development difficulties.

Survey was all-inclusive. This program did especially well in the survey because of the customer interest and engagement in the program, which began with the initial RFP. ${ }^{20}$ This was a very experienced customer in systems engineering.

This project does not fit well into this survey since it is not a "standard" contracted development effort. Because it is an internally funded development, there was no contract requiring submittal of planning documents so they were tailored out of the project.

Classified, Best Effort Technology Development program with no EVMS since activities are level of effort.

This project was recently completed, was successful, and leveraged into next phase.

Complicated and convoluted contractual arrangement make program very hard to manage. Late or deficient GFI/GFE and BFE/BFI hinders program execution and adds cost. Lack of strong and sound systems engineering at the prime contractor level impacts program.

Contract is $50 \%$ complete, but without a definitive contract with the prime contractor. Project has received incremental (unbudgeted funding since inception). Proceeding under prime contractor through successive rolling wave baseline reviews lasting $\sim 6$ months

This contract has evolved, both in contract type and role, over 7 years. We were able to re-establish system engineering discipline over a 4-prime contract Enterprise that was out of control two years ago. Since then, the Enterprise has become much more stable

Program executed ahead of plan until environmental quality test failure occurred with Shock Testing. Additional efforts associated with getting through shock testing created cost and schedule over run.

We have worked with INCOSE to try to define useful Systems Engineering Effectiveness metrics. None have been useful to date other than requirements metrics, which are only a small part of Systems Engineering.

Good processes plagued by an unwillingness to follow these, combined with compressed schedule and reduced budget profiles negotiated by Business Development negotiations often plague the program's effective systems engineering program execution.

Although cost and schedule increases were experienced on the program, our original proposal cost was about equal to the final cost of the project, and most of the major schedule deliveries were met or nearly met.

This project is driven by an immediate need in the field by the troops in IRAQ and is on an extremely tight deployment schedule with the biggest success criteria based on reliability, endurance, and successful [technical performance].

This particular contract was a competition - two contractors executing in parallel, with a downselect to one. Project did not need to be as difficult as it was. A more amicable, open working relationship with the customer would have made things easier.

20 request for proposal 


\section{P.1 Is there anything else that you would like to tell us about your project or this survey? (cont.)}

Strong relationship allowing the customer to feel confident in your ability to lead coupled with thorough understanding and execution of systems engineering process is key to success.

Previous experience has indicated that the level of systems engineering and performance tracking implemented should be tailored to the size of the project. In the past our organization tried a one size fits all approach to critical path management and

This was an R\&D project with challenging goals. Customer requirements creep made execution challenging and forced us, within the budget, to spend efforts on lower priority issues at the expense of higher priority ones.

The project was a system-of-system architecture study, and resulted in identification of a number of preferred alternative solutions. Several sections of this survey do not really apply (risk management, verification, validation).

Project has experienced technical challenges in implementation and has had to undergo a redesign to a key component, significantly impacting cost and schedule

This is a very large program (> 5M LLOC) developed over 15 years, and continues to evolve. Contractor SE discipline and oversight waned several years ago at customer direction (SETA teams performed that role).

This survey contains questions that, I believe, are not pertinent to the engineering effort and in fact, are sensitive and company proprietary.

I think the survey should collect additional information regarding the "acquirer" since their interaction, capabilities (or lack thereof) and involvement can have a profound impact on the execution of a program and the effective utilization of resources.

SE processes are well-defined and the staff is trained on how to apply them to a program. Often, the program office tries to take short cuts as a cost-savings incentive, by eliminating steps in the SE process, or not funding SE tasks

The project is currently in Technology Development. My responses to this survey encompassed the current [phase] and the previous Requirements Maturation phase.

Follow on programs were needed and [executed] to get to a useful level of functionality.

This is primarily a study contract.

This is a joint service project. It can be very difficult to get multiple services to agree on common requirements. So far, no major issues. Due to project value EVMS system has not been required.

The unplanned activities and cost increase encountered were attributed to our subcontractor. Our subcontractor was also not fixed price. The subcontractor was involved in our SE process, but their cost and schedule estimates, SE inputs, risk inputs and were inaccurate.

Some difficulty in differentiating "agree," "strongly agree," "disagree," and "strongly disagree." Would be useful if some examples were provided by the survey as to what the differentiation is.

At times, the answers to the questions seemed to assume formal SE tenets were in place. Several times I had to estimate based on our practices.

This project took marginal capability $\mathrm{GFE}^{21}$ that was advertised as qualified, discovered the faults, recovered to CDR maturity and regression re-qualified. Additionally two major capabilities upgrades were incorporated and regression tested.

Development completed in 2009. Program is in production with change orders issued against IDIQ tables. Proposal for 5 year contract extension anticipated before Sept. 2012.

Award fee has not been given yet.

Having a good standard process doesn't necessarily guarantee success. There needs to enough flexibility in the process to work within the customer boundaries and limitations.

This project, though broad in scope, proves that the design at all levels can be pulled together through strong system engineering leadership at all levels. This leadership ensures that all of the pieces, from all IPTs, contribute to meeting interface requirements.

21 government furnished equipment 


\section{P.1 Is there anything else that you would like to tell us about your project or this survey? (cont.)}

Project was executed to an initial plan (based on proposal) which was deeply flawed as it was generated by those unfamiliar with the program challenges. One month in, everyone knew we had no chance of meeting cost or schedule.

My project is a mix of development and $O \& M,{ }^{22}$ with a vast majority of the hours being LOE. ${ }^{23}$

This program is probably different compared to most programs. We work from a very simple $\mathrm{SOW}^{24}$ and virtually develop all system requirements on our own and then gain buy-in from the customer as opposed the customer providing an $\mathrm{SRD}^{25}$ upfront with crisp requirements.

Customer/acquirer consistently talks about SE but never practices SE. Customer practices SE Management in name and function without understanding relationship to the execution of SE.

Project did not maintain an up-to-date market view regarding their deliverables.

The scope was poorly understood at the signing of the contract. There was no understanding of what architecture would be needed that would be able to meet the requirements at the start of the project.

Well managed technically very challenging project

Project is recovering performance to original baseline in a very competitive marketplace. Competitors equally struggle to meet baseline performance requirements.

Novel design. Not supported by prescriptive requirements. This industry relies on prescriptive requirements.

Our schedule problems were mostly due to poor subcontractor schedule performance; subcontractor had an FFP ${ }^{26}$ subcontract otherwise cost overruns would have been tremendous.

This is an internal product development project where the company (Marketing) is the acquirer. The acquirer is not an independent 3rd party or government.

The program would give one the indication that performance is bad. However, breaking out the highly variable and unpredictable front-end, SE requirements development has been invaluable. In my opinion, this will result in a program that will perform near plan.

Most core IPT members have 20+ years of experience each and the team has good cohesion, with very little member turnover in the past three years. The $\mathrm{PM}^{27}$ is extremely proactive and very results oriented.

22 operations and maintenance

23 level of effort

24 statement of work

25 system requirements document

26 firm fixed price

27 program manager 


\section{Conclusion}

The results of this study, as presented in the report The Business Case for Systems Engineering Study: Results of the SE Effectiveness Survey [Elm 2012b], clearly show that the deployment of SE best practices has a significant positive affect on project performance. Armed with this knowledge, many organizations will want to take steps to improve their project performance through deployment of improved SE practices. The first step in such improvements is to gain an understanding of current SE practices. This understanding can be accomplished through using the questionnaire developed for this study (see the appendix) to assess the organization's projects. This assessment forms an SE deployment baseline for the organization.

The data presented in this report constitute a benchmark for the application of SE practices and the production of SE artifacts in the development of systems. System developers may use this benchmark as a reference against which to compare their SE deployment baseline. Comparison between the baseline and benchmark data contained in this report can identify areas of strength and weakness. Process improvement efforts can then be initiated to address identified weaknesses. 


\section{Appendix: Survey Questionnaire}

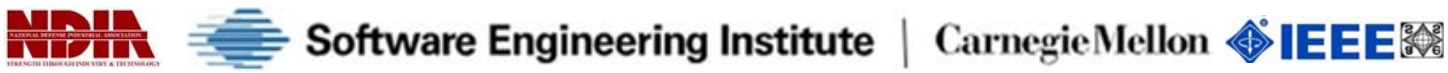

\section{The Effectiveness of Systems Engineering: A Survey}

The National Defense Industrial Association (NDIA), the IEEE Aerospace and Electronic Systems Society (IEEE-AESS) and the Software Engineering Institute (SEI) welcome you to your personalized questionnaire for our survey on "The Effectiveness of Systems Engineering." Our hope is that your participation will help your project and organization evaluate the effectiveness of their Systems Engineering practices relative to the successes and challenges reported by others throughout the industry.

Most of the information necessary to complete the questionnaire should be easily accessible or familiar to you or perhaps an informed designee. It should take about 30 to 45 minutes to complete the questionnaire. Please provide your best estimates if quantitative measurements are unavailable.

Please complete the questionnaire as candidly and completely as you possibly can. The results will be useful to you, us and others only to the extent that all survey participants do so. There is no need to hide weaknesses or embellish strengths. Remember that your response will be anonymous. Neither the SEI nor anyone else will know the person, project, or organization reflected in your response. The information, collected under promise of non disclosure by the SEI, will be held in strict confidence and will not be released in any manner. Survey results will be reported only in summary aggregate form. Individual responses will NOT be exposed. No attribution to people, projects, or organizations will be made.

A detailed summary report of the survey results will be prepared by the SEl. The report will provide a baseline against which you can compare the performance of your project and organization. As a reward for participating in this survey, the report will be initially released only to those who fully complete a survey questionnaire. The report will be not be publicly released until one year later.

Thank you once again for your help with this important activity. Please feel free to contact us at sei-analysis@sei.cmu.edu if you have any difficulty with the questionnaire. 


\section{CHARACTERIZATION OF THE PROJECT, PRODUCT, CONTRACT, AND ORGANIZATION}

\section{A. ABOUT THIS PROJECT}

The information gathered here and in the next few sections will be used by the survey analysts to categorize the participating projects and organizations in order to better understand the responses to subsequent questions about systems, Systems Engineering practices, and project performance.

The terms "Project", and "Program", are used interchangeably throughout this survey. Both refer to any temporary endeavor, having a defined beginning and end, undertaken to meet unique goals and objectives. Such endeavors are characterized by a defined set of objectives, a defined budget or cost estimate, and a defined schedule or period of performance. In crafting your response to this survey, it is important that you keep in mind a clear idea of the scope of the project for which you are responding. This will help to ensure that your responses regarding applied Systems Engineering activities and your responses regarding project performance relate to the same body of work.

Following are several statements that have been used to characterize various development projects. How well do the statements describe this project?

1. The project is challenging because there is no precedent for what is being done. (Please select one)

O Strongly disagree

O Disagree

O Agree

O Strongly Agree

2. This project is challenging because significant constraints are placed on the quality attributes (e.g. reliability, scalability, security, supportability, etc.) of the product. (Please select one)

O Strongly disagree

O Disagree

O Agree

O Strongly Agree

3. The project is challenging because the size of the development effort is large. (Please select one)

S Strongly disagree

O Disagree

O Agree

O Strongly Agree 
4. The project is challenging because the technology needed for this project is not mature or otherwise poses a high risk. (Please select one)

O Strongly disagree

O Disagree

O Agree

Strongly Agree

5. The project is challenging because there are extensive needs for interoperability with other systems (Please select one)

Strongly disagree

O Disagree

O Agree

O Strongly Agree

6. The project is challenging because there are insufficient resources (e.g. people, funding) available to support the project. (Please select one)

Strongly disagree

O Disagree

O Agree

Strongly Agree

7. The project is challenging because there are insufficient skills and subject matter expertise available to support the project. (Please select one)

Strongly disagree

O Disagree

O Agree

O Strongly Agree

8. The project is challenging for other reasons (Please describe briefly)

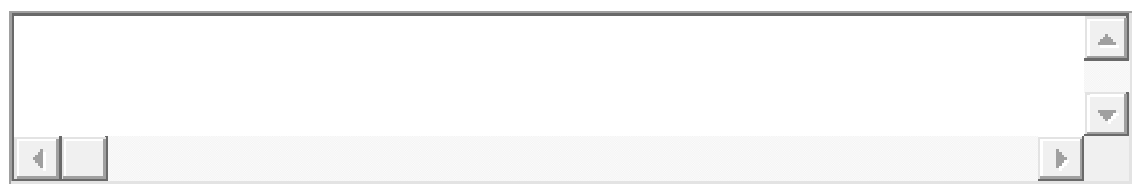

9. In the past, this project team has successfully completed projects of similar scope. (Please select one)

O Strongly disagree

O Disagree

O Agree

O Strongly Agree 
10. The requirements supplied by the customer for this project are well-defined (Please select one)

O Strongly disagree

O Disagree

O Agree

Strongly Agree

11. The requirements supplied by the customer for this project have not changed sufficiently to generate a significant impact on the project. (Please select one)

O Strongly disagree

O Disagree

O Agree

O Strongly Agree

12. What percentage of the customer technical requirements were marked "To Be Determined" or equivalent at time of contract award? (Please specify -- numbers only, without the percentage sign)

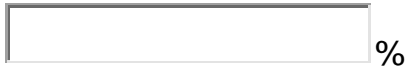

13. What percentage of the customer's technical requirements are currently marked "To Be Determined" or equivalent? (Please specify an approximate percentage -- without the percentage sign)

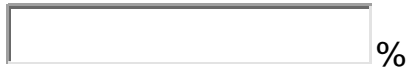

14. Do you separately budget and track Systems Engineering activities? (Please select one)

O Yes

O No

O Don't Know

15. Approximately what percentage of non-recurring engineering (NRE) does Systems Engineering represent? (Please specify an approximate percentage -- without the percentage sign)

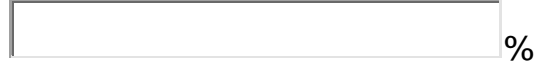


16. How are Systems Engineering activities estimated and budgeted? (Please check all that apply)

$\square \quad$ They are budgeted as a percentage of the total development cost

$\square \quad$ They are estimated using a parametric cost model (e.g., COSYSMO, SEER, SLIM, TruePlanning)

$\square \quad$ They are estimated on a task-by-task basis

$\square \quad$ Other (please describe)

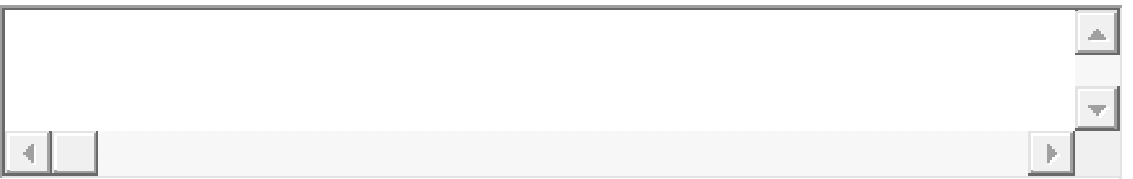

17. Which of the following best describes the ultimate end-user of this product? (Please select one)

O Government (USA) - defense related

O Government (USA) - not defense related

O Government (non-USA) - defense related

O Government (non-USA) - not defense related

O Industrial / Commercial

O Private Consumer

O Other (Please describe)

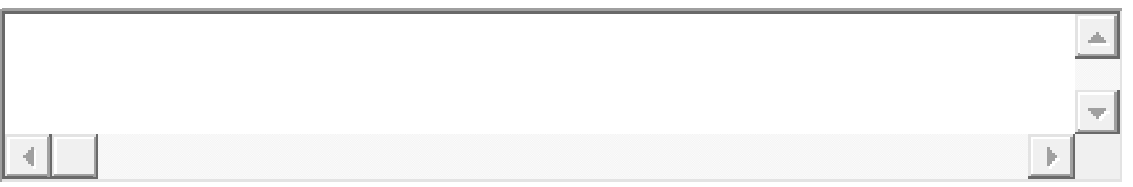




\section{B. ABOUT THE CONTRACT}

1. What is the current total contract value of this project? (Please specify in US dollars -numbers only, without a dollar sign or commas)

$$
\text { US dollars }
$$

2. What was the initial contract value of this project? (Please specify in US dollars -- numbers only, without a dollar sign or commas)

\section{US Dollars (\$)}

3. The change in contract value is primarily due to: (Please select one)

Not applicable; contract value has not changed significantly

O Change in the technical scope of the project

O Unplanned increases in the cost of the project

Other (please explain)

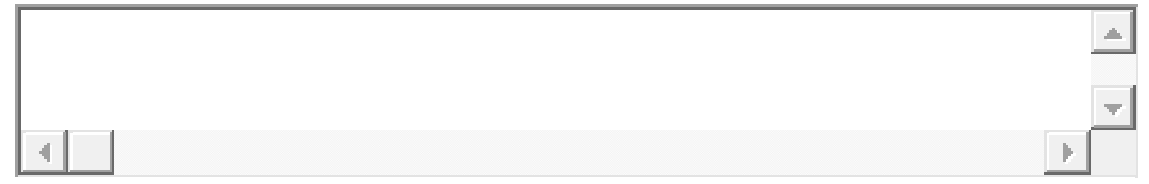

4. What is the current total planned duration of this project or contract? (Please specify in months - numbers only)

Calendar months

5. What was the initial total planned duration of this project or contract? (Please specify in months - numbers only)

Calendar months

6. The change in schedule is primarily due to: (Please select one)

O Not applicable; schedule has not changed significantly

O Change in the technical scope of the project

O Unplanned increases in the schedule for executing the project

O Customer driven increases in the schedule for executing the project

O Other (please explain)

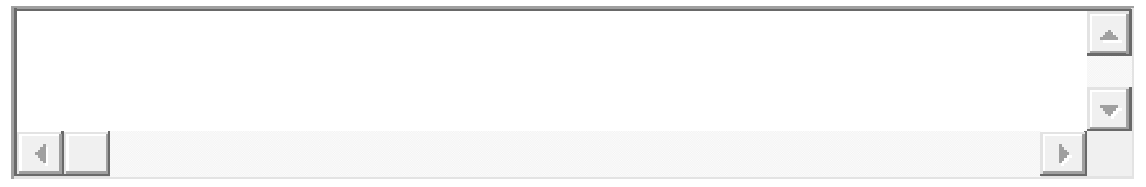

7. What was the initial total budget for this project?

US dollars (\$) 
8. What is the current total budget for this project?

US dollars (\$)

9. The change in budget is primarily due to: (Please select one)

O Not applicable; budget has not changed significantly

O Change in the technical scope of the project

O Unplanned increases in the cost of executing the project

Customer driven increases in the cost of executing the project

Other (please explain)

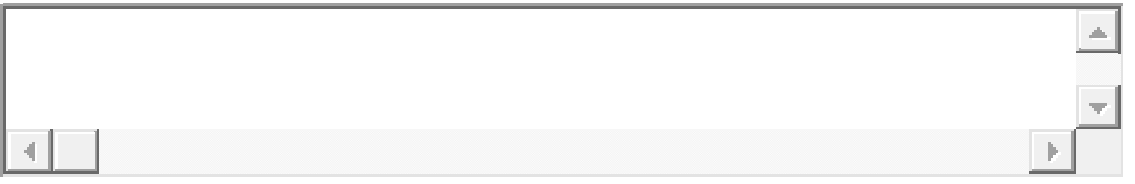

10. How many contract change orders have been received? (Please specify a number, approximate if necessary)

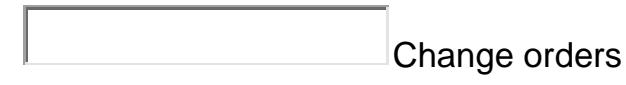

11. This contract, includes provisions for additional payments based on meeting or exceeding cost, schedule, and/or performance targets (e.g., incentive fees, award fees). (Please select one)

O Strongly disagree

Disagree

O Agree

O Strongly Agree

12. What is the current completion status of this project? (Please specify an approximate percentage -- without the percentage sign -- e.g., 60 for a project that is $60 \%$ complete)

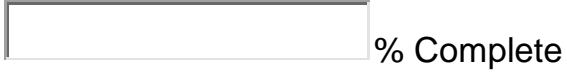

13. What type of contract(s) was awarded for this project? (Please select one)

$O$ This is a fixed-price contract - the total contract value is primarily determined by the initial contract. (e.g., FFP, FPIF, FFP-LOE).

$O$ This is a cost-reimbursable contract - the total contract value is primarily determined by my cost of executing the contract (e.g., CPFF, CPAF, CPIF).

O This contract does not fit the categories listed above. (Please describe) 


\section{ABOUT THE ORGANIZATION}

By "organization" we mean an administrative structure within which (possibly many) projects or similar work efforts are organized under common management and policies.

When thinking about your organization, please answer for the unit to which this project reports administratively, e.g., a site, division or department, not for a larger enterprise of which the organization to which you report may be a part.

Following are several statements that have been used to characterize various development organizations. How well do the statements describe this project's parent organization?

1. This organization has successfully completed projects similar in scope to this one in the past. (Please select one)

O Strongly disagree

O Disagree

O Agree

O Strongly Agree

2. Within this organization ... (Please select one)

O Systems Engineering skills and responsibilities are contained in a separate department.

O Systems Engineering skills and responsibilities are distributed throughout other departments.

3. Which of these best describes your industry or service? (Please select one)

O Industrial Manufacturing and Services - Aerospace and Defense

O Industrial Manufacturing and Services - Electronic and Electrical Equipment

O Industrial Manufacturing and Services - Other (please specify)

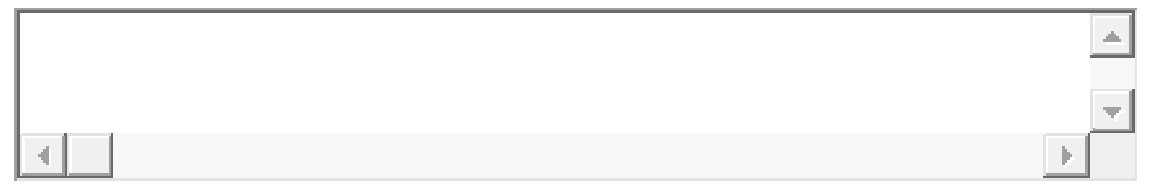

O Transportation

O Energy

O Communications

O Consumer Goods and Services

O Health Care

O Other (please specify)

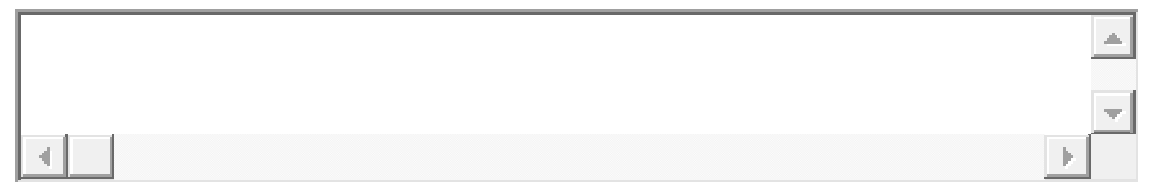

4. Please enter the country in which most of the design and development engineering will be/was performed. 
5. Is anything else particularly important in characterizing your project, product, contract, or organization within which it resides. (Please describe here)

\begin{tabular}{|l|l|l|}
\hline 1 & & -1
\end{tabular}




\section{SYSTEMS ENGINEERING CAPABILITIES ASSESSMENT}

This and the next few sections ask you about the Systems Engineering activities performed on this project. Most of the questions ask about the existence and quality of tangible work products. Note that the pertinent information often may be distributed throughout multiple documents or other work products; it need not necessarily be located in one particular place.

Following are several statements about work products and activities that are sometimes used for systems development. Please use the following definitions to describe their use on this project:

Strongly Disagree: The work product does not exist or is never used on this project.

Disagree: The work product is of insufficient quality or is not used regularly at appropriate occasions on this project.

Agree: The work product or practice is of good quality and it is used regularly on this project, although not necessarily as often as it could be.

Strongly Agree: The work product or practice is of exceptional quality and it is used at nearly all appropriate occasions on this project.

\section{PROJECT PLANNING}

1. This project utilizes/utilized a documented set of Systems Engineering processes for the planning and execution of the project. (Please select one)
O Strongly disagree
O Disagree
O Agree
S Strongly Agree

2. This project has/had an accurate and up-to-date Work Breakdown Structure (WBS) that included task descriptions and work package descriptions. (Please select one)

O Strongly disagree

O Disagree

O Agree

O Strongly Agree

3. This project has/had an accurate and up-to-date Work Breakdown Structure (WBS) that was based upon the product structure. (Please select one)

Strongly disagree

O Disagree

O Agree

Strongly Agree 
4. This project has/had an accurate and up-to-date Work Breakdown Structure (WBS) that was developed with the active participation of those who perform the systems engineering activities. (Please select one)

Strongly disagree

O Disagree

A Agree

O Strongly Agree

5. This project has/had an accurate and up-to-date Work Breakdown Structure (WBS) that was developed and maintained with the active participation of all relevant stakeholders (e.g., developers, maintainers, testers, inspectors, etc.). (Please select one)

Strongly disagree

O Disagree

O Agree

O Strongly Agree

6. This project's Technical Approach is complete, accurate and up-to-date. (Please select one)

O Strongly disagree

O Disagree

O Agree

O Strongly Agree

7. This project's Technical Approach is developed and maintained with the active participation of those who perform the Systems Engineering activities. (Please select one)
O Strongly disagree
O Disagree
O Agree
O Strongly Agree

8. This project's Technical Approach is developed and maintained with the active participation of all appropriate functional stakeholders. (Please select one)

O Strongly disagree

O Disagree

O Agree

O Strongly Agree

9. This project has a top-level plan, such as an Integrated Master Plan (IMP), that is an event-driven plan (i.e., each accomplishment is tied to a key project event). (Please select one)

O Strongly disagree

O Disagree

O Agree

O Strongly Agree 
10. This project has a top-level plan, such as an Integrated Master Plan (IMP), that documents significant accomplishments with pass/fail accomplishment criteria for both business and technical elements of the project. (Please select one)

Strongly disagree

O Disagree

A Agree

O Strongly Agree

11. This project has a top-level plan, such as an Integrated Master Plan (IMP), that is consistent with the Work Breakdown Structure (WBS). (Please select one)

Strongly disagree

O Disagree

O Agree

O Strongly Agree

12. This project has an integrated event-based schedule that is structured as a networked, multi-layered schedule of project tasks required to complete the work effort. (Please select one)

O Strongly disagree

O Disagree

O Agree

O Strongly Agree

13. This project has an integrated event-based schedule that contains a compilation of key technical accomplishments (e.g., a Systems Engineering Master Schedule). (Please select one)

Strongly disagree

O Disagree

O Agree

O Strongly Agree

14. This project has an integrated event-based schedule that references measurable criteria (usually contained in the Integrated Master Plan) required for successful completion of key technical accomplishments. (Please select one)

Strongly disagree

O Disagree

O Agree

O Strongly Agree

15. This project has an integrated event-based schedule that is consistent with the Work Breakdown Structure (WBS). (Please select one)
O Strongly disagree
O Disagree
O Agree
O Strongly Agree 
16. This project has an integrated event-based schedule that identifies the critical path of the program schedule. (Please select one)

O Strongly disagree

O Disagree

O Agree

O Strongly Agree

17. This project has a plan or plans for the performance of technical reviews with defined entry and exit criteria throughout the life cycle of the project. (Please select one)

O Strongly disagree

O Disagree

O Agree

O Strongly Agree

18. The Systems Engineering function actively participates in the development and updates of the project planning. (Please select one)

S Strongly disagree

O Disagree

O Agree

O Strongly Agree

19. Those who perform Systems Engineering activities actively participate in tracking/reporting of task progress. (Please select one)

O Strongly disagree

O Disagree

O Agree

O Strongly Agree

20. The acquirer provided this project with a Systems Engineering Plan in a timely manner. (Please select one)

O Strongly disagree

O Disagree

O Agree

O Strongly Agree

21. This project has a plan or plans that include details of the management of the integrated technical effort across the project (e.g., a Systems Engineering Management Plan or a Systems Engineering Plan). (Please select one)

O Strongly disagree

O Disagree

O Agree

O Strongly Agree 
22. The Systems Engineering Management Plan (or equivalent) developed by the project team is aligned and consistent with the Systems Engineering Plan). (or equivalent) provided by the acquirer. (Please select one)

O Strongly disagree

O Disagree

O Agree

O Strongly Agree 


\section{E. INTEGRATED PRODUCT TEAMS}

1. This project makes effective use of integrated product teams (IPTs). (Please select one)

O Strongly disagree

O Disagree

O Agree

O Strongly Agree

2. My acquirer participates in my integrated product teams (IPTs) for this project. (Please select one)

O Strongly disagree

O Disagree

O Agree

O Strongly Agree

3. My suppliers actively participate in my integrated product teams (IPTs). (Please select one)

S Strongly disagree

O Disagree

O Agree

O Strongly Agree

4. This project has an integrated product team (IPTs) with assigned responsibility for Systems Engineering. (Please select one)

O Strongly disagree

O Disagree

O Agree

O Strongly Agree

5. This project has Systems Engineering representation on each integrated product teams (IPTs). (Please select one)

Strongly disagree

O Disagree

O Agree

O Strongly Agree 


\section{F. RISK MANAGEMENT}

1. This project has a Risk Management process that creates and maintains an accurate and up-to-date list of risks affecting the project (e.g., risks to cost, risks to schedule, risks to performance) (Please select one)

O Strongly disagree

O Disagree

O Agree

O Strongly Agree

2. This project has a Risk Management process that creates and maintains up-to-date documentation of risk mitigation plans and contingency plans for selected risks (Please select one)

O Strongly disagree

O Disagree

O Agree

O Strongly Agree

3. This project has a Risk Management process that monitors and reports the status of risk mitigation activities and resources. ((Please select one)

O Strongly disagree

O Disagree

O Agree

O Strongly Agree

4. This project has a Risk Management process that assesses risk against achievement of an event-based schedule (Please select one)

O Strongly disagree

O Disagree

O Agree

O Strongly Agree

5. This project's Risk Management process is integrated with project decision-making. (Please select one)

O Strongly disagree

O Disagree

O Agree

O Strongly Agree

6. This project's Risk Management process is integrated with program cost and/or earned value management. (Please select one)

O Strongly disagree

O Disagree

O Agree

O Strongly Agree 
7. This project's Risk Management process is integrated with program scheduling (e.g., risks are incorporated in the program master schedules). (Please select one)

O Strongly disagree

O Disagree

O Agree

O Strongly Agree

8. This project's Risk Management process integrates subcontract or supplier risk management processes. (Please select one)

Strongly disagree

O Disagree

O Agree

O Strongly Agree 


\section{G. REQUIREMENTS DEVELOPMENT AND MANAGEMENT}

1. This project maintains an up-to-date and accurate listing of all requirements specified by the customer, to include regulatory, statutory, and certification requirements. (Please select one)

O Strongly disagree

O Disagree

O Agree

S Strongly Agree

2. This project maintains an up-to-date and accurate listing of all requirements derived from those specified by the customer. (Please select one)

Strongly disagree

O Disagree

O Agree

Strongly Agree

3. This project maintains up-to-date and accurate documentation clearly reflecting the hierarchical allocation of both customer and derived requirements to each element (subsystem, component, etc.) of the system in the configuration baselines. (Please select one)

O Strongly disagree

O Disagree

O Agree

Strongly Agree

4. This project documents and maintains accurate and up-to-date descriptions of operational concepts and their associated scenarios. (Please select one)

O Strongly disagree

O Disagree

O Agree

O Strongly Agree

5. This project documents and maintains accurate and up-to-date descriptions of use cases (or their equivalent). (Please select one)

S Strongly disagree

O Disagree

O Agree

O Strongly Agree

6. This project documents and maintains accurate and up-to-date descriptions of product installation, maintenance and support concepts. (Please select one)

Strongly disagree

O Disagree

O Agree

O Strongly Agree 
7. This project has documented criteria for identifying authorized requirements providers to avoid requirements creep and volatility. (Please select one)

O Strongly disagree

O Disagree

O Agree

O Strongly Agree

8. This project has documented criteria (e.g., cost impact, schedule impact, authorization of source, contract scope, requirement quality) for evaluation and acceptance of requirements. (Please select one)

O Strongly disagree

O Disagree

O Agree

O Strongly Agree

9. The requirements for this project are approved in a formal and documented manner by relevant stakeholders. (Please select one)

O Strongly disagree

O Disagree

O Agree

O Strongly Agree

10. This project performs and documents requirements impact assessments for proposed requirements changes (Please select one)

Strongly disagree

Disagree

O Agree

O Strongly Agree

11. This project develops and documents project requirements based upon stakeholder needs, expectations, and constraints. (Please select one)

O Strongly disagree

O Disagree

O Agree

O Strongly Agree

12. This project has an accurate and up-to-date requirements management system. (Please select one)

Strongly disagree

O Disagree

O Agree

Strongly Agree 
13. For this project, the requirements documents are managed under a configuration control process. (Please select one)

O Strongly disagree

O Disagree

O Agree

O Strongly Agree

14. For this project, the requirements documents are accessible to all relevant project staff. (Please select one)

S Strongly disagree

O Disagree

O Agree

O Strongly Agree 


\section{H. TRADE STUDIES}

1. Stakeholders impacted by trade studies are involved in the development and performance of those trade studies. (Please select one)

Strongly disagree

O Disagree

O Agree

O Strongly Agree

2. This project performs and documents trade studies between alternate solutions in a timely manner, and based upon definitive and documented selection criteria. (Please select one)

Strongly disagree

O Disagree

O Agree

O Strongly Agree

3. Documentation of trade studies is maintained in a defined repository and is accessible to all relevant project staff. (Please select one)

O Strongly disagree

O Disagree

O Agree

Strongly Agree 


\section{PRODUCT ARCHITECTURE}

1. This project maintains accurate and up-to-date descriptions (e.g. interface control documents, models, etc.) defining interfaces in detail. (Please select one)

Strongly disagree

O Disagree

O Agree

O Strongly Agree

2. Interface definition descriptions are maintained in a designated location, under configuration management, and accessible to all who need them. (Please select one)

O Strongly disagree

O Disagree

O Agree

O Strongly Agree

3. For this project, the product high-level structure is documented, kept up to date, and managed under configuration control. (Please select one)

Strongly disagree

O Disagree

O Agree

O Strongly Agree

4. For this project, the product high-level structure is documented using multiple views (e.g. functional views, module views, etc.). (Please select one)

Strongly disagree

O Disagree

O Agree

Strongly Agree

5. For this project, the product high-level structure is accessible to all relevant project personnel. (Please select one)

O Strongly disagree

O Disagree

O Agree

O Strongly Agree 


\section{J. PRODUCT INTEGRATION}

1. This project has accurate and up-to-date documents defining its product integration process, plans, criteria, etc. throughout the life cycle. (Please select one)
Strongly disagree
O Disagree
O Agree
O Strongly Agree 


\section{K. VERIFICATION}

1. This project has accurate and up-to-date documents defining the procedures used for the test and verification of systems and system elements. (Please select one)
O Strongly disagree
O Disagree
O Agree
Strongly Agree

2. This project has accurate and up-to-date documents defining acceptance criteria used for the verification of systems and system elements. (Please select one)
S Strongly disagree
O Disagree
O Agree
Strongly Agree

3. This project has a documented and practiced review (e.g. peer reviews, design reviews, etc.) process for work products that defines entry and exit criteria. (Please select one)

O Strongly disagree

O Disagree

O Agree

O Strongly Agree

4. This project has a documented and practiced review (e.g. peer reviews, design reviews, etc.) process that includes training the reviewers to conduct reviews. (Please select one)

Strongly disagree

O Disagree

O Agree

O Strongly Agree

5. This project has a documented and practiced review (e.g. peer reviews, design reviews, etc.) process that defines criteria for the selection of work products (e.g., requirements documents, test plans, system design documents, etc.) for review. (Please select one)

O Strongly disagree

O Disagree

O Agree

O Strongly Agree

6. This project has a documented and practiced review (e.g. peer reviews, design reviews, etc.) process that tracks action items to closure. (Please select one)
S Strongly disagree
O Disagree
O Agree
O Strongly Agree 
7. This project has a documented and practiced review (e.g. peer reviews, design reviews, etc.) process that addresses identified risks and risk mitigation activities during reviews. (Please select one)

Strongly disagree

O Disagree

O Agree

O Strongly Agree

8. This project has a documented and practiced review (e.g. peer reviews, design reviews, etc.) process that examines completeness of configuration baselines. (Please select one)

Strongly disagree

O Disagree

O Agree

O Strongly Agree

9. This project conducts non-advocate reviews (e.g. reviews by qualified personnel with no connection to or stake in the project) and documents results, issues, action items, risks, and risk mitigations (Please select one)

O Strongly disagree

O Disagree

O Agree

O Strongly Agree 


\section{VALIDATION}

1. This project has accurate and up-to-date documents defining the procedures used for the validation of systems and system elements. (Please select one)
O Strongly disagree
O Disagree
O Agree
S Strongly Agree

2. This project has accurate and up-to-date documents defining acceptance criteria used for the validation of systems and system elements. (Please select one)
O Strongly disagree
O Disagree
O Agree
O Strongly Agree 


\section{CONFIGURATION MANAGEMENT}

1. This project maintains a listing of items managed under configuration control. (Please select one)

O Strongly disagree

O Disagree

O Agree

S Strongly Agree

2. This project has a configuration management system that charters a Change Control Board to disposition change requests. (Please select one)

O Strongly disagree

O Disagree

O Agree

O Strongly Agree

3. This project maintains records of requested and implemented changes to configurationmanaged items. (Please select one)

Strongly disagree

O Disagree

O Agree

O Strongly Agree

4. This project creates and manages configuration baselines (e.g., functional, allocated, product). (Please select one)

O Strongly disagree

O Disagree

O Agree

O Strongly Agree 


\section{N. PROJECT PERFORMANCE: EARNED VALUE MANAGEMENT}

1. This project creates and manages cost and schedule baselines. (Please select one)
O Strongly disagree
O Disagree
O Agree
O Strongly Agree

2. Earned Value Management System (EVMS) data are available to decision makers in a timely manner (i.e. current within 2 weeks). (Please select one)
O Strongly disagree
O Disagree
O Agree
Strongly Agree

3. The requirement to track and report Earned Value Management System (EVMS) data is levied upon the project's suppliers. (Please select one)

O Strongly disagree

O Disagree

O Agree

O Strongly Agree

4. Variance thresholds for the Cost Performance Index (CPI) and Schedule Performance Index (SPI) are defined, documented, and used to determine when corrective action is needed. (Please select one)

O Strongly disagree

O Disagree

O Agree

O Strongly Agree

5. The Earned Value Management System (EVMS) is linked to the technical effort through the Work Breakdown Structure (WBS), the Integrated Master Plan (IMP), (or equivalent), and the Integrated Master Schedule (IMS) (or equivalent). (Please select one)
O Strongly disagree
O Disagree
O Agree
Strongly Agree 
6. When is the Earned Value Management System (EVMS) baseline updated? (Please select as many as apply)

$\square \quad$ Only at contract initiation

Whenever a contract change order or renewal is received

Incrementally in rolling wave planning

$\square \quad$ Whenever the project is reprogrammed due to a pre-determined cost or schedule variance

$\square \quad$ At periodic intervals

$\square \quad$ Other (Please describe briefly)

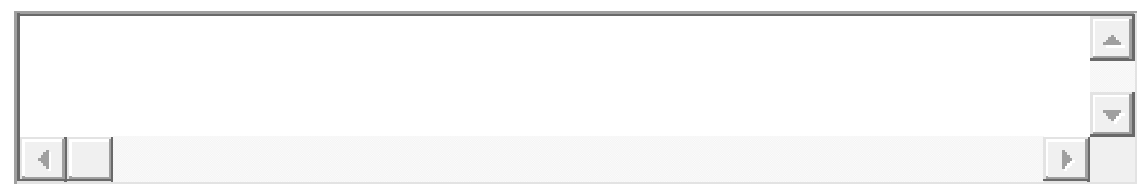

7. What is the projected cost variance at completion for the current contract baseline? (Please specify an amount in US Dollars (\$), using + signs for any overruns and - signs for any underruns)

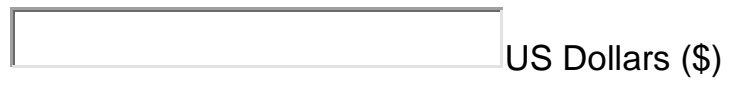

8. What is the projected schedule variance at completion for the current contract baseline? (Please specify in months, using + signs for any late delivery and - signs for early delivery)

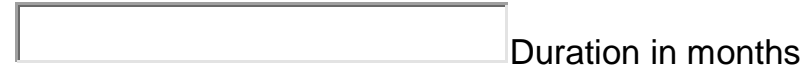

9. What is the current cumulative (or final) EVMS Cost Performance Index (CPI) for this project? (Please specify a number)

10. What is the current cumulative (or final) EVMS Schedule Performance Index (SPI) for this project? (Please specify a number) 


\section{O. OTHER PERFORMANCE INDICATORS}

1. What percentage of available Award Fees have been received by this project in the current period of performance? (Please specify an approximate percentage -- without the percentage sign. Enter "n/a" if this contract does not include Award Fees.)

2. What percentage of available Award Fees have been received by this project to date (i.e., in all periods)? (Please specify an approximate percentage -- without the percentage sign. Enter "n/a" if this contract does not include Award Fees.)

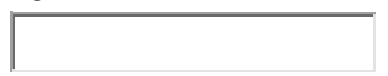

3. Requirements are being satisfied and remain on track to be satisfied in the product releases as originally planned; they are not being deleted or deferred to later releases. (Please select one)

O Strongly disagree

O Disagree

O Agree

O Strongly Agree

4. Overall, this project is performing per the schedule established in the current Integrated Master Schedule (IMS) approved by the acquirer. (Please select one)
Strongly disagree
O Disagree
O Agree
O Strongly Agree

5. The schedule of this project's critical path, when compared to the current Integrated Master Schedule (IMS) approved by the acquirer is ... (Please select one)

O Greater than 6 months late

O 3 to 6 months late

O 1 to 3 months late

O Within plus or minus 1 month

O 1 to 3 months early

O 3 to 6 months early

6. This project collects and tracks (or will collect and track) reports of problems from fielded items. (Please select one)

S Strongly disagree

O Disagree

O Agree

O Strongly Agree 
7. This project conducts (or will conduct) engineering assessments of all field trouble reports. (Please select one)

O Strongly disagree

O Disagree

O Agree

O Strongly Agree

8. I believe that my customer is satisfied with this project's performance with respect to the schedule. (Please select one)

Strongly disagree

O Disagree

O Agree

O Strongly Agree

9. I believe that my customer is satisfied with this project's performance with respect to cost. (Please select one)

Strongly disagree

O Disagree

O Agree

O Strongly Agree

10. I believe that my customer is satisfied with this project's performance with respect to satisfaction of requirements. (Please select one)

O Strongly disagree

O Disagree

O Agree

O Strongly Agree

11. What performance indicators (beyond cost and schedule) have been particularly useful for managing your project? (Please describe here)

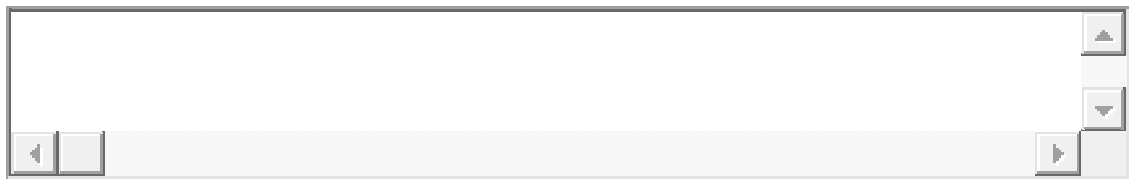

12. What other kinds of performance related information would have been helpful for your project or program, but was unavailable? (Please describe here)

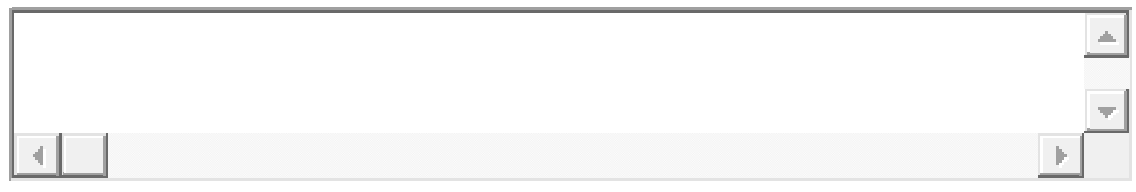


13. What indicators do you use in your project or organization to determine Systems Engineering effectiveness? (Please describe here)

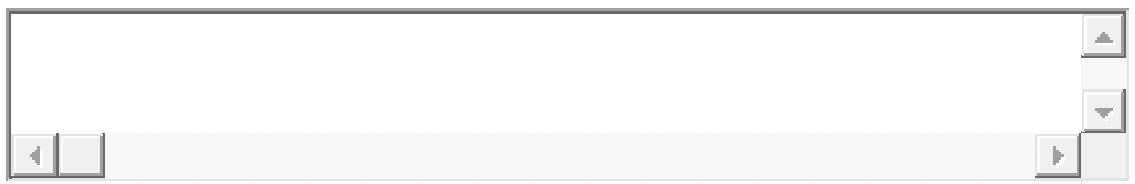

14. What indicators of Systems Engineering effectiveness are regularly reviewed across projects by higher level management? (Please describe here)

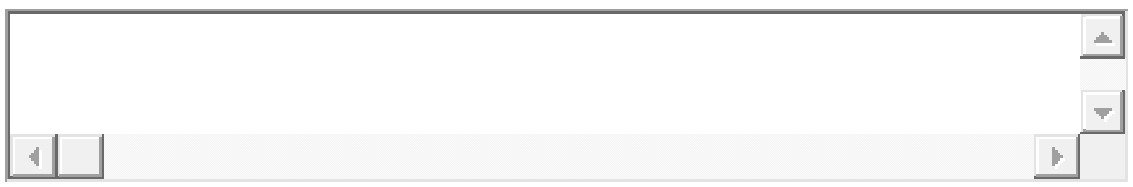




\section{P. IN CONCLUSION}

1. Is there anything else that you would like to tell us about your project or this survey? (Please describe here)

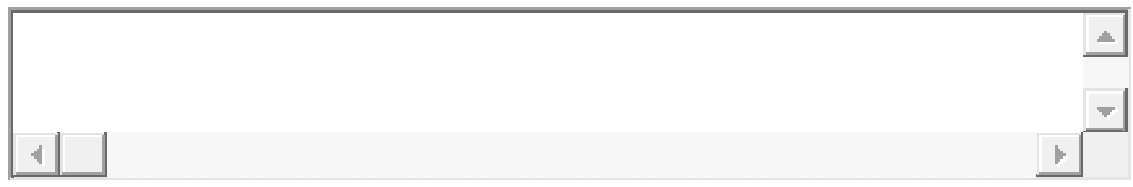

Thank you very much for your time and effort!

Please be sure to use the Save button. That will take you to the final page where you may SUBMIT your response.

Copyright 2012, Carnegie Mellon University. 


\section{References}

URLs are valid as of the publication date of this document.

\section{[Elm 2008]}

Elm, J.; Goldenson, D.; El Emam, K.; Donatelli, N.; Neisa, A. A Survey of Systems Engineering Effectiveness - Initial Results (CMU/SEI-2008-SR-034). Software Engineering Institute, Carnegie Mellon University, 2008. http://www.sei.cmu.edu/library/abstracts/reports/08sr034.cfm

\section{[EIm 2012a]}

Elm, J. The Business Case for Systems Engineering Study: Assessing Project Performance from Sparse Data (CMU/SEI-2012-SR-010). Software Engineering Institute, Carnegie Mellon University, 2012. http://www.sei.cmu.edu/library/abstracts/reports/12sr010.cfm

\section{[EIm 2012b]}

Elm, J. \& Goldenson, D. The Business Case for Systems Engineering Study: Results of the SE Effectiveness Survey (CMU/SEI-2012-SR-009). Software Engineering Institute, Carnegie Mellon University, 2012. http://www.sei.cmu.edu/library/abstracts/reports/12sr009.cfm 


\begin{tabular}{|c|c|c|c|c|}
\hline \multicolumn{3}{|c|}{ REPORT DOCUMENTATION PAGE } & \multicolumn{2}{|c|}{$\begin{array}{l}\text { Form Approved } \\
\text { OMB No. 0704-0188 }\end{array}$} \\
\hline \multicolumn{5}{|c|}{$\begin{array}{l}\text { Public reporting burden for this collection of information is estimated to average } 1 \text { hour per response, including the time for reviewing instructions, search- } \\
\text { ing existing data sources, gathering and maintaining the data needed, and completing and reviewing the collection of information. Send comments regard- } \\
\text { ing this burden estimate or any other aspect of this collection of information, including suggestions for reducing this burden, to Washington Headquarters } \\
\text { Services, Directorate for information Operations and Reports, } 1215 \text { Jefferson Davis Highway, Suite 1204, Arlington, VA 22202-4302, and to the Office of } \\
\text { Management and Budget, Paperwork Reduction Project (0704-0188), Washington, DC 20503. }\end{array}$} \\
\hline $\begin{array}{l}\text { 1. AGENCY USE ONLY } \\
\text { (Leave Blank) }\end{array}$ & \multicolumn{2}{|l|}{$\begin{array}{ll}\text { 2. } & \text { REPORT DATE } \\
& \text { November } 2012\end{array}$} & \multicolumn{2}{|c|}{$\begin{array}{l}\text { 3. REPORT TYPE AND DATES } \\
\text { COVERED } \\
\text { Final }\end{array}$} \\
\hline \multicolumn{3}{|l|}{ 4. TTLEANDSUBTTLE } & \multicolumn{2}{|c|}{$\begin{array}{ll}5 . & \text { FUNDING NUMBERS } \\
& \text { FA8721-05-C-0003 }\end{array}$} \\
\hline \multicolumn{5}{|c|}{$\begin{array}{ll}6 . & \text { AUTHOR(S) } \\
& \text { Joseph P. Elm, Dennis R. Goldenson }\end{array}$} \\
\hline \multicolumn{3}{|l|}{$\begin{array}{l}\text { 7. PERFORMNG ORGANZATIONNAM } \\
\text { Software Engineering Institute } \\
\text { Carnegie Mellon University } \\
\text { Pittsburgh, PA } 15213\end{array}$} & \multicolumn{2}{|c|}{$\begin{array}{l}\text { 8. PERFORMNG ORGANZATION } \\
\text { REPORT NUMBER } \\
\text { CMU/SEI-2012-SR-011 }\end{array}$} \\
\hline \multicolumn{3}{|c|}{$\begin{array}{l}\text { 9. SPONSORING/MONTORING AGENCY } \\
\text { AFLCMC/PZE/Hanscom } \\
\text { Enterprise Acquisition Division } \\
20 \text { Schilling Circle } \\
\text { Building } 1305 \\
\text { Hanscom AFB, MA 01731-2116 }\end{array}$} & \multicolumn{2}{|c|}{$\begin{array}{l}\text { 10. SPONSORING/MONTORING } \\
\text { AGENCY REPORT NUMBER }\end{array}$} \\
\hline \multicolumn{5}{|l|}{ 11. SUPPLENENTARY NOTES } \\
\hline \multicolumn{3}{|c|}{$\begin{array}{l}\text { 12A DISTRIBUTIONAVAILABIUTY STATEMENT } \\
\text { Unclassified/Unlimited, DTIC, NTIS }\end{array}$} & \multicolumn{2}{|c|}{ 12B DISTRIBUTIONCODE } \\
\hline \multicolumn{5}{|c|}{$\begin{array}{l}\text { This report contains detailed response data from The Effectiveness of Systems Engineering: A Survey. The survey had the goal of quan- } \\
\text { tifying the connection between the application of systems engineering (SE) best practices to projects and programs and the performance } \\
\text { of those projects and programs. The survey population consisted of projects and programs executed by system developers reached } \\
\text { through the National Defense Industrial Association (NDIA) Systems Engineering Division, the Institute of Electrical and Electronics En- } \\
\text { gineers (IEEE) Aerospace and Electronic Systems Society, and the International Council on Systems Engineering (INCOSE). Analysis of } \\
\text { survey responses revealed strong statistical relationships between project performance and several categories of SE best practices. The } \\
\text { survey results show notable differences in the relationship between SE best practices and performance between more challenging and } \\
\text { less challenging projects. The statistical relationship with project performance is quite strong for survey data of this kind when both SE } \\
\text { capability and project challenge are considered together. }\end{array}$} \\
\hline \multirow{2}{*}{\multicolumn{3}{|c|}{$\begin{array}{l}\text { 14. SUBJECT TERMS } \\
\text { systems-engineel } \\
\text { 16. PRICE CODE }\end{array}$}} & \multicolumn{2}{|c|}{$\begin{array}{l}\text { 15. NUMBER OF PAGES } \\
\underline{118} 118 \\
\end{array}$} \\
\hline & & & & \\
\hline $\begin{array}{l}\text { 17. SECURITY CLASSIFCATIONOF } \\
\text { REPORT } \\
\text { Unclassified }\end{array}$ & $\begin{array}{l}\text { 18. SECURITY CLASSIFCATION } \\
\text { OFTHIS PAGE } \\
\text { Unclassified }\end{array}$ & \multicolumn{2}{|c|}{$\begin{array}{l}\text { 19. SECURITY CLASSIFCATION } \\
\text { OF ABSTRACT } \\
\text { Unclassified }\end{array}$} & $\begin{array}{l}\text { 20. LMTATIONOF } \\
\text { ABSTRACT } \\
\text { UL }\end{array}$ \\
\hline
\end{tabular}

